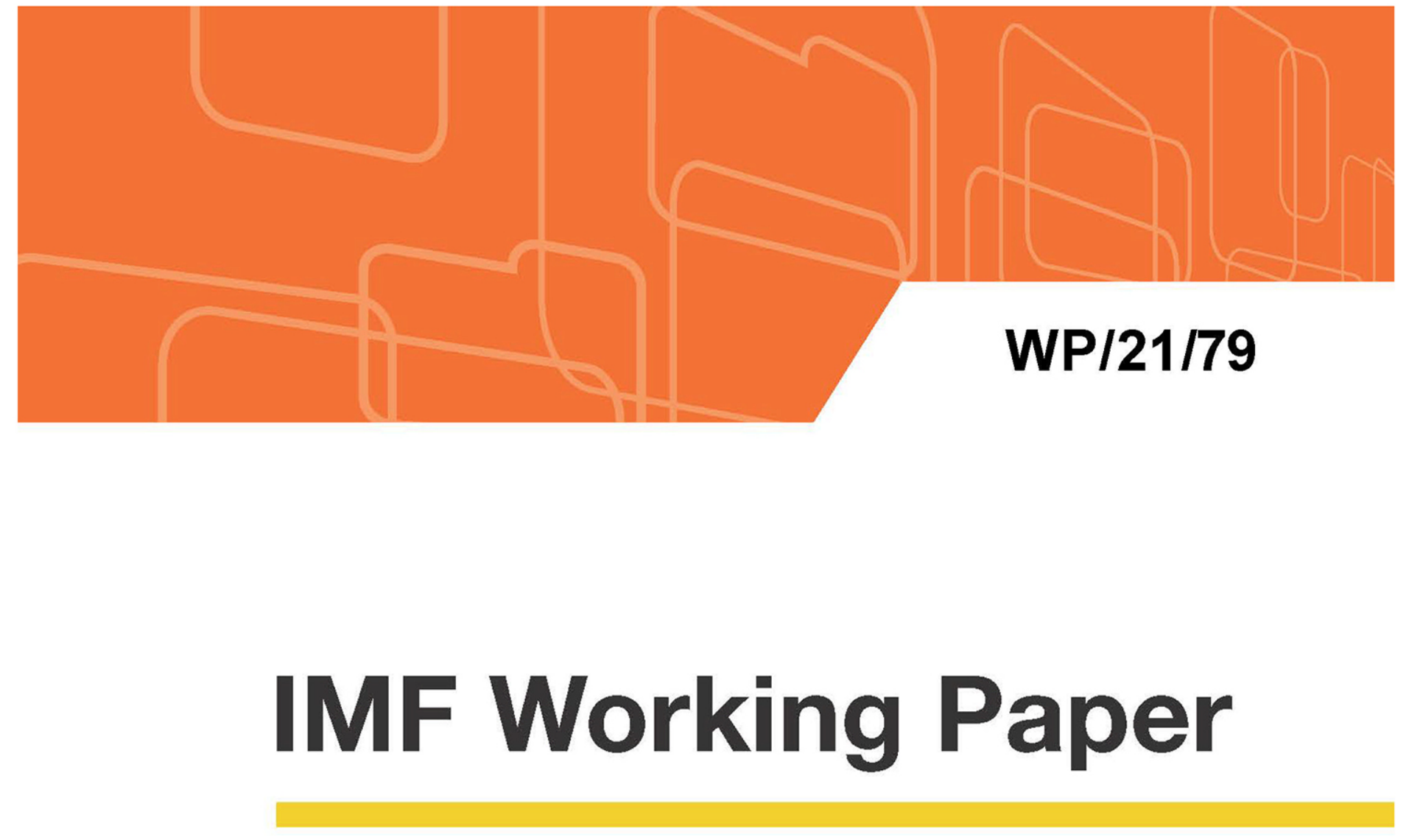

\title{
Pricing Protest: The Response of Financial Markets to Social Unrest
}

by Philip Barrett, Mariia Bondar, Sophia Chen, Mali Chivakul, and Deniz Igan

IMF Working Papers describe research in progress by the author(s) and are published to elicit comments and to encourage debate. The views expressed in IMF Working Papers are those of the author(s) and do not necessarily represent the views of the IMF, its Executive Board, or IMF management.

$$
\text { I N T E R N A T I O N A L M O N E T A R Y F U N D }
$$




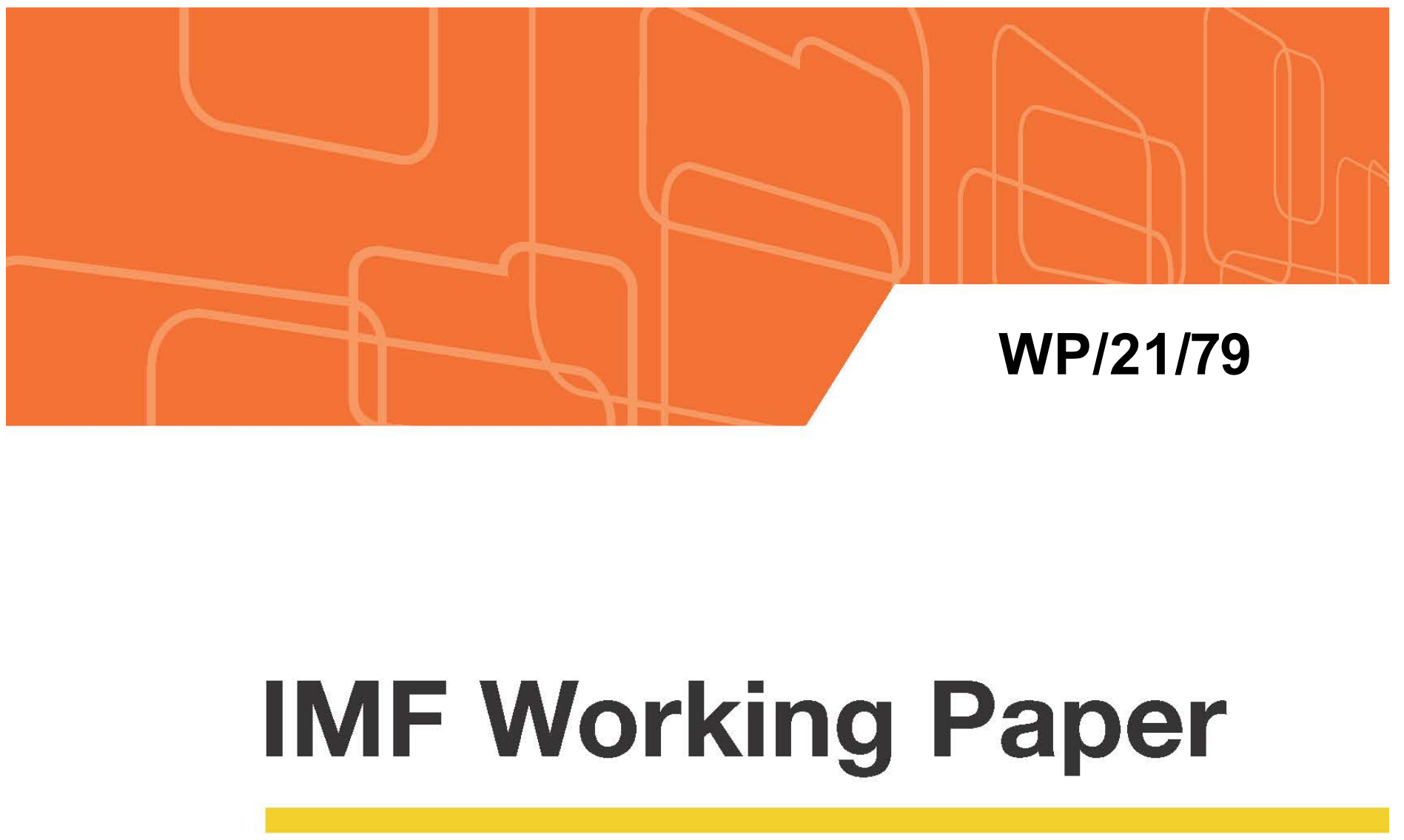

\section{Pricing Protest: The Response of Financial Markets to Social Unrest}

by Philip Barrett, Mariia Bondar, Sophia Chen, Mali Chivakul, and Deniz Igan

IMF Working Papers describe research in progress by the author(s) and are published to elicit comments and to encourage debate. The views expressed in IMF Working Papers are those of the author(s) and do not necessarily represent the views of the IMF, its Executive Board, or IMF management.

I N T E R N A T I O N A L M O N E T A R Y F U N D 


\title{
IMF Working Paper
}

Research Department

\author{
Pricing Protest: The Response of Financial Markets to Social Unrest \\ Prepared by Philip Barrett, Mariia Bondar, Sophia Chen, Mali Chivakul, Deniz Igan ${ }^{\dagger}$ \\ Authorized for distribution by Maria Soledad Martinez Peria
}

March 2021

\section{IMF Working Papers describe research in progress by the author(s) and are published to} elicit comments and to encourage debate. The views expressed in IMF Working Papers are those of the author(s) and do not necessarily represent the views of the IMF, its Executive Board, or IMF management.

\begin{abstract}
Using a new daily index of social unrest, we provide systematic evidence on the negative impact of social unrest on stock market performance. An average social unrest episode in an typical country causes a 1.4 percentage point drop in cumulative abnormal returns over a two-week event window. This drop is more pronounced for events that last longer and for events that happen in emerging markets. Stronger institutions, particularly better governance and more democratic systems, mitigate the adverse impact of social unrest on stock market returns.
\end{abstract}

JEL Classification Numbers: E66, E70, G10, H10

Keywords: Social unrest; stock markets; abnormal returns; event study; institutions

Authors’ E-Mail Addresses: pbarrett@imf.org; mariia.bondar@hof.uni-frankfurt.de; ychen2@,imf.org; mchivakul@,imf.org; $\underline{\operatorname{digan} @ \text {,imf.org }}$

\footnotetext{
${ }^{\dagger}$ Luisa Calixto, Chenxu Fu, and Manzoor Gill provided excellentresearch a ssistance. We thank Tohid Ata shbar, Martin Cihak, Sandile Hlatshwayo, and the participants of IMF Macro-Financial Research seminar for their helpful comments and suggestions, and Antonio Spilimbergo for valuable discussions.
} 


\section{Contents}

1 Introduction $\quad \underline{2}$

2 Measuring Social Unrest $\quad \underline{5}$

2.1 Identifying social unrest events from daily media reports . . . . . . . $\underline{5}$

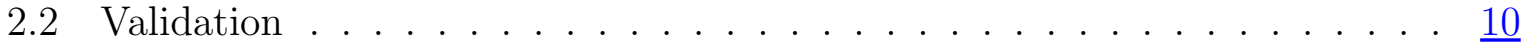

3 Data and Methodology $\quad \underline{14}$

3.1 Data . . . . . . . . . . . . . . . . . . . . 14

3.2 Event-study approach . . . . . . . . . . . . . . . . . $\underline{16}$

3.3 Regression analysis . . . . . . . . . . . . . . . . 18

3.4 Control variable regression . . . . . . . . . . . . . . . . . 19

4 Main results $\quad \underline{21}$

4.1 Cumulative abnormal returns . . . . . . . . . . . . . . . 21

4.2 Regression results . . . . . . . . . . . . . . . . . . 23

4.3 Heterogeneities: duration and income . . . . . . . . . . . . . $\underline{25}$

4.4 The role of institutions . . . . . . . . . . . . . . . . . 27

4.5 The role of elections . . . . . . . . . . . . . . . . . 31

5 Robustness checks $\quad \underline{33}$

6 Discussion $\quad \underline{39}$

7 Conclusion $\quad \underline{42}$

$\begin{array}{ll}\text { Appendix } & \underline{47}\end{array}$ 


\section{Introduction}

Social unrest - large protests, riots, or other forms of civil disorder and conflict - has become a major concern for financial market participants in recent years. For example, in a Wells Fargo/Gallup 2017 survey, investors ranked conflicts and political climate as top threats for investment climate. ${ }^{1}$ Market participants' worries likely stem from the potential economic and financial consequences of social unrest. Social unrest can disrupt economic and financial activities, or have indirect impacts on consumer and investor confidence. Social unrest may also lead to policy changes that may obstruct (or enhance) economic development in the long run with implications for the financial market performance.

This paper provides new systematic evidence on the impact of social unrest events on stock markets in countries where these events occur. We take advantage of the high-frequency and forward-looking nature of stock prices to identify the potential effects of social unrest. Under the standard assumption that stock prices quickly incorporate investors' view on the value of the firms, there should be an abnormal decrease in stock return around a social unrest event if investors view social unrest as bad news and lower the valuation of firms.

We construct a new daily dataset of social unrest events in 72 countries from 2011 to 2020. This dataset builds on Barrett et al. (2020), who construct a monthly index of social unrest based on media reports, the Reported Social Unrest Index (RSUI). We use this as a starting point for our work for four reasons: (i) RSUI is broad-based, covering more than a hundred countries; (ii) its criteria are consistent and transparent; (iii) it is corroborated by consensus narratives in multiple case studies, and (iv) it identifies event months - periods of time with major social unrest. We count daily media reports within event months to identify start and end dates of social unrest events. We then collect daily stock price data for 156 social unrest events in our sample period.

We use a cross-country event study approach, following an expansive literature which goes back to Brown and Warner (1985) and MacKinlay (1997) and has applications in different settings (e.g. Forbes (2004) on spillovers during the Asian financial crisis, Guidolin and La Ferrara (2007) on the effects of the Angolan civil war and Raddatz (2011) on the effect

\footnotetext{
${ }^{1}$ Source: $\quad$ https://www08.wellsfargomedia.com/assets/pdf/commercial/retirement-employeebenefits/perspectives/q217-gallup-retirement-survey.pdf
}

CInternational Monetary Fund. Not for Redistribution 
of debt relief announcements). We estimate a market model to calculate the abnormal returns around the dates of social unrest events. We formally test the hypothesis that these abnormal returns are equal to 0 using various procedures. This approach allows us to reasonably attribute the abnormal returns to the event of interest rather than other factors which could be driving stock price movements.

We find a significant and negative effect of social unrest on cumulative abnormal returns. On average, social unrest events lower cumulative abnormal returns by 1.4 percentage points over two weeks. The effect is more pronounced for events that last longer and for events that occurred in emerging markets. We also find that the negative impact of a social unrest event is mitigated by stronger institutions, in particular, better governance and more democratic systems.

Stock market performance can provide useful insights into the broader effects of social unrest on the economy. The forward-looking, information-aggregating nature of stock markets gives clues about future economic performance. For instance, social unrest could increase uncertainty in production and investment, and influence sentiment and confidence as well as the likelihood and success of economic reforms. All of these may have potentially long-lasting effects on the real economy (see Bloom et al. (2007), Bloom (2009), Bloom (2014) and Montone and Zwinkels (2020)).

Our paper contributes to the literature along several dimensions. First, to the best of our knowledge, ours is the first study to provide systematic evidence on stock market reactions to social unrest. The bulk of the literature is based on case studies of a single event or a cluster of closely related events in the same region (see, for instance, Epstein and Schnietz (2002), Abdelbaki (2013), Mousavi and Ouenniche (2014), Acemoglu et al. (2017)). While they offer valuable insights into specific events, results based on case studies may not apply in other contexts, since the identified effects might arise from peculiarities of the event or the location. A related but separate literature focuses on a specific, and often severe, form of social unrest, such as wars and coups (Rigobon and Sack (2005), Guidolin and La Ferrara (2007), Guidolin and La Ferrara (2010) and Dube et al. (2011) among others). Our paper complements the literature by offering evidence from a large sample of countries and a diverse set of social unrest events. This broad-based evidence not only overcomes the issues of external validity in case studies, but also allows us to explore variations across events and examine the role of institutions.

We also contribute to a large literature that examines the real and financial effects of political instability and political uncertainty. Many researchers have looked for the impact 
of political and social instability on growth, output and investment (Alesina and Perotti (1996), Alesina et al. (1996), Jong-A-Pin (2009), Aisen and Veiga (2013), Bernal-Verdugo et al. (2013), Blum and Gründler (2020), Sedik and Xu (2020), Hlatshwayo and Redl (2020b), Hadzi-Vaskov et al. (2020) among others). However, drawing causal inference from macroeconomic data is challenging for several reasons. First, social unrest events tend to occur in countries with poor economic performance and during periods of economic hardship. June 2020 unrest in Lebanon is one prominent example - a devaluation of Lebanese pound in the midst of a severe economic crisis triggered mass protests. ${ }^{2}$ Second, even if a causal link exists, social unrest will likely affect economic performance with a delay that makes identifying the effect using time series difficult.

Finally, our paper also contributes to the new and growing literature on measuring risk and uncertainty using big data approaches. Baker et al. (2016), for instance, construct a monthly economic policy uncertainty index (EPU) based on newspaper articles related to policy uncertainty. Azzimonti (2018) uses newspaper article count to measure the degree of political disagreement and construct a partisan conflict index (PCI). Other media-based indices to measure uncertainty and risk include Manela and Moreira (2017), Ahir et al. (2018) and Caldara and Iacoviello (2018). Application of big data approaches to social unrest is limited. One notable exception is Barrett et al. (2020), who develop a monthly reported social unrest index (RSUI) based on the number of media articles related to social unrest. In this paper we extend their monthly RSUI to daily frequency.

The rest of the paper is organized as follows. Section 2 introduces a new daily measure of social unrest based on media coverage of the unrest events. Section 3 discusses the empirical strategy. Section 4 presents the main results. Section 5 conducts robustness and placebo tests. Sections 6 and 7 conclude.

\footnotetext{
${ }^{2}$ Of course, it may also be the case that people go on the street to protest when economic conditions are good, and their livelihoods are secure, but they have political or social grievances.
} 


\section{Measuring Social Unrest}

We develop a method for high frequency identification of major social unrest events. The basic idea is to use spikes in daily press coverage of social unrest to identify start and end dates of each social unrest event. Our approach builds on Barrett et al. (2020), who show that large increases in media reports correlate closely with consensus narratives of social unrest at the monthly frequency.

\subsection{Identifying social unrest events from daily media reports}

We start with the monthly event list from Barrett et al. (2020). The authors use the number of articles from major international news sources to create indices of social unrest for 130 countries. These indices exhibit very large spikes that are associated with major episodes of social unrest. The authors develop quantitative criteria to formalize these spikes and identify a list of social unrest events at the country-month frequency. They compare these events against consensus narratives for a number of case studies, showing that they align closely, and conclude that this method captures actual major social unrest events. $^{3}$

We use Factiva, a press aggregation service, to search for articles in a short window around the 336 country-month unrest events identified by Barrett et al. (2020) between 2011 and 2020. We use the same set of sources (major English-language international news media - see Appendix Table A1 for a list of sources) and apply the same search criteria as Barrett et al. (2020) to identify unrest-related media reports. The relevant articles related

\footnotetext{
${ }^{3}$ For a detailed comparison of monthly media-based social unrest index with other data sources (namely, ACLED and CNTS), see Barrett et al. (2020). Media-based social unrest index might suffer from one drawback - the selection of media sources. It is possible that some social unrest events are covered only in the local newspapers in languages other than English. If social unrest in advanced economies is more likely to be covered by international media compared to unrest in emerging or developing countries, our sample of events might be subject to sample selection bias. Barrett et al. (2020) show, however, that monthly social unrest index is robust to the choice of news outlets, and to inclusion of search terms in French and Arabic. It is reasonable to assume that the same robustness applies to the daily index. Finally, the monthly media-based social unrest index relies on newspaper articles, and doesn't use social media activity (Facebook, Twitter etc.) or Google Trends data to identify social unrest events. Although social media coverage may be useful in specific cases, it is near-impossible to separate true unrest-related information from disinformation generated by "trolls", bots, and the like in a broader sample.
} 
to country $k$ must include words such as "protest", "riot" or "revolution". They must also exclude certain terms to avoid counting reports about previous events or revolutionthemed movies. The selected articles must be at least 100 words long and must mention the name of the country in question (see Table 1 for details).

While there is of course some degree of arbitrariness in the search terms and sources, we justify our approach on two grounds. First, as Barrett et al. (2020) show, the approach works well at monthly frequency: social unrest events are sufficiently obvious and interesting to international press, so that they are consistently identified regardless of the specifics of the search. The identification works particularly well for high-profile events, such as the Egyptian revolution of February 2011, the abrupt overthrow of the government of Burkina Faso in November 2014, the Latin American protests of Autumn 2019, and the Belarusian protests starting in Summer 2020. Events as newsworthy as these are relatively forgiving of the precise details of a media-based methodology for identifying events. Second, in Section 2.2 we test our identification strategy in several case studies. If our approach performs well against reasonable external descriptions of events, robustness to variation in languages, sources and search terms is ensured. We return to this point in Section 2.2.

Table 1: Article search criteria

\begin{tabular}{ll}
\hline \hline Must include & Country name AND ("protest*" OR "riot*" OR "revo- \\
& $\begin{array}{l}\text { lution" OR (("civil" or "domestic") within } 10 \text { words of } \\
\text { "unrest") }\end{array}$ \\
Must exclude & $\begin{array}{l}\text { Country-specific terms OR "vote of protest" OR } \\
\text { "protest vote" OR "protestant*" OR "anniversary" OR }\end{array}$ \\
& "war" OR "memorial" OR "movie" \\
Location tag Country $k$ & Subject tag \\
Word count & Domestic Politics Or Civil Unrest \\
\hline \hline
\end{tabular}

We download all articles that match this set of search criteria for 2 months before and after each event month. Restrictions on the volume of daily-frequency queries in Factiva preclude downloading longer daily time series. This is why our starting point using Barrett et al. (2020) is essential: it helps us to narrow down the time window. We then count the number of articles filed on each day during this 5-month window. We use this article count to compute a daily Social Unrest (SU) index:

CInternational Monetary Fand. Not for Redistribution 


$$
S U_{k t}=\frac{x_{k t}}{\frac{1}{60} \sum_{t=-60}^{-1} x_{k t}}
$$

where $x_{k t}$ is the number of articles about social unrest in country $k$ per day $t$ (where $t$ corresponds to the day within the 5-month window relative to the beginning of the event month, such that $t=0$ on the first day of the event month, and $t \in[-60,90])$, and $\frac{1}{60} \sum_{t=-60}^{-1} x_{k t}$ is the two-month pre-event average number of relevant articles. Normalizing the number of articles relative to the pre-event average ensures that the $S U_{k t}$ abstracts from any factors that are constant during the country-specific event period. It excludes all forms of media bias which results in more or less media coverage in a given country. Because the numerator is calculated for each event, this normalization also eliminates potential media bias in the time series, for example, due to changing perceptions of a given country.

Timing is a crucial element of the event-study methodology. Our working hypothesis, which we verify in Section 2.2, is that major social unrest events occur suddenly and generate sizeable press coverage. It is therefore important that we identify the exact date that marks the beginning of each unrest event in our sample. This is what we refer to as "day 0". We designate day 0 to be the first day in the event month when $S U_{k t}>15$, i.e. when the number of unrest-related articles on day $t$ exceeds pre-event average by a factor of $15 .{ }^{4}$ Hereafter, we use $s$ to denote the number of days relative to day 0 (thus, $s=0$ is the day when $S U_{k t}>15$ for the first time).

There is a trade-off in choosing the threshold to identify event dates. A high threshold has the advantage of having a lower likelihood of false positive. At the same time, it is more likely to exclude less severe events. A fifteen-fold increase - about 6 standard deviations of the pre-event index - is a relatively high threshold. Under this threshold, 133 of the 336 monthly events are excluded from the daily event list. These include Arab Spring events in Jordan and Syria in 2011, Togolese protests in 2017, and the racial justice protests in the US in June 2020 (see Table 2 for details on sample attrition, and Table A2 in the

\footnotetext{
${ }^{4}$ In Section 4 we adjust day 0 for the timing difference between the event occurrence and the filing of the news article, given difference in time zones. Getting the timing right is important because we use local stock market data. For example, if a matching article filed in New York references an event in Korea, day 0 for such event has to be shifted one day earlier. A similar article about unrest in Chile does not. We also reassign day 0 to one (two) days prior if the event happens on a Saturday (Sunday) to facilitate merging with stock market data. All the validity checks, however, are based on unadjusted day 0 , as we compare to events at local time.
}

CInternational Monetary Fand. Not for Redistribution 
Appendix for the full list of events). ${ }^{5}$ In Section 5, we test the robustness of our results to the choice of threshold and the alternative event identification criteria.

Table 2: Social unrest events 2011-2020: Summary Statistics

\begin{tabular}{lcccc}
\hline Region & Monthly events & Daily events & Average peak $S U_{k t}$ & Average duration \\
\hline Africa & 68 & 52 & 76.9 & 2.3 \\
Asia-Pacific & 38 & 21 & 83.5 & 3.4 \\
Europe & 91 & 58 & 107.1 & 5.5 \\
Mid. East \& Cent. Asia & 91 & 39 & 135 & 5.5 \\
Western Hemisphere & 48 & 33 & 88.8 & 3.8 \\
\hline World & 336 & 203 & 99.3 & 4.2 \\
\hline
\end{tabular}

${ }^{a}$ Monthly events are from Barrett et al. (2020), Daily events are those that satisfy $S U_{k t}>15$.

b Averages are computed for the sample of daily events.

An important issue for financial market event studies is whether the event could have been reasonably predicted. If so, the market would have reacted when information about the forthcoming event was revealed, rather than at the time of the event itself. To check potential anticipation effects, we plot the median index in Figure 1. The median of $S U_{k t}$ is very flat until day 0. Even on the day before an event, the value of the median index is equal to the pre-event average. ${ }^{6}$ Overall, this suggests that our method for identifying the daily start of social unrest events picks a clear starting point with no obvious change in media coverage before an event. In Section 4 we further check the robustness of our results to anticipation effects.

\footnotetext{
${ }^{5}$ Another reason why some monthly social unrest events are excluded from our daily sample is extremely high pre-event average. In rare cases when social unrest starts at the very end of a given month, but carries over to the next month, the denominator of equation (1) is too high to find the day with $S U_{k t}>15$. This is what happened with 2020 racial justice protests in the US: although most protests happened in June, the first massive outbreak of unrest followed the killing of George Floyd on May 25. In the trade-off between weaker inclusion criterion (resulting in more events) and stricter inclusion criterion we choose the latter, since it minimizes the likelihood of misidentification of day 0. As long as end-month timing does not occur only for particular event types (as seems reasonable), our estimates based on a somewhat smaller sample will remain unbiased.

${ }^{6}$ The median is our preferred measure of central tendency for this exercise as the mean is largely affected by a small number of outliers which, given the index's lower bound of zero, are skewed to the upside. This upside skew also explains the apparent persistence of unrest when using the mean $S U_{k t}$. In contrast, the median value is less than one within 10 days of the event beginning.
} 


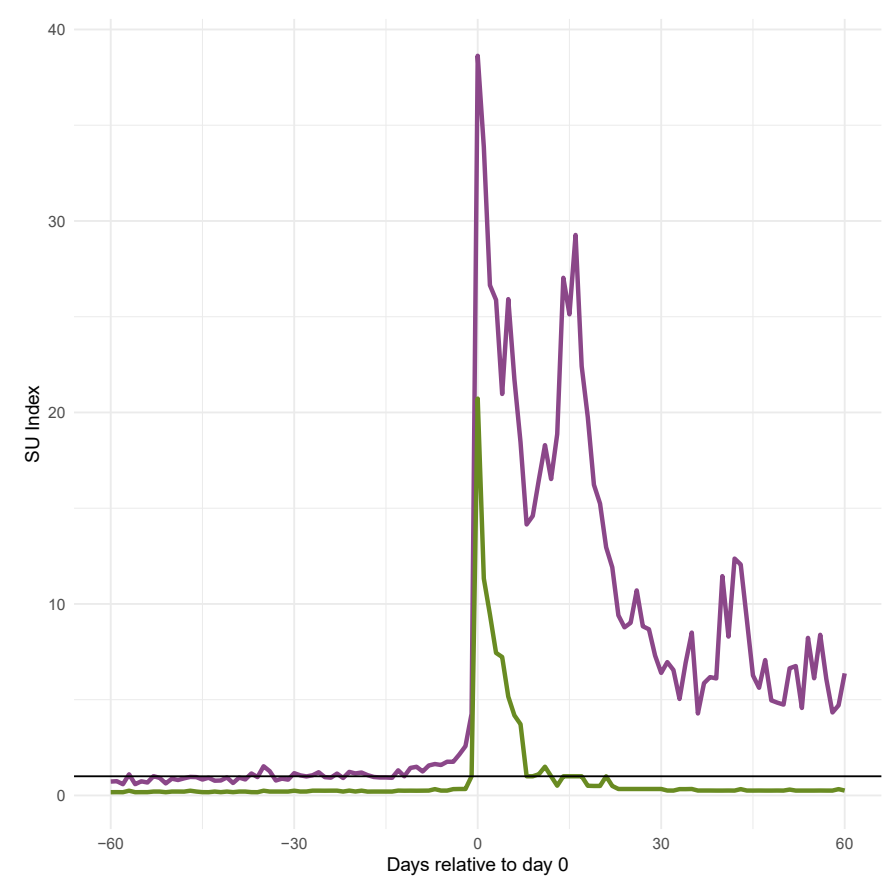

Figure 1: Mean $S U_{k t}$ (purple line) and median $S U_{k t}$ (green line).

We also use $S U_{k t}$ to determine the duration of an event. We define the end of an event as the last day of a series starting on day 0 when $S U_{k t}>1$, and define the duration of an event as the number of days between the beginning and the end of an event. ${ }^{7}$ We think of the duration of the event as a proxy for event severity: the longer the duration, the more severe the unrest. We exploit this assumption in Section 4.3. Of course, this is not without drawbacks. In particular, it is possible that the media coverage of the event decreases for some time, and then recovers rapidly as unrest escalates again. This is more likely to be the case when there are waves of tightly bunched protest events. In this case, our measure of duration would only capture the length of the initial round of unrest, thus underestimating the true unrest duration.

An interesting implication of our approach is in regard to the definition of what constitutes social unrest. Drawing tight boundaries around the definition of social unrest is inherently a very challenging task, and we do not aim to do this. Instead, we suggest a systematic method to broadly reflect a consensus view of major social unrest events. Of course, if our sources do not accurately reflect this consensus view - perhaps due to bias, herding effects or challenges to reporting in particular countries - neither will our measure. This is exactly why we devote the next section to the validation of our event-dating methodology.

\footnotetext{
${ }^{7}$ The duration is capped at 30 calendar days.
} 


\subsection{Validation}

To check the validity of our daily event identification, we run three exercises to compare our data to narrative descriptions from external sources. In the first exercise, we compare our data with a peer-reviewed dataset of coups d'état compiled by Powell and Thyne (2011). One advantage of using coups as a testbed for our method is that coups are particularly well-defined and well-recorded events: those engaged in them have obvious incentives to be quick, unexpected, and to announce their actions publicly.

Table 3: Comparing dates of social unrest with Coup d'etat Dataset

\begin{tabular}{lclclc}
\hline Country & Coup & Weekday & Unrest & Weekday & Days after coup \\
\hline Burkina Faso & $2014-10-30$ & Thursday & $2014-11-01$ & Saturday & 2 \\
Mali & $2012-03-22$ & Thursday & $2012-03-23$ & Friday & 1 \\
Turkey & $2016-07-15$ & Friday & $2016-07-16$ & Saturday & 1 \\
Mali & $2020-08-18$ & Tuesday & $2020-08-19$ & Wednesday & 1 \\
Egypt & $2013-07-03$ & Wednesday & $2013-07-03$ & Wednesday & 0 \\
Burkina Faso & $2015-09-17$ & Thursday & $2015-09-17$ & Thursday & 0 \\
Zimbabwe & $2017-11-15$ & Wednesday & $2017-11-15$ & Wednesday & 0 \\
Sudan & $2019-04-11$ & Thursday & $2019-04-11$ & Thursday & 0 \\
Burundi & $2015-05-13$ & Wednesday & $2015-05-08$ & Friday & -5 \\
Egypt & $2011-02-11$ & Friday & $2011-02-02$ & Wednesday & -9 \\
Thailand & $2014-05-22$ & Thursday & $2014-05-08$ & Thursday & -14 \\
\hline
\end{tabular}

Table 3 lists the start dates of 11 social unrest events from our data and compares them with the dates of coups d'état or coup attempts from Powell and Thyne (2011). The modal difference between two sets of dates is zero. For the four cases where our measure lags that of Powell and Thyne (2011), the difference is essentially a rounding issue, arising because we subdivide time into discrete units. In Turkey, military activity began very late at night on July 15. As a result, most media coverage of this event occurred on the following day. Moreover, given that the event itself did not begin until after markets had closed on the $15^{\text {th }}$, the $16^{\text {th }}$ of July is the right dating from a financial markets' perspective. Rounding similarly explains the difference in the case of Mali. In Burkina Faso, the difference arises because the event straddles the start of a new month. ${ }^{8}$

\footnotetext{
${ }^{8}$ The daily index exceeds 15 on October 30, in line with Powell and Thyne (2011), but because most of the unrest articles occur in November, November is identified as the event month. As a result, we date the event start day to the $1^{\text {st }}$ of November. Of course, one could further refine our media-based approach to prevent this particular case, but any methodology which divides time into discrete intervals will always fail in some edge cases.
} 
For the three remaining events in which we pre-date the coup identified by Powell and Thyne (2011) - Burundi, Egypt in February 2011 and Thailand - the coups were a consequence of previous social unrest, and thus the dates we identify are the days of the earlier unrest escalation, and not the coup itself. In Thailand, for instance, our approach identifies exactly the start of a political crisis resulting from the removal of the prime minister by the Constitutional Court on May $7^{\text {th }} 2014$. A coup by the Army followed two weeks later.

This exercise clearly shows that media-based social unrest index can be used to identify the beginning of major social unrest events with precision. In all of the 11 coup cases the dates from $S U_{k t}$ criterion match the Powell and Thyne (2011) dataset either exactly, or with a small reasonable lag. The precision of the results is even more striking considering that $S U_{k t}$ is calibrated to search for any instances of unrest, and the word "coup" is not even a part of our article search criteria.
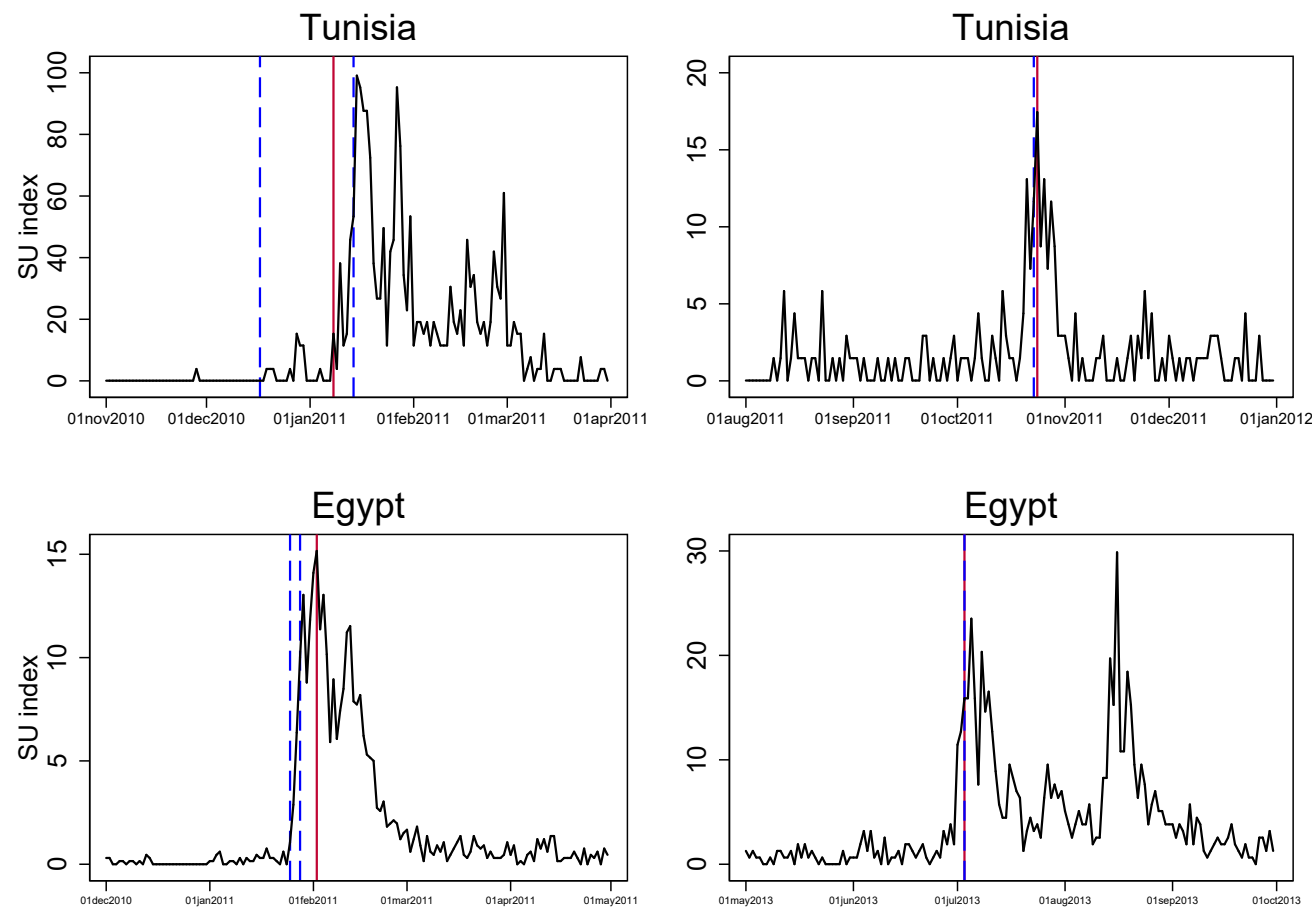

Figure 2: $S U_{k t}$. Red line - date identified using criterion $S U_{k t}>15$; blue dashed lines dates from an external source. Source: Worth (2016) as cited in Barrett et al. (2020)

In our second verification exercise, we evaluate the validity of day 0 identification against external data sources, using the Arab Spring in Egypt and Tunisia as examples. These countries were two of the most affected by the events of 2011, with governments in 
both countries falling as a result of the protests. Barrett et al. (2020) identify two event months for each country around this time: one in early 2011 (January for Tunisia, February for Egypt), and one later as post-revolutionary political turmoil continued (around the October 2011 elections in Tunisia, and the overthrow of the government in July 2013 in Egypt). Figure 2 plots $S U_{k t}$ for these periods, marking the dates identified in our data (red solid lines), as well as those from a reliable external source Worth (2016) (blue dashed lines).

In the rightmost charts, the alignment of our method with the other source is clear, with no difference in Egypt and a difference of only one day in Tunisia. For the early-2011 events (leftmost charts), the gap between the dating of our data and Worth (2016) reflects reasonable differences in identifying the start of Arab Spring when the tension built up over a series of events. For example, in Tunisia the first event cited by Worth (2016) is the December $16^{\text {th }}$ self-immolation of Mohammed Bouazizi. Despite some protests in late December, it was not until the death of Mr. Bouazizi in the evening of January 4 that mass demonstrations began. We date the start of unrest to January 7 , which is very close to this. ${ }^{9}$

Of course, the slow-building nature of some protests could affect the precision of day 0 , identified in our data, since media coverage of unrest in the preceding months affects $S U_{k t}$ through the pre-event average in the denominator. To ensure that these events do not introduce bias, and that our results are not driven by the Arab Spring events alone, we check the robustness of our results after excluding Arab Spring events from our sample (see Section 5).

In the third verification exercise, we compare our data on the 2019 wave of protests in South America with external sources. Figure 3 shows that the dates identified in our data coincide almost perfectly with those from external sources. Further validity checks are presented in Appendix (Figures A2 and A3).

\footnotetext{
${ }^{9}$ We do see a small spike in $S U_{k t}$ on the $4^{\text {th }}$ of January: according to our data, there was one media report related to social unrest on that day. However, since some protests in Tunisia started already in December, the pre-event average (the denominator in expression (1)) is relatively high, and $S U_{k t}=3.9$.
} 

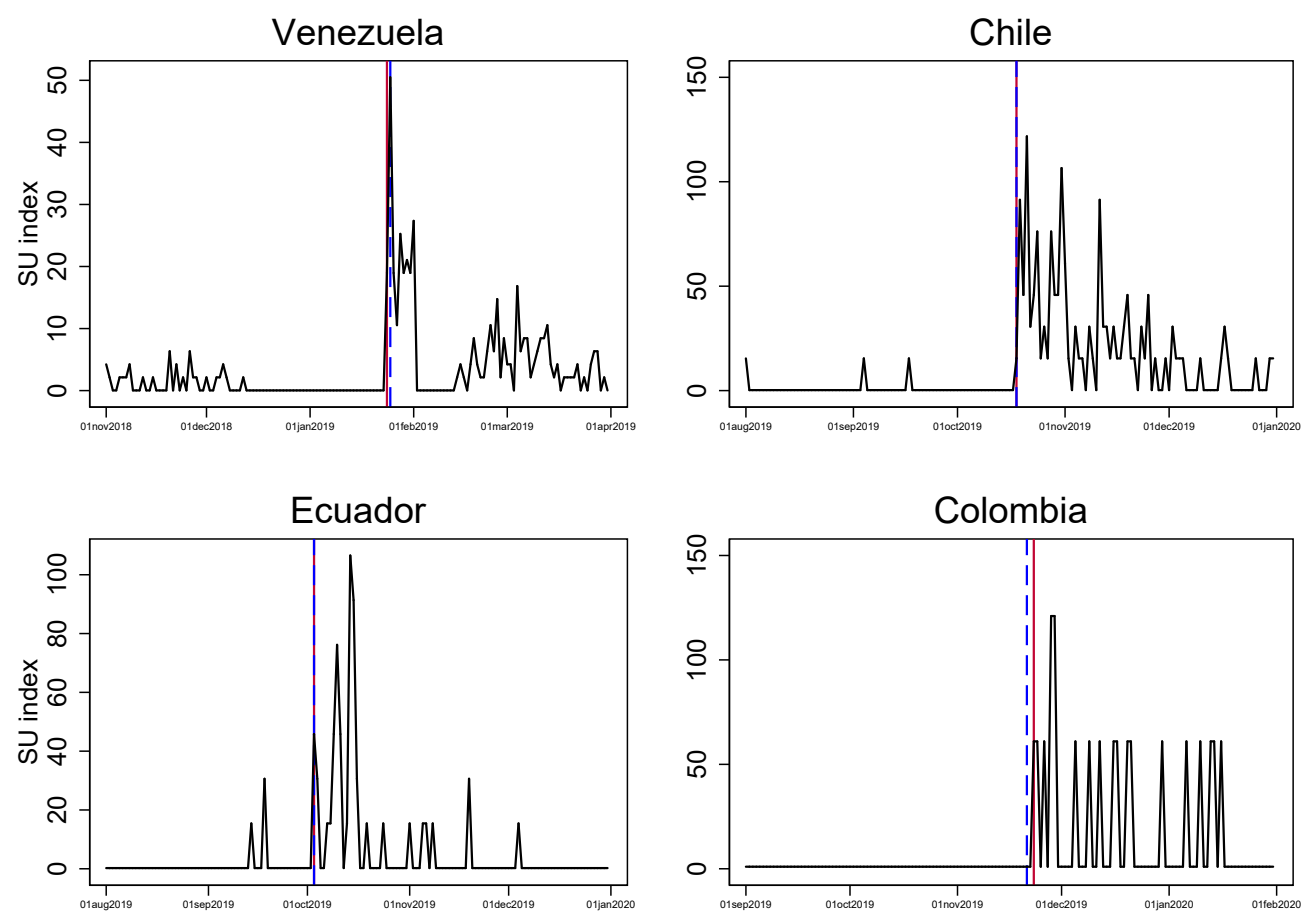

Figure 3: $S U_{k t}$. Red line - date identified using criterion $S U_{k t}>15$; blue dashed line date from external sources. Sources: Briceño-Ruiz (2019) as cited in Barrett et al. (2020) for Venezuela, Latin America Monitor (2020) for Colombia, Aljazeera news reports for Chile and Ecuador. Since the first spike of the $S U_{k t}$ in Ecuador is outside of the event month (October), it is not marked as day 0.

Overall, our high-frequency media-based index dates social unrest events with reasonable accuracy. More importantly, it has several advantages over narrative approaches and alternative data sources in identifying and dating social unrest events. Its criteria are consistent and transparent. It eliminates the need to search for and verify additional sources of information. And unlike other sources of unrest data, it can be constructed without the substantial time lag. 


\section{$3 \quad$ Data and Methodology}

\subsection{Data}

We merge our data on social unrest events with stock market indices for each country. Since the latter is not available for some countries (in particular some of the Middle Eastern and African countries), we drop 47 of the 203 daily events. Given that stock market data is only available on business (rather than calendar) days, we gather stock index information for approximately 50 business days either side of day $0 .{ }^{10}$ To adjust for events that happen over the weekend, we reassign day 0 to one (two) day(s) prior if the event fell on a Saturday (Sunday). To take into account possible time difference between the event and media coverage, we move day 0 one day back in countries from the Asia and Pacific region.

Our final sample contains 156 social unrest events across 72 countries, with over 15,000 daily observations. Our country sample has a broad coverage by geographical region and income group (Figure 4). The average duration of social unrest event in our final sample is 4.5 days. ${ }^{11}$ Despite losing some events, our sample includes some of the most well-known episodes of social unrest in the last decade (see Appendix Table A2 for a full list of events). As the country maps make clear, unrest often occurs in regional clusters, most notably the Arab Spring events in the Middle East in 2011 and the series of protests throughout Latin America in 2019. ${ }^{12}$

Data on stock indices, global and regional indices, as well as trading volume, exchange rate and bond yield come from Bloomberg and Datastream. Additional variables such as GDP per capita, market capitalization, inflation, interest rates, current account balance and government debt are from the IMF's International Financial Statistics and World Economic Outlook, and the World Federation of Exchanges Database.

\footnotetext{
${ }^{10}$ The exact number of days depends on whether day 0 happens to be in the beginning or the end of the event month.

${ }^{11}$ This number is slightly higher than the average duration of 4.2 days for the full sample of 193 daily events as shown in Table 2 .

${ }^{12}$ We find no evidence that clustered events have a significantly different impact on stock market behavior compared to non-clustered events (Table A12).
} 


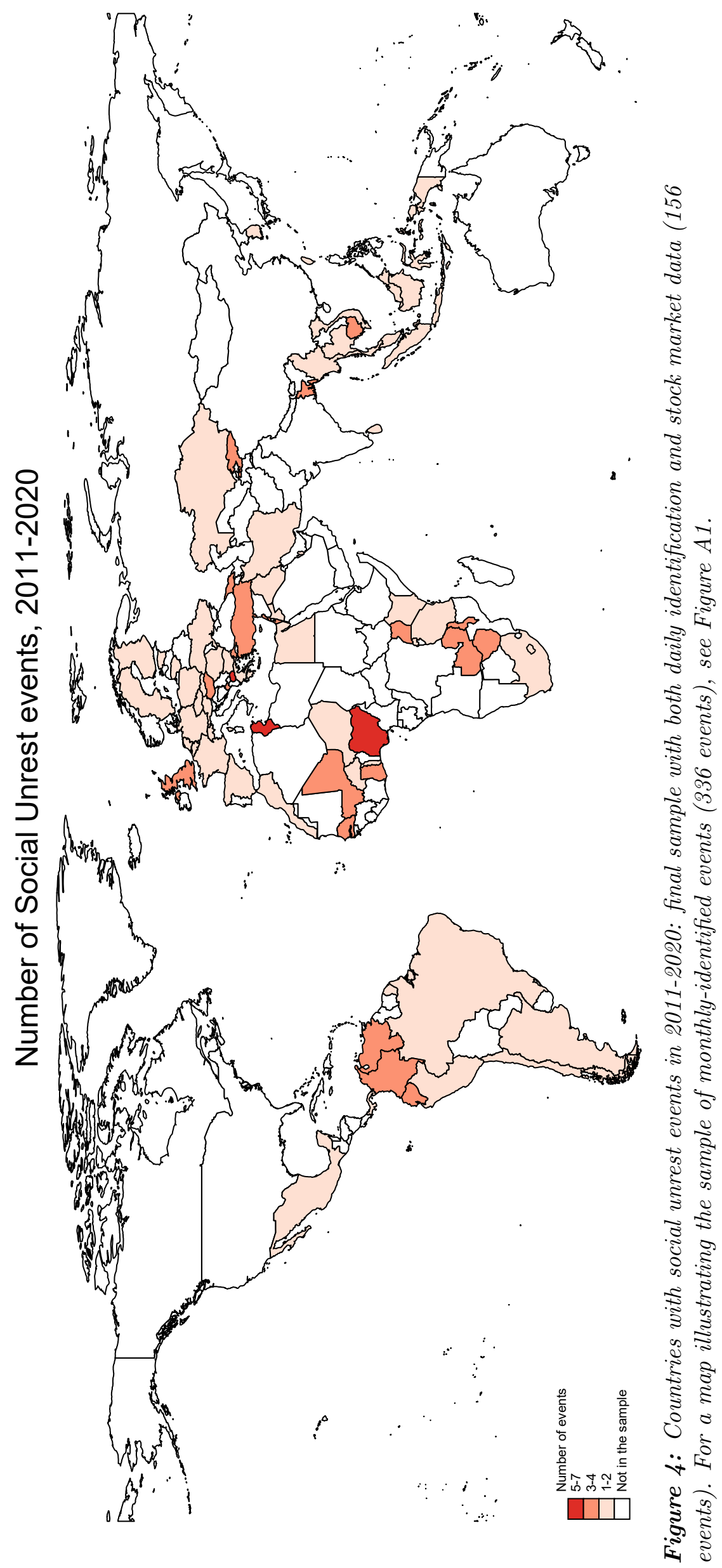

CInternational Monetary Fänd. Not for Redistribution 


\subsection{Event-study approach}

We follow the standard event-study methodology (MacKinlay (1997)) to quantify the impact of social unrest events on stock returns. First, we use the market model approach to calculate normal returns for each event $i$ :

$$
\begin{array}{r}
R_{i s}=a_{i}+b_{i} R_{m s}+\varepsilon_{i s} \\
\mathbb{E}\left(\varepsilon_{i s}\right)=0 \\
\operatorname{var}\left(\varepsilon_{i s}\right)=\sigma_{\varepsilon}^{2}
\end{array}
$$

where $R_{i s}$ are the returns of stock market index $i$ on day $s$, and $R_{m s}$ are the returns of the market portfolio on this day. ${ }^{13}$ Returns are measured as difference in log of stock market index between two business days. Given the cross-country nature of our study, in our headline results we use the returns of global stock market index MSCI ACWI as market returns. ${ }^{14}$ Equation (2) is estimated using OLS over the estimation period of [-50, -11] business days before the event. The estimation is performed for each event $i$ separately the estimated coefficients $a_{i}$ and $b_{i}$ are event-specific. We then compute abnormal returns $\left(A R_{i s}\right)$ as the difference between actual returns and the returns implied by the market model:

$$
A R_{i s} \equiv \hat{\varepsilon}_{i s}=R_{i s}-\hat{a}_{i}-\hat{b}_{i} R_{m s}
$$

where $\hat{a}_{i}$ and $\hat{b}_{i}$ are estimated in equation (2). Finally, we aggregate abnormal returns across events:

$$
A R_{s}=\frac{1}{N} \sum_{i} A R_{i s}
$$

Hence, for each day $s$ in the event window we obtain the estimate of average abnormal returns across all social unrest events in our sample.

The cumulative abnormal returns are the sum of average abnormal returns between day

\footnotetext{
${ }^{13}$ Strictly speaking, the level of our analysis is event - thus subscript $i$ stands for event. Since each event "belongs" to a certain country with a certain stock market index, we should interpret $i$ in regression (2) as stock market index of the country in which event $i$ happened. For simplicity, we write "stock market index $i "$.

${ }^{14}$ We replicate our exercise using alternative measures of market portfolio - other global and regional indices (e.g. S\&P Global 100, MSCI World, DJ Global Titans), as well as other approaches to compute abnormal returns. See Section 5 for details.
} 
0 (day of the event) and day $\tau$ :

$$
C A R_{0, \tau}=\sum_{s=0}^{\tau} A R_{s}
$$

The significance of both abnormal and cumulative abnormal returns is estimated using the Brown and Warner (1985) t-statistics. ${ }^{15}$

The event window is an important choice in the estimation. A short event window reduces the likelihood that confounding factors may contaminate the result and is suited for short events, such as an announcement of merger and acquisition or debt relief (see Campbell et al. (2010) for a literature summary). Yet a long event window is suited for big events that take time to unfold. For example, Forbes (2004) uses 2- and 12-weeks event windows to study the effect of the Asian financial crisis on stock returns. Social unrest events may be short or long. A protest may last for a day; coups may last for a few days; major events such as Arab Spring protests lasted for weeks. We address this nature of social unrest events in several ways. We estimate abnormal returns for up to 25 business days after the unrest event. ${ }^{16}$ This allows us to capture potential longer impacts of the events. For the regression analysis in Section 3.3, we focus on 4- and 8-day windows because, as we will show, the largest effects tend to occur in the immediate aftermath of an event. ${ }^{17}$ The crucial identification assumptions of the event study are that the timing of social unrest events is exogenous and correctly identified. As discussed earlier, we took careful steps to ensure the accuracy of the event timing in our dataset. This accuracy is also important for the exogeneity assumption. This is because even when the outburst of social discontent is expected to some degree (for instance, if unrest is caused by an economic shock, or by a controversial political decision), the exact timing of a social unrest event is rarely predictable and thus close to random. ${ }^{18}$ According to Figure 1, there is no evidence on anticipation effects in media coverage. As we will show, the unpredictability of the

\footnotetext{
${ }^{15}$ Alternative significance tests are presented in Table A6 of the Appendix.

${ }^{16} \mathrm{We}$ also compute cumulative abnormal returns for the period 10 to 1 business days (inclusive) before the event. This allows us to assess the possible pre-event trends in stock index returns. By construction, cumulative abnormal returns on day -1 are equal to zero. This guarantees that cumulative abnormal returns are consistently estimated around day 0 and facilitates interpretation of the observed effects.

${ }^{17}$ The results for 1-, 2-, 3- and 5-day windows are available upon request.

${ }^{18}$ Hlatshwayo and Redl (2020a) show that past unrest, inflation in food prices and unrest in neighboring countries are the important drivers of social unrest in the year ahead. Hlatshwayo and Redl (2020b) conduct a series of exogeneity tests of social unrest, using machine-learning techniques and instrumental variable approach. The authors find that social unrest has a significantly negative impact on output even after controlling for potential endogeneity.
}

CInternational Monetary Fønd. Not for Redistribution 
timing of events is further corroborated by the absence of pre-event trends in cumulative abnormal returns.

A common challenge to identification in event studies is that other shocks could affect the outcome variable simultaneously. This concern is most relevant in settings with only a few events. It is somewhat lessened in our setting as we have a large sample of crosscountry events over time. This makes it impossible for a single omitted factor to drive our results. Instead, the assumption we need to identify the conditional mean impact of unrest is that other shocks are not systematically correlated with the timing of unrest. We conduct a placebo test in Section 5, checking if stock market returns follow a similar pattern in countries not affected by social unrest.

\subsection{Regression analysis}

We complement the event-study approach with regression analysis. The regression approach has several advantages over the event-study approach. First, it allows for a multivariate setting in which characteristics of the event can be controlled for. Second, it relaxes the assumption on a linear relationship in the market model (2). Third, it improves the efficiency in the estimation of the market model (in case of low number of observations in the estimation period). ${ }^{19}$ Finally, it addresses the well-known clustering problem in the event study approach, which occurs when event windows of different crosssectional units overlap in calendar time. Not addressing the clustering problem leads to a cross-sectional correlation of abnormal returns and can result in over-rejecting the null hypothesis (Kolari and Pynnonen (2010)).

We estimate the following multivariate regression:

$$
R_{i s}=\beta_{0}+\beta_{1} \times \mathbb{1}\left[\text { Unrest }_{i s}\right]+S+S^{2}+\gamma_{k}+\delta_{s}+\varepsilon_{i s}
$$

where $R_{i s}$ are the daily stock index returns, $S$ and $S^{2}$ control for time trend (number of days since day 0, following Arteaga-Garavito et al. (2020)), and $\gamma_{k}$ and $\delta_{s}$ are country and weekday fixed effects respectively. We estimate regression (6) over a period of $[-50,+50]$ business days around the event. The variable of interest is $\mathbb{1}\left[\right.$ Unrest $\left._{i s}\right]$ - a dummy variable equal to one on days within the event window. We focus on two event windows: $[0,+3]$

\footnotetext{
${ }^{19}$ According to MacKinlay (1997), the effectiveness of the market model approach depends on the $R^{2}$ of regression (2): low $R^{2}$ implies high variance of the resulting abnormal returns.
}

CInternational Monetary Find. Not for Redistribution 
and $[0,+7]$ days after the event. We apply Newey-West variance estimator to account for heteroskedasticity and autocorrelation in standard errors (up to lag 2). The coefficient of interest is $\beta_{1}$ - it measures the effect of social unrest on the average 4- or 8-day returns after the event. Under the assumption that the timing of social unrest episodes is exogenous conditional on covariates, $\beta_{1}$ can be interpreted as the average causal effect of social unrest on stock market performance.

The event-study and regression analysis differ in three important regards. First, the eventstudy approach computes event-specific counterfactuals, estimating different loadings (the $a_{i}$ and $b_{i}$ ) on the global portfolio for different events. In contrast, the estimated coefficients for the regression approach represent the average impact of unrest conditional on covariates $\left(\beta_{1}\right)$, which is by construction identical for all events. Second, the counterfactuals computed across the two methods have different functional forms. In the event-study case, only returns on the global portfolio matter, whereas the regression setting allows for additional controls (country and weekday fixed effects, quadratic time trend). Finally, the data used to inform the counterfactuals differs across the methods. In the event-study case, only pre-event data is used to estimate counterfactual returns, whereas in the regression setting post-event returns also matter. The advantage of the regression approach is that it uses more data. The disadvantage is that if the unrest has an effect on daily returns at horizons longer than the event window, the post-event data will be wrongly labeled as untreated and will bias the coefficient estimates towards zero. ${ }^{20}$

One final advantage of the regression methodology is that it allows us to look at the effect of social unrest on variables other than stock returns for which there is no obvious benchmark - trading volume, bond yield and exchange rate. We discuss some of these additional results in Section 6.

\subsection{Control variable regression}

High-frequency data is important for our purpose - it guarantees that our results are not driven by unobserved simultaneous factors. However, most, if not all, country-specific indicators are unavailable in daily frequency. Therefore, they cannot be controlled for

\footnotetext{
${ }^{20}$ There is also a more minor difference: the units of the event study and regression approaches are a little different. The former uses cumulative abnormal returns, whereas the latter estimates the average daily abnormal returns. When comparing the two directly we therefore multiply estimate of $\beta_{1}$ in equation (6) by the number of days in the event window.
} 
in the regression model (6). We use two approaches to account for heterogeneity across countries. First, we split the sample by country characteristics and include the interactions of country group dummies into the regression. Second, we use a control variable regression model in which cumulative abnormal returns are regressed on a vector of control variables of interest. Following Forbes (2004), we re-estimate our market model over the period of $[-50,+50]$ days around the event:

$$
R_{i s}=\alpha_{i}+\beta_{i} R_{m s}+\omega_{i} \mathbb{1}\left[\text { Unrest }_{i s}\right]+\mu_{i s}
$$

where $\mathbb{1}\left[\right.$ Unrest $\left._{i s}\right]$ is a dummy equal to 1 on event-window days (for $s \in[0,+3]$ ). We then use the estimated coefficient $\hat{\omega}_{i}$ (i.e. 4-day average abnormal returns for event $i$ ) as the dependent variable in equation (8):

$$
\hat{\omega}_{i}=\boldsymbol{F}_{\boldsymbol{i}} \boldsymbol{\Psi}+\eta_{i}
$$

Note the absence of time subscript $s$ in equation (8) - the regression is no longer timedependent, and the vector of control variables $\boldsymbol{F}_{\boldsymbol{i}}$ can include regressors that don't vary daily. An advantage of this control variable approach over interacting a sample split dummy is that we can consider multiple variables at the same time and examine whether they are simultaneously important. ${ }^{21}$

\footnotetext{
${ }^{21}$ One obvious drawback of this approach is that the number of observations in control variable regression is limited to the number of cross-sectional units (events).
} 


\section{Main results}

\subsection{Cumulative abnormal returns}

Figure 5 presents our main results from the event-study approach.

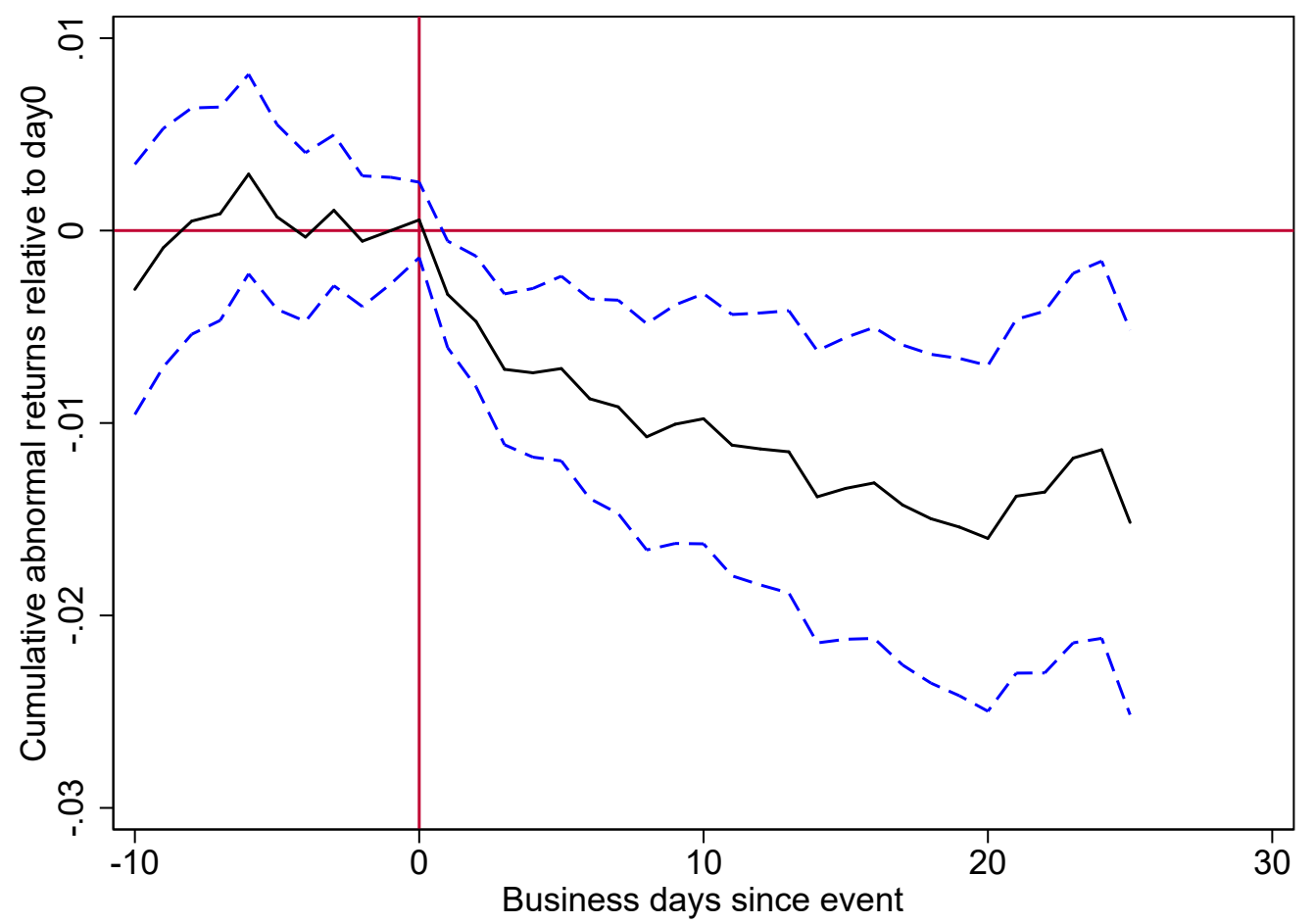

Figure 5: Cumulative abnormal returns based on market model from equation (2). Market returns based on MSCI ACWI. Blue dashed lines - 95\% confidence intervals, computed using Brown and Warner (1985) t-statistics.

We find that social unrest leads to a significant reduction in stock market returns. Cumulative abnormal returns drop by around 0.72 percentage points three days after the unrest event relative to day -1 . The returns continue to decline afterwards, reaching -1.4 percentage points two weeks after the event. The effect is not only statistically significant over the whole event window, but also economically meaningful: a 1.4 percentage point decline corresponds to the ninety-fifth percentile of the two-week cumulative returns distribution during the pre-event sample. In other words, the unconditional probability of observing the change of such magnitude in two-weeks cumulative returns before the event 
is only 5 percent. ${ }^{22}$

The estimated effect of social unrest is of a similar magnitude to that in the literature. Epstein and Schnietz (2002), for instance, find that Fortune 500 companies experienced a 1.86 percent decline in their cumulative abnormal returns after WTO protests in Seattle in 1999. The magnitude of a decline in cumulative abnormal returns that we observe following a social unrest event is larger than the decline in the Dow Jones Industrial Average index following the terrorist events such as World Trade Center Bombing in 1993 (0.59\%) or Embassy Bombing in Kenya in 1998 (0.59\%, see Chen and Siems (2004)). ${ }^{23}$ Several additional results in Figure 5 are worth noting. First, the negative impact of social unrest on stock return is not short-lived. Cumulative abnormal returns remain significantly negative at least 25 business days after the unrest event (i.e. the end of our event window). We also observe no reversion to zero over a longer time horizon, as shown in Appendix Figure A4. The long duration of the impact implies that social unrest may have a level effect on stock market performance, leading to permanently lower valuation. Second, the results presented in Figure 5 are robust to the choice of market portfolio. They are qualitatively and quantitatively similar if we use an alternative global stock index in the market model (e.g. S\&P Global, see Appendix Figure A5). Last but not least, we see no trend in the period leading up to the event. Figure 5 shows that cumulative abnormal returns on days before the event are not significantly different from zero. This result implies that events are not priced in by market participants in the pre-event period. It further corroborates our identification assumption on the unpredictability of the event timing. Overall, given that abnormal returns before the event are not different from zero, and that the probability of observing such a drop in buy-and-hold returns in the pre-event sample is very low, we can reasonably interpret the observed decline as a causal effect of social unrest on stock market performance.

\footnotetext{
${ }^{22}$ To calculate the distribution of returns, we compute 14-day buy-and-hold returns for each of the available pre-event days for each event, i.e. the returns between day -25 and -11 , between day -26 and -12 and so on until day -60 to day -46 . We then summarize the distribution across all events.

${ }^{23}$ To our knowledge, Acemoglu et al. (2017) is the only other paper that looks at the effects of social unrest on stock market performance in the event-study framework. The authors find the effect of protests in Egypt in 2011 to be much larger - 8-day cumulative abnormal returns drop by 14.5 percentage points. However, it is important to note that the authors concentrated on the returns of the firms connected to political power (and thus more severely affected by the political instability).
} 


\subsection{Regression results}

Table 4 reports the main results of the regression model (6). The two columns correspond to two different regressions with 4- and 8-day event windows respectively.

Table 4: Estimating equation (6); dependent variable - stock market index returns

\begin{tabular}{lcc}
\hline \hline & {$[0,+3]$} & {$[0,+7]$} \\
\hline Dummy for social unrest & $-0.00165^{* *}$ & $-0.00109^{*}$ \\
& $(0.001)$ & $(0.001)$ \\
\hline Country FE & Yes & Yes \\
Weekday FE & Yes & Yes \\
Observations & 15075 & 15075 \\
F-stat & $1.969^{* * *}$ & $1.949^{* * *}$ \\
\hline \hline
\end{tabular}

Newey-West standard errors with 2 lags in parentheses.

${ }^{*} p<0.10,{ }^{* *} p<0.05,{ }^{* * *} p<0.01$

We find that social unrest reduces stock market returns by 16.5 basis points on average in the first four days after the event. This effect attenuates somewhat over the longer event window, reaching 10.9 basis points over 8 business days after the event. We report the Newey-West (heteroskedasticity- and autocorrelation adjusted) standard errors with lag 2 in the table parenthesis. ${ }^{24}$ Our error assumptions are thus less restrictive compared to the Brown and Warner (1985) t-statistics reported in the event-study approach. The fact that our estimates are statistically significant at the $5 \%$ level in both approaches gives us confidence that we do not falsely reject the null hypothesis of zero cumulative abnormal returns.

We also use regression analysis to check the existence of anticipation effects. To do this we change the definition of event window by including day -1 into the interval. Appendix Table A3 shows that although the coefficient $\beta_{1}$ over both event windows is still statistically significant and negative, it is much smaller in absolute value. In other words, including day -1 before the event reduces the magnitude of a drop in returns during the event window, implying little anticipation effect the day before the event. This result is also consistent with the absence of pre-event trend in cumulative abnormal returns in Figure 5 .

\footnotetext{
${ }^{24}$ The choice of lag does not affect the results.
} 
To provide further comparison between results from the two approaches, we estimate equation (6) for 25 different event windows, and plot adjusted coefficients $\beta_{1}$ against cumulative abnormal returns from Figure 5. We adjust the coefficients by multiplying them with the number of days in the event window (thus, coefficient from the first column of Table 4 is multiplied by 4 , the coefficient from the second column - by 8 and so on). This adjustment corrects for the difference in magnitude between cumulative (event-study) and average (regression) returns. The results of comparison are summarized in Figure 6.

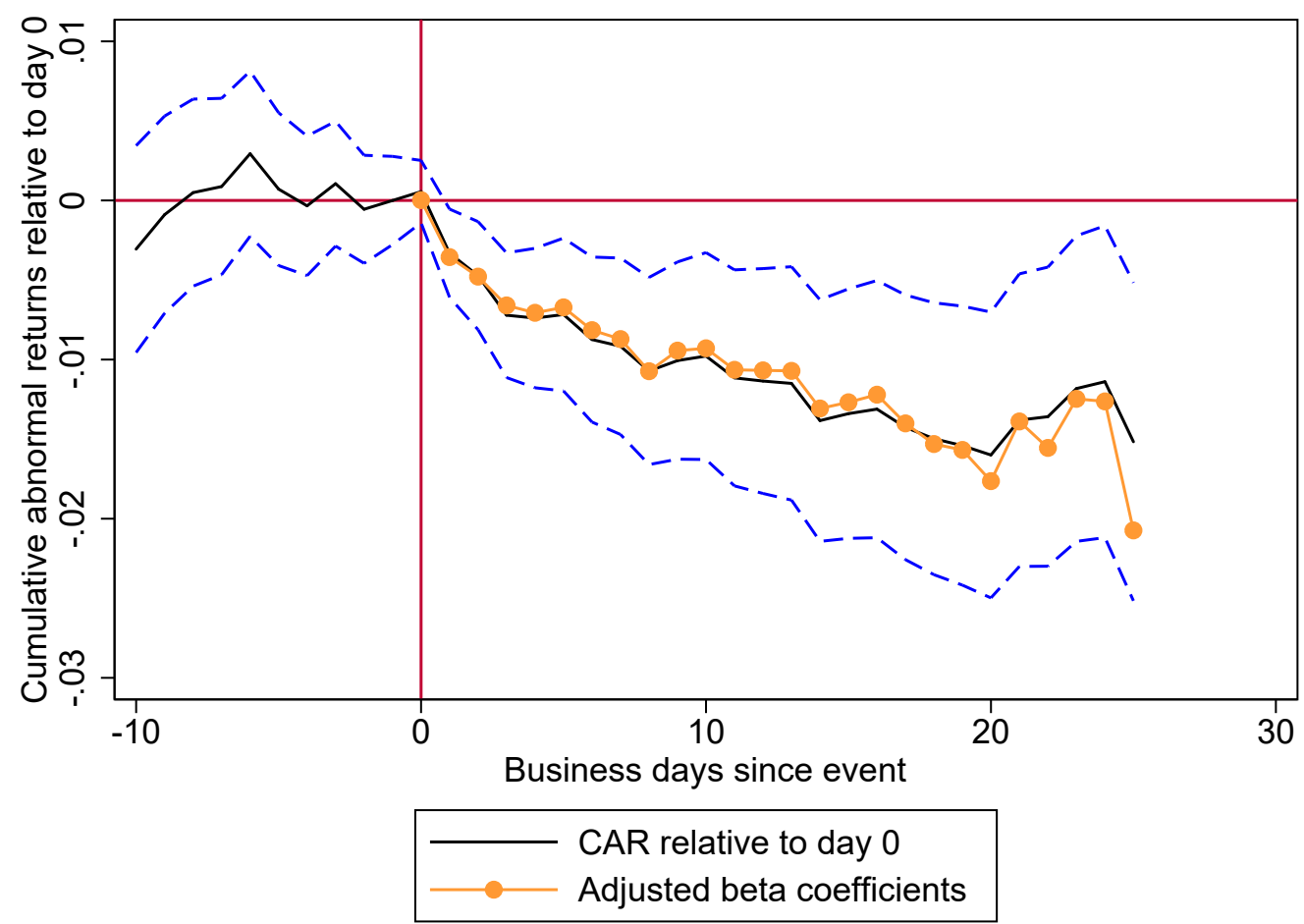

Figure 6: Cumulative abnormal returns. Based on market model from equation (2), market returns based on MSCI ACWI. Blue dashed lines - 95\% confidence intervals, computed using Brown and Warner (1985) t-statistics. Orange line connects beta coefficients from equation (6) multiplied by the number of days in the event window.

This comparison shows that our results are not sensitive to the choice of empirical approach. Regardless of whether we use event-study or regression, the estimates are quantitatively and qualitatively unchanged. We will come back to the robustness of our results in Section 5. 


\subsection{Heterogeneities: duration and income}

We have established that social unrest leads, on average, to a sharp and persistent reduction in stock market returns in the country where unrest occurs. We next investigate potential heterogeneities in this effect across events and countries. We first ask whether long- and short-duration events differ. We plot the results on Figure 7.

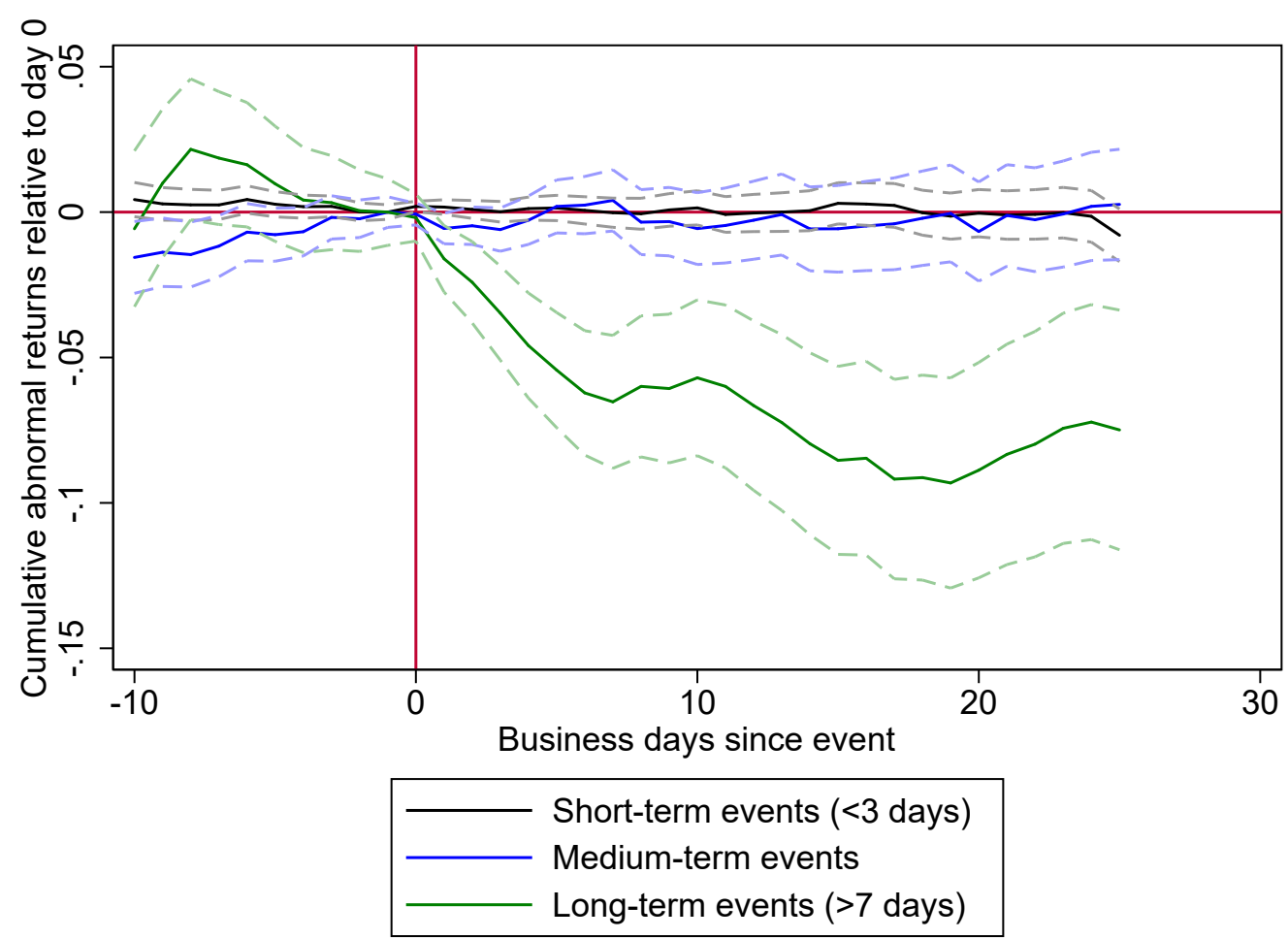

Figure 7: Cumulative abnormal returns by duration groups. Based on market model from equation (2), market returns based on MSCI ACWI. Dashed lines - $95 \%$ confidence intervals, computed using Brown and Warner (1985) t-statistics.

To investigate the role of event duration, we classify events as short-term (last for less than 3 days), medium-term (last between 3 and 7 days), or long-term (last for more than 7 days). ${ }^{25}$ The majority (54\%) of the events in our sample are short-term. Longterm events constitute $16 \%$ of the sample (25 out of 156 events, with average duration of 16.5 days). They include, among others, Arab Spring protests in Tunisia, Egypt and Iran in 2011, Ukrainian civil unrest in 2013 ("Euromaidan"), Greek anti-austerity protests of 2012 and French "Yellow vests" movement of 2018. Our list of long-term events seems

\footnotetext{
${ }^{25}$ Recall, that the average event in our sample lasts for 4.5 days.
} 
reasonable when compared to external sources, as it includes many instances of social instability that are commonly known to have lasted for days and even weeks. Appendix Table A2 shows the duration of each event in our sample.

We find that the duration of the event matters: the longer the event, the larger are the stock market reactions. Figure 7 clearly indicates that the average effect we found in our baseline results is driven by long-term events and, to a lesser extent, by medium-term events (see Appendix Table A4 for the results of regression estimation). The impact of long-term events is statistically significant and substantial in magnitude: cumulative abnormal returns decrease by as much as 8 percentage points in countries that experience persistent social instability. ${ }^{26}$ The magnitude of the response is closer to the 14.5 percentage point drop in cumulative abnormal returns that Acemoglu et al. (2017) report for 2011 Arab Spring protests in Egypt.

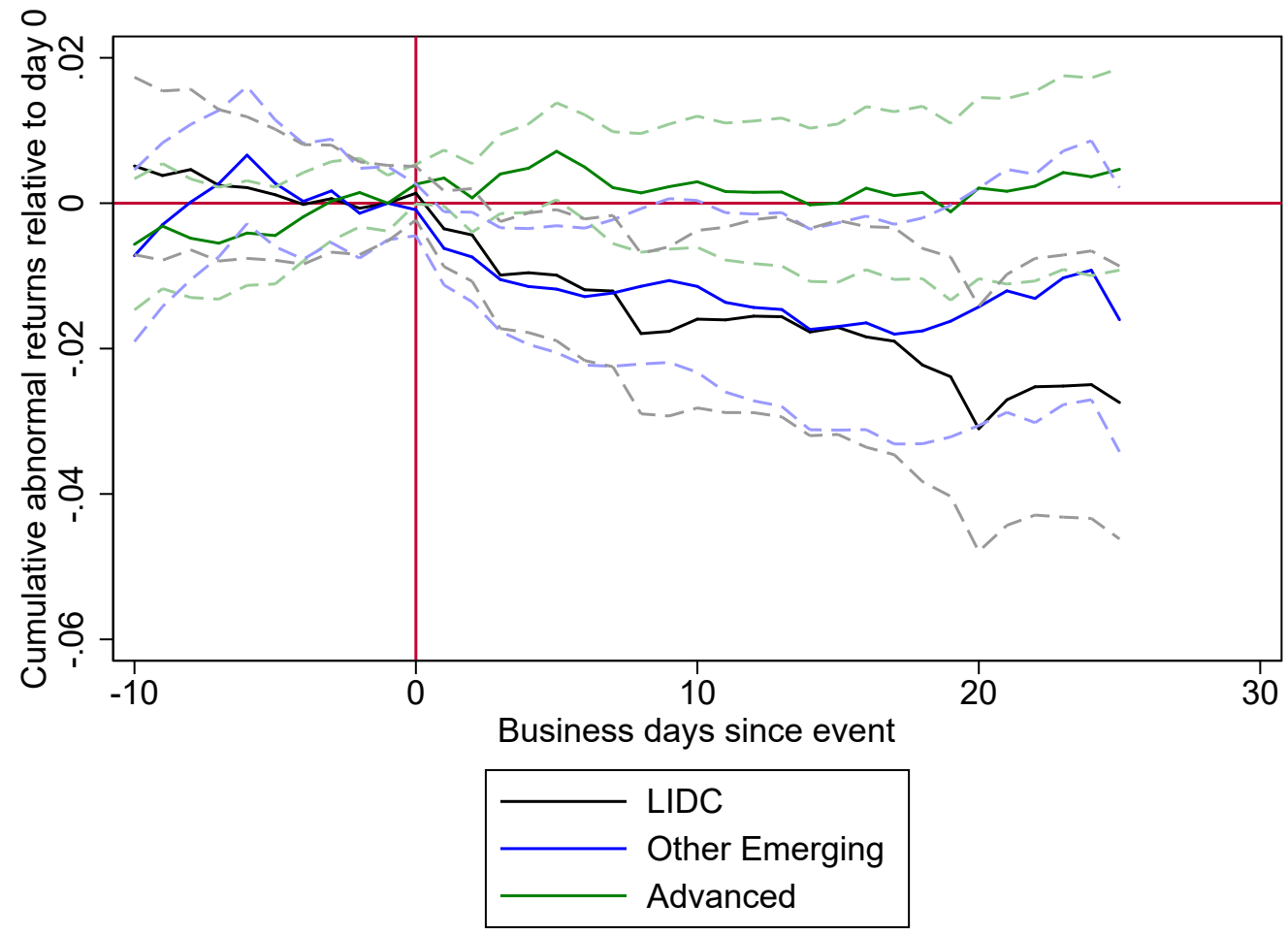

Figure 8: Cumulative abnormal returns by country income groups. Based on market model from equation (2), market returns based on MSCI ACWI. Dashed lines - 95\% confidence intervals, computed using Brown and Warner (1985) t-statistics.

Next, we investigate the role of economic development. We split our sample of events into three groups based on country income level (advanced economies, low-income

${ }^{26}$ The results are similar if we split events into two groups based on median duration. 
developing countries - LIDC, and other emerging and developing economies - EMDE) and repeat the procedure. Figure 8 and Table A5 show the results. We find that the decrease in the cumulative abnormal returns of stock market indices is driven by events in EMDE and LIDC. ${ }^{27}$ Stock markets in advanced economies on average are not subject to the negative consequences of social unrest - the estimate for advanced economies is never significantly different from zero. This result is in line with the anecdotal evidence that US stock market reacts very mildly to protests on police brutality (Sraders (2020)) Of course, country characteristics such as income may be the result of other factors, such as a country's political and social institutions. We turn to this issue in the next section.

\subsection{The role of institutions}

The literature on the effects of social and political instability highlights the importance of institutions in mitigating its negative consequences. Eldor and Melnick (2004), for instance, find that market liberalization reforms contribute to coping with terrorist attacks and help markets function efficiently. According to Bernal-Verdugo et al. (2013), the recovery of output after social instability incidents depends on whether the country implements reforms that improve the level of governance. In this section, we examine whether institutions matter for stock market reactions to social unrest.

We first look at the role of democratic institutions. We split our sample of events into two groups based on the Polity Score developed by the Center for Systemic Peace. ${ }^{28}$ The Polity Score is a widely used measure of the degree of regime authority. It ranges from -10 (hereditary monarchy) to +10 (consolidated democracy). We use the median Polity Score in our sample (score of 6 ) as a threshold. ${ }^{29}$ We use the Polity5 dataset which covers the period of 1800-2018, and, assuming that Polity Score doesn't vary much over time, impute 2018 Polity Score dummy values for the events that happened in 2019 and 2020. The results are presented in Figure 9.

\footnotetext{
${ }^{27}$ Note, that although cumulative abnormal returns for the LIDC are significant at $5 \%$ level starting from day 8, regression coefficients for LIDC are not statistically significant, albeit important in terms of magnitude. This happens because confidence intervals computed using Newey-West variance estimator are generally wider. This is the only instance in which our event-study results are not entirely corroborated by regression.

${ }^{28}$ The data are available at https://www.systemicpeace.org/polityproject.html

${ }^{29}$ This threshold also coincides with what Polity Project defines as democracies $(+6,+10)$ as opposed to anocracies $(-5,+5)$ and autocracies $(-10,-6)$.
} 


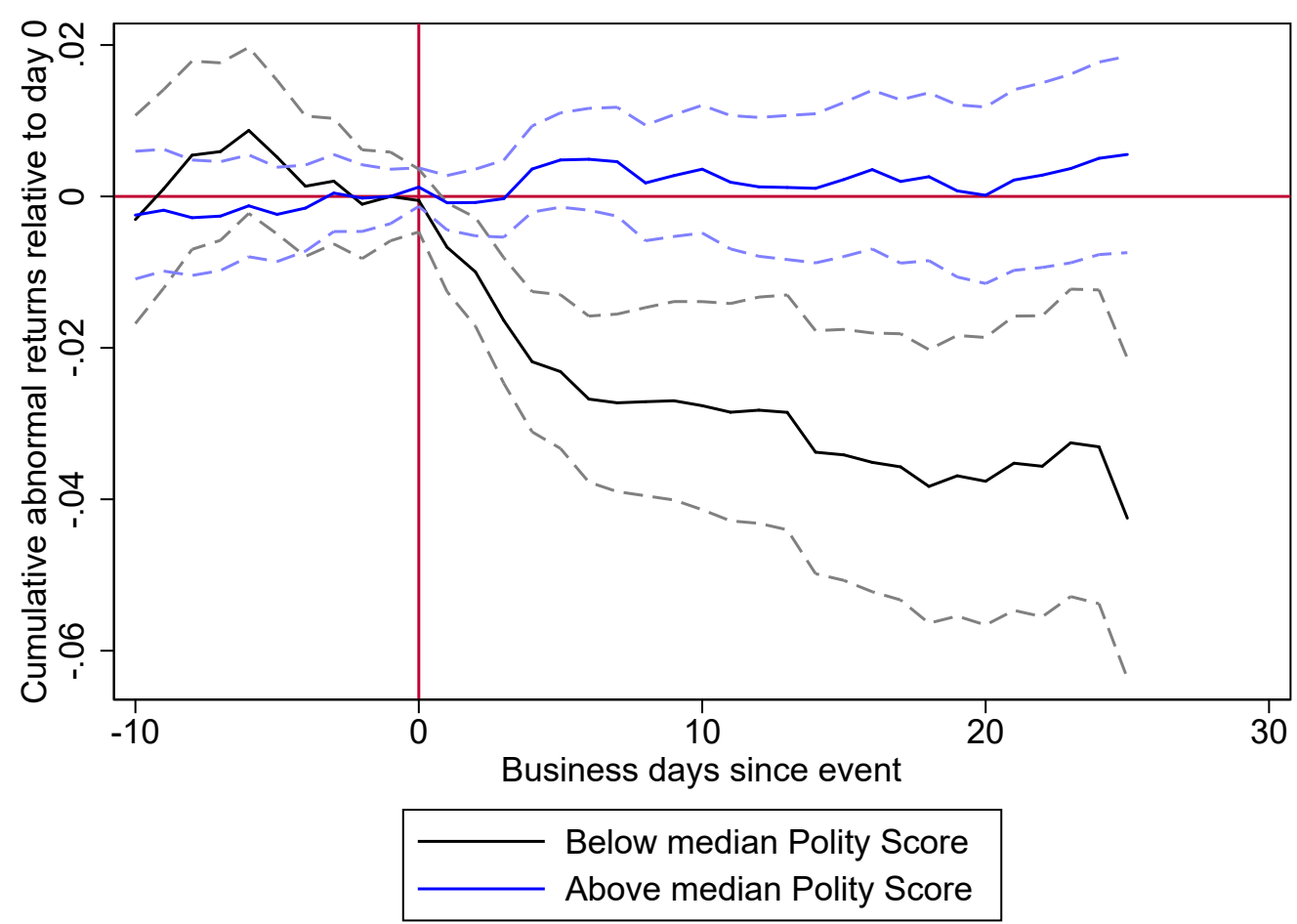

Figure 9: Cumulative abnormal returns by Polity Score. Based on market model from equation (2), market returns based on MSCI ACWI. Dashed lines - 95\% confidence intervals, computed using Brown and Warner (1985) t-statistics.

Figure 9 has a clear message: the negative effect of social unrest on stock index returns is pronounced only in countries with below median Polity Score. The impact of social unrest is more negative in less democratic countries: cumulative abnormal returns in these countries drop by more than 3 percentage points over the 14-day event window. The impact on the economies with above median Polity Score seems to be negligible: the cumulative abnormal returns are never significantly different from zero.

We further look at additional indicators of institutional quality - World Governance Indicators. $^{30}$ WGI Project compiles data on traditions and institutions from various sources into six governance indicators: Rule of Law, Control of Corruption, Government Effectiveness, Regulatory Quality, Political Stability and Voice and Accountability. We use the percentile ranking of countries for each of these indicators to split our sample into two groups based on the median. Since WGI indicators are only available for 2011-2019, we impute 2019 values for the events in 2020. The results are summarized in Figure 10.

${ }^{30}$ The data are available at https://info.worldbank.org/governance/wgi/ 


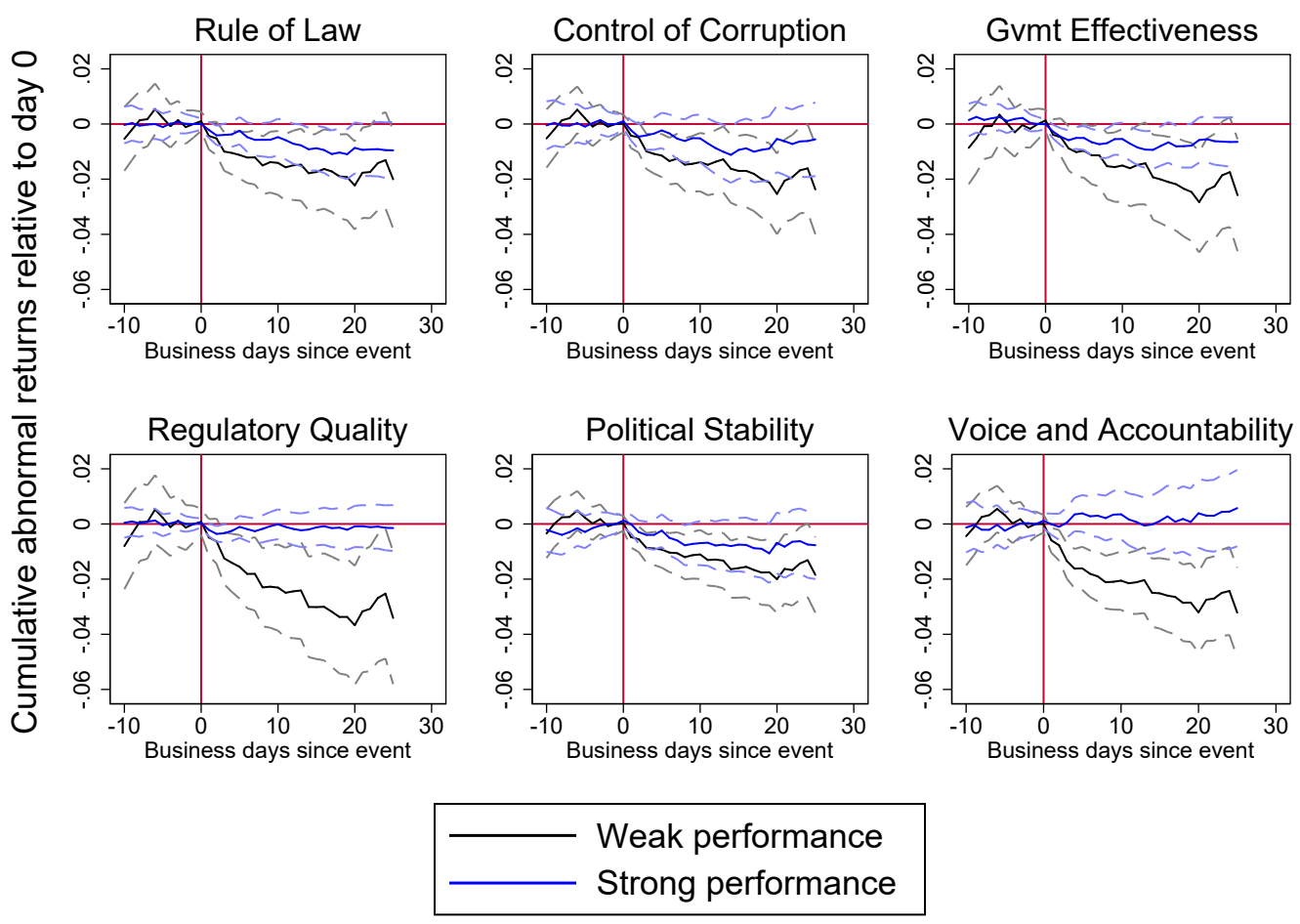

Figure 10: Cumulative abnormal returns by groups based on World Governance Indicators, 2011-2020. CARs based on market model from equation (2), market returns based on MSCI ACWI. Dashed lines - 95\% confidence intervals, computed using Brown and Warner (1985) t-statistics.

Governance indicators along two dimensions - Regulatory Quality and Voice and Accountability - have a statistically significant impact on stock market performance after social unrest. In both cases social unrest events affect cumulative abnormal returns only in countries with weak (below median) governance. Regulatory Quality indicator captures governance features which promote or prevent the development of the private sector (e.g. price controls, investment freedom, discriminatory taxes etc.). The measure of Voice and Accountability is similar in interpretation to Polity Score: this indicator aggregates information on democracy, freedom of press and political rights.

The results in Figures 9 and 10 point to the importance of governance institutions. Democracy, civil freedoms and government accountability, as well as quality of private sector regulation play a crucial part in shaping the consequences of social unrest events. The aftermath of social unrest is more severe in countries with weak institutions: the stock markets in these economies seem to be the most vulnerable to social instability. 
Table 5: Estimating equation (8) - control variable regression; dependent variable - average 4-day abnormal returns.

\begin{tabular}{lcccc}
\hline \hline & $(1)$ & $(2)$ & $(3)$ & $(4)$ \\
\hline Medium event & -0.00178 & & -0.00185 & -0.00149 \\
& $(0.002)$ & & $(0.001)$ & $(0.001)$ \\
Long event & $-0.00736^{* *}$ & & $-0.00807^{* *}$ & $-0.00778^{*}$ \\
& $(0.004)$ & & $(0.004)$ & $(0.004)$ \\
LIDC & & -0.00283 & $-0.00442^{*}$ & -0.00276 \\
& & $(0.002)$ & $(0.002)$ & $(0.002)$ \\
EMDE & & $-0.00335^{* * *}$ & $-0.00361^{* * *}$ & $-0.00258^{*}$ \\
& & $(0.001)$ & $(0.001)$ & $(0.001)$ \\
Polity score above median & & & & $0.00257^{*}$ \\
& & & & $(0.001)$ \\
\hline $\mathrm{N}$ & 156 & 156 & 156 & 155 \\
\hline \hline Standard errors in parentheses & & & & \\
$* p<0.10,{ }^{* *} p<0.05,{ }^{* * *} p<0.01$ & & & \\
\hline
\end{tabular}

The heterogeneity analysis conducted in previous sections suggests that the influence of social unrest on stock market behavior across the world depends on several eventand country-characteristics: duration of social unrest, country income group and quality of institutions. One potential concern is that some of these parameters are correlated. For instance, it is possible that the strong negative effect of unrest in LIDC and EMDEs is driven by the fact, that social unrest in these countries tends to be more long-term. To check whether the three factors are simultaneously and independently important, we use the control variable approach summarized in Section 3.4. The results of estimating equation (8) are presented in Table 5.

The first two columns of Table 5 show the results that consider only event duration (column 1) or only country income group (column 2). Column 3 shows results that consider both country income (with advanced economies as reference category) and duration (with short-term events as reference category) groups. Although the two variables are negatively correlated (since the coefficients of income decrease), both income and duration coefficients are statistically significant, at least for long events in EMDEs. Column 4 further includes a dummy variable equal to 1 if country is above median Polity Score. Despite a small number of observations, the coefficients of duration, income and Polity 
Score are statistically significant at the $10 \%$ level. As before, long duration of social unrest implies starker decrease in average abnormal returns, while democratic institutions partly mitigate the effect. The coefficient of EMDE dummy, however, is smaller in magnitude. This result seems to suggest that country income group (at least in case of LIDC) serves as a proxy for democracy in regressions with omitted Polity Score dummy.

\subsection{The role of elections}

According to Table 5, the quality of democratic institutions - as measured by Polity Score - is an important predictor of the stock market reaction to social unrest even after controlling for income and duration. It is possible, however, that the democracy indicator reflects some underlying country-specific features, not captured in our control variable regression. For instance, one could argue that the countries with above median Polity Score also exhibit high regulatory quality and effective governance (our analysis of World Governance Indicators in Figure 10 provides some indirect evidence of this possibility). If this is the case, the democracy indicator in Table 5 serves as a proxy for unobserved quality of governance.

In order to disentangle the two channels, we use data on lower chamber legislative elections at a constituency level from Constituency-Level Elections Archive (CLEA). ${ }^{31}$ CLEA records the dates and the outcomes of elections from as early as 1788 . We generate a dummy variable equal to one if the elections occur within $[-50,+50]$ business days around the social unrest event. Thus, we can distinguish between election-related social unrest events and other types of social unrest. By the nature of collected information, CLEA provides election data for a selected pool of countries that have regular elections. Thus, we conduct our heterogeneity analysis on a reduced set of countries. ${ }^{32}$ Out of 140 social unrest events in our reduced set, only 21 happen simultaneously with lower chamber elections, and can be classified as election-related. We then estimate equation (6), including interaction term $S U \times$ Elections. Since our regression equation controls for country fixed effects, the coefficient of the interaction term captures the difference between electionrelated unrest and all the other unrest events within countries. The results are presented in Table 6 .

\footnotetext{
${ }^{31}$ The data are available at http://www.electiondataarchive.org/

${ }^{32}$ Specifically, we exclude 16 events in Egypt, Hong Kong SAR, Jordan, Kyrgyzstan, Morocco, Mali, Panama, Qatar and Vietnam from our final sample of 156 events.
} 
Table 6: Estimating equation (6); dependent variable - stock market index returns. Includes interaction terms between Social Unrest dummy and Election dummy.

\begin{tabular}{lcc}
\hline \hline & {$[0,+3]$} & {$[0,+7]$} \\
\hline Dummy for social unrest & $-0.00191^{* *}$ & $-0.00166^{* *}$ \\
& $(0.001)$ & $(0.001)$ \\
SU*Elections & $0.00295^{* *}$ & $0.00214^{*}$ \\
& $(0.001)$ & $(0.001)$ \\
\hline Country FE & Yes & Yes \\
Weekday FE & Yes & Yes \\
Observations & 13529 & 13529 \\
\hline \hline
\end{tabular}

Newey-West standard errors with 2 lags in parentheses.

${ }^{*} p<0.10,{ }^{* *} p<0.05,{ }^{* * *} p<0.01$

The coefficient of the interaction term $S U \times$ Elections is positive and statistically significant. Although on average social unrest in democratic countries leads to a 19 b.p. decline in stock market returns, social unrest related to election outcomes actually improves stock market performance by 10 b.p. Thus, politically-conditioned social unrest leads to an increase in stock market returns. This finding has several important implications. First, it confirms the previously documented absence of stock market reaction to unrest in countries with above median Polity Score (Figure 9) and above median Voice and Accountability indicator (Figure 10). Second, it shows that the lack of statistically significant decrease in CAR is explained primarily by the quality of democratic institutions, rather than by differences along other institutional dimensions (such as governance). We will return to a more comprehensive discussion of the mechanisms behind these results in Section 6. 


\section{Robustness checks}

We perform a series of robustness checks. We first use alternative approaches to calculate cumulative abnormal returns. We then explore alternative event thresholds and the different ways of determining day 0 . We conclude this section with a placebo exercise. As was mentioned in Section 3.3, one of the potential drawbacks of using global stock market index as market portfolio is weak correlation between MSCI ACWI and stock indices of some countries. This results in low $R^{2}$ in the market model estimation. To check whether this weak correlation affects our baseline results, we first constructed an alternative market portfolio, in which we substituted MSCI ACWI with regional MSCI indices for the corresponding countries: MSCI Europe, MSCI Emerging Europe, MSCI Emerging Asia and MSCI Emerging Markets. We then re-estimated cumulative abnormal returns and found no differences to baseline estimation (Figure 11).

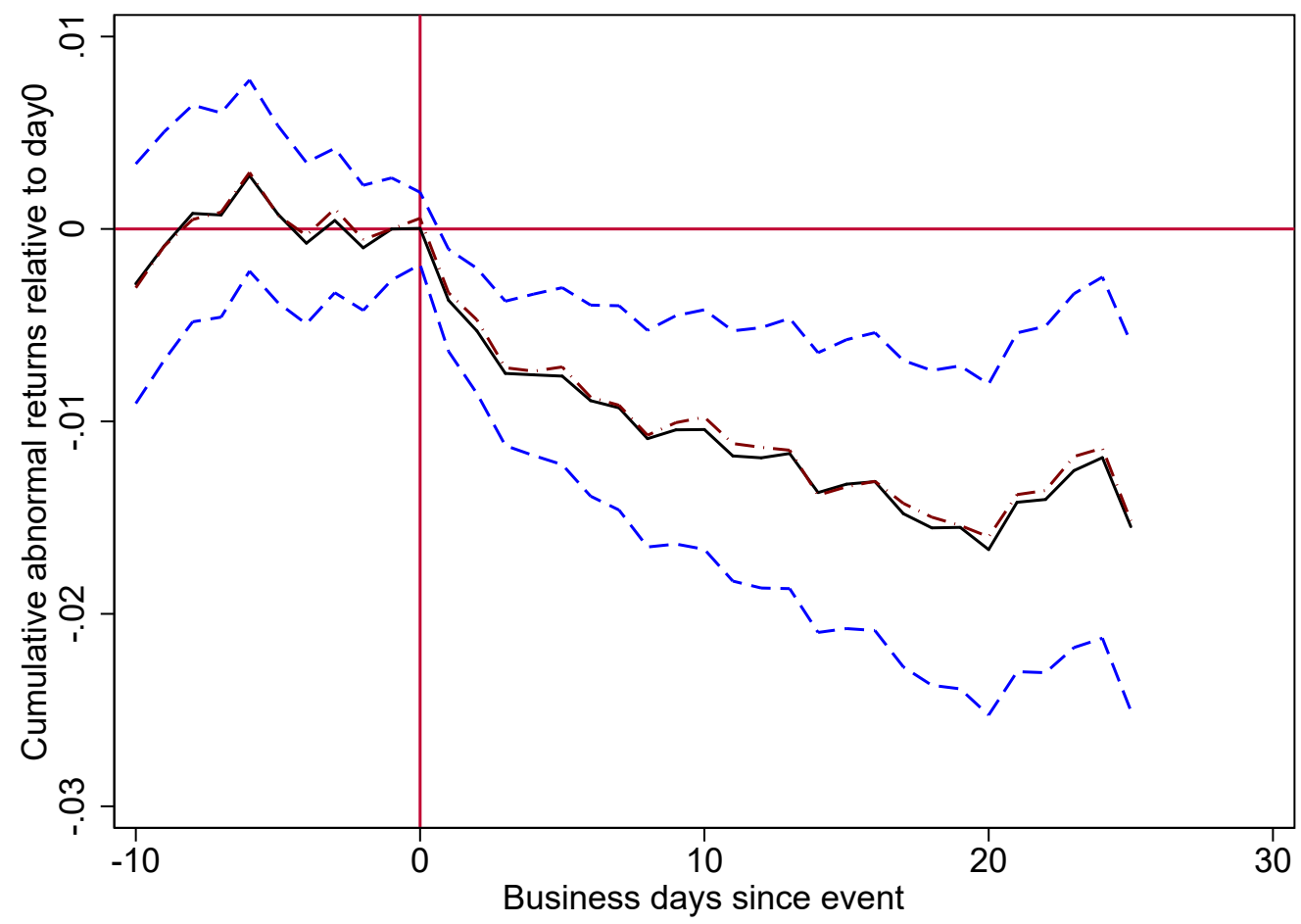

Figure 11: Cumulative abnormal returns. Based on market model from equation (2), market returns based on global and regional MSCI indices. Blue dashed lines - 95\% confidence intervals, computed using Brown and Warner (1985) t-statistics. Red dash-dot line-main results. 
An alternative way of estimating abnormal returns was suggested by Chen and Siems (2004). Instead of using the market model, the authors compute abnormal returns for each day $s$ for each event $i$ as simply the difference between actual stock index returns and the pre-event average returns:

$$
A R_{i s}=R_{i s}-\frac{1}{40} \sum_{s=-50}^{-11} R_{i s}
$$

Figure 12 shows that our baseline results are robust to the alternative event-study specification - we see the absence of pre-trend before day 0 , and the same downwardsloping returns after day 0.

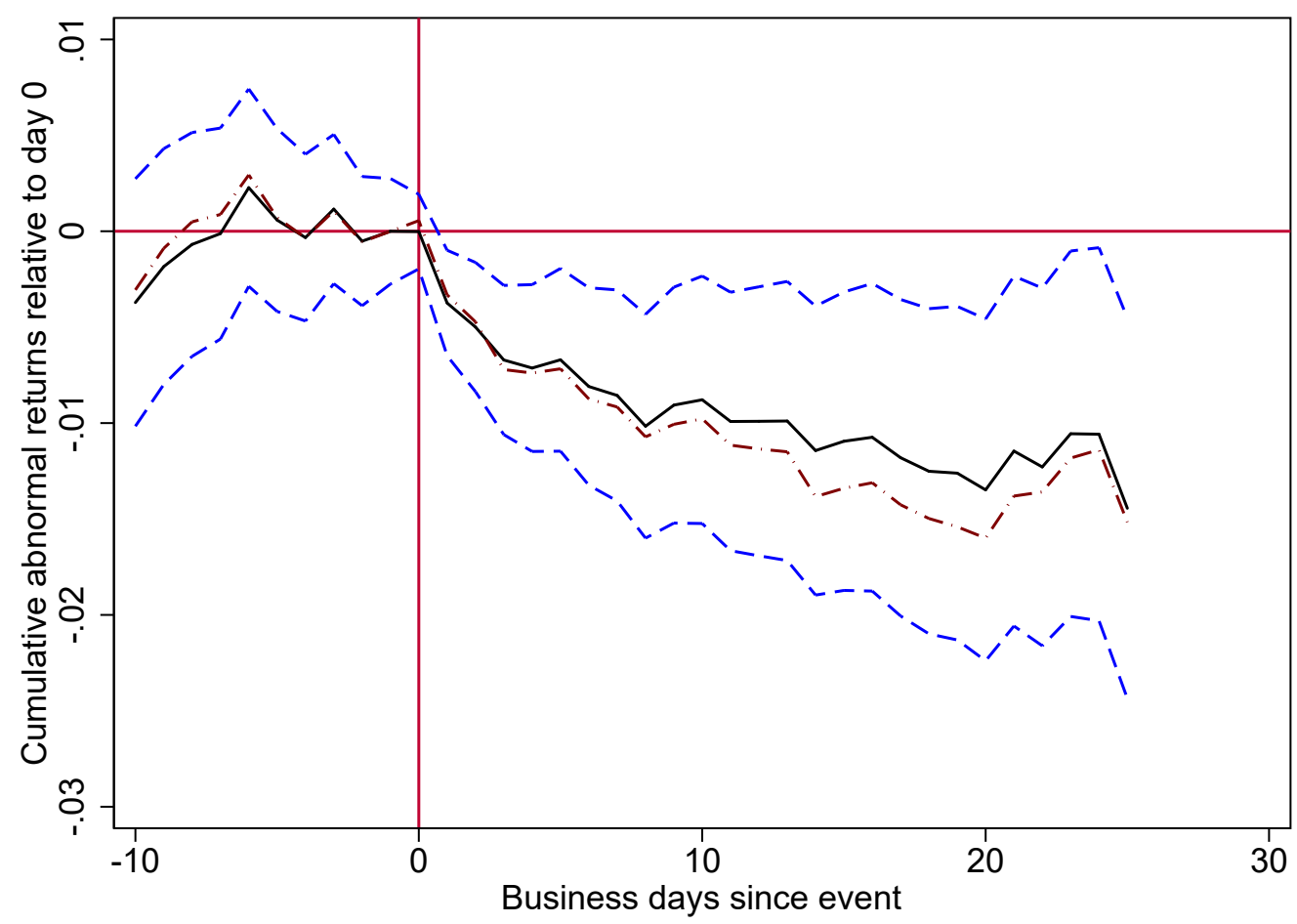

Figure 12: Cumulative abnormal returns. Abnormal returns computed according to equation (9) (Chen and Siems (2004)). Blue dashed lines - 95\% confidence intervals, computed using Brown and Warner (1985) t-statistics. Red dash-dot line-main results.

Overall, results from these alternative approaches indicate that the negative effect of social unrest on stock market returns is not an artifact of a particular estimation technique and is robust to various empirical specifications. ${ }^{33}$

\footnotetext{
${ }^{33}$ Additionally, Table A6 in the Appendix shows the results of alternative significance tests for cumulative abnormal returns.
} 
We next explore robustness of the timing of the events with several alternative approaches. First, we select a less strict threshold for determining the beginning of the event: we define day 0 as the first day when $S U_{k t}$ exceeds 10 (i.e. tenfold increase in the number of unrestrelated articles, or around 4 standard deviations of the pre-event index). This allows us to include more events (186) to check that our results are not driven by sample selection. Figure 13 shows that our baseline results are robust to the inclusion of events with lower media coverage. ${ }^{34}$

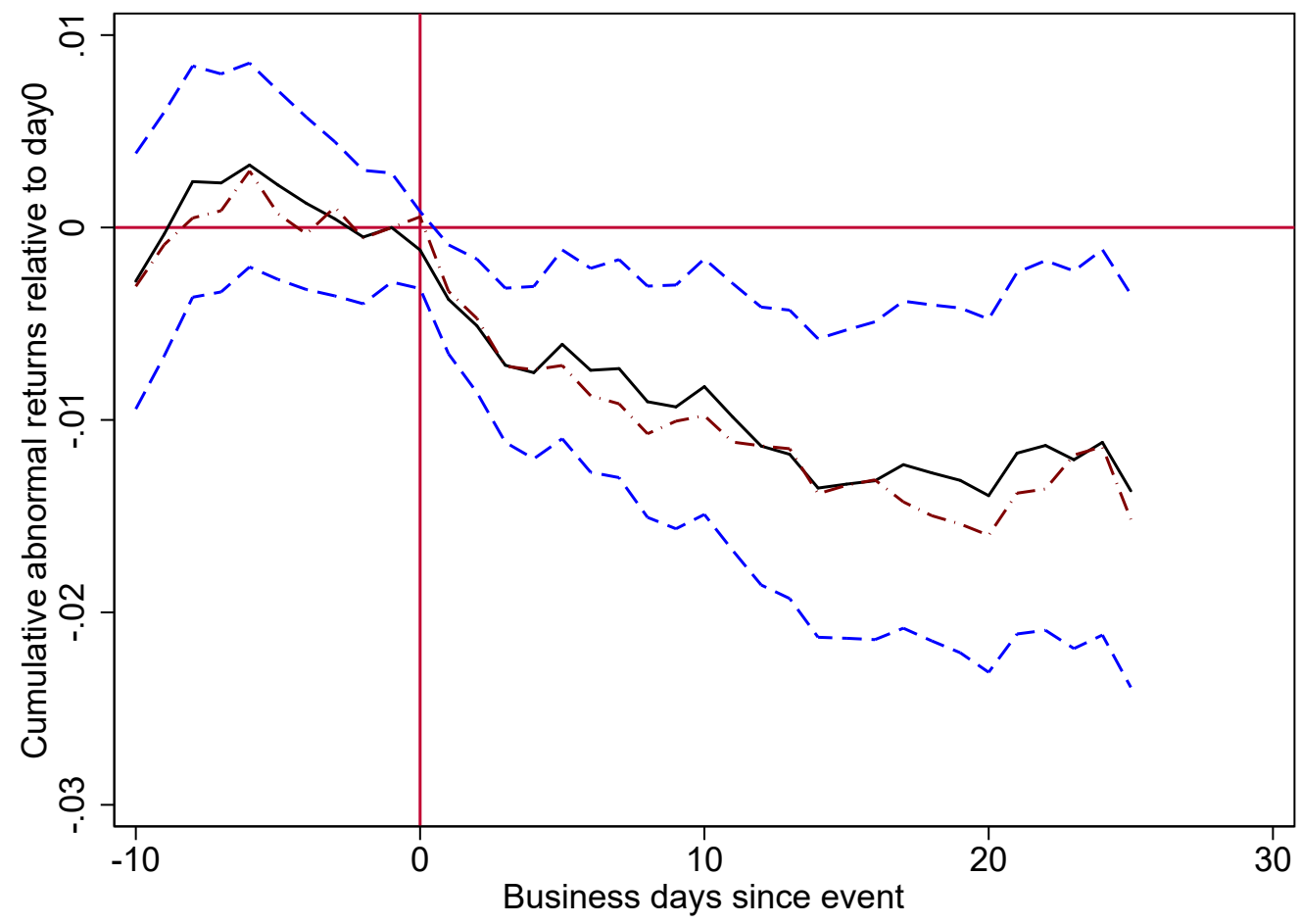

Figure 13: Cumulative abnormal returns. Based on market model from equation (2), market returns based on MSCI ACWI. Blue dashed lines - 95\% confidence intervals, computed using Brown and Warner (1985) t-statistics. Red dash-dot line - main results. Sample defined by alternative day 0 threshold: $S U_{k t}>10$.

Second, we explore alternative ways of defining day 0 that are not based on a level threshold. Our baseline results are based on the assumption that the beginning of social unrest coincides with the day when $S U_{k t}$ exceeds a threshold of 15 . Table 7 summarizes $\beta_{1}$ coefficients from equation (6) with 4-day event window for each of the

\footnotetext{
${ }^{34}$ The regression results on the extended sample are presented in Tables A7, A8 and A9 of the Appendix. Although some of the coefficients are no longer statistically significant, our main results on the effect of social unrest and unrest duration remain unchanged.
} 
alternative definitions of day 0: $\max$ (day with maximum number of $\operatorname{articles}^{35}$ ), first (day when $S U_{k t}>1$ for the first time), consecutive (first day in a series with positive $S U_{k t}$ that includes day with maximum number of articles), growth (day of the highest daily growth in $S U_{k t}$ ), and $S D 2$ (day when $S U_{k t}$ exceeds its all-time country mean by more than 2 standard deviations).

Table 7: Estimating equation (6); dependent variable - stock market index returns. Each column represents an alternative way of defining the beginning of the event. Event window $[0,+3]$

\begin{tabular}{lccccc}
\hline \hline & Max & First & Consecutive & Growth & SD2 \\
\hline Dummy for social unrest & -0.000378 & -0.000489 & $-0.00101^{*}$ & $-0.00139^{* *}$ & $-0.00110^{*}$ \\
& $(0.001)$ & $(0.000)$ & $(0.001)$ & $(0.001)$ & $(0.001)$ \\
\hline Country FE & Yes & Yes & Yes & Yes & Yes \\
Weekday FE & Yes & Yes & Yes & Yes & Yes \\
Observations & 25139 & 24329 & 25053 & 24992 & 24266 \\
\hline \hline
\end{tabular}

Newey-West standard errors with 2 lags in parentheses.

${ }^{*} p<0.10,{ }^{* *} p<0.05,{ }^{* * *} p<0.01$

The results in Table 7 deserve additional elaboration. The first two methods max and first - are more likely to misidentify the actual beginning of social unrest event. The date with maximum number of articles is probably situated on the right-hand side of day 0: we would expect maximum media coverage of the event to happen only when it is clear that social unrest is consequential and internationally important. On the contrary, the first day with $S U_{k t}>1$ is likely to happen before any unrest occurs, simply because some observations have to be above the average. Nevertheless, we include these results for transparency. In both of these cases the beta coefficients are not statistically different from zero despite large number of observations. To the extent that these two methods inaccurately identify the start of unrest, the insignificance of these results also serves as a placebo test for our main results. Columns 3-5 contain the results of estimating equation (6) with three alternative dates for day 0 - consecutive, growth and SD2. All of these methods perform well, with the magnitudes of the effect similar to those in our baseline case.

In Section 2.2, we discussed the concern about misidentification of day 0. As evidenced

\footnotetext{
${ }^{35}$ In all definitions the day is selected during the month of the event as identified by Barrett et al. (2020).
} 
by the validity checks, it can be very difficult to identify precisely the beginning of social unrest even when using external sources. This may be a serious problem for very long events with unrest subsiding and resuming over weeks and months (as was the case with some of the Arab Spring events). To check whether these extreme events with potentially imprecisely identified cut-off dates are biasing our results, we repeat our baseline estimation excluding the Arab Spring events of January and February 2011 from our sample (8). Our baseline results remain unchanged.

Table 8: Estimating equation (6); dependent variable - stock market index returns. Sample excludes the Arab Spring events in January and February 2011.

\begin{tabular}{lcc}
\hline \hline & {$[0,+3]$} & {$[0,+7]$} \\
\hline Dummy for social unrest & $-0.00156^{* *}$ & $-0.00105^{*}$ \\
& $(0.001)$ & $(0.001)$ \\
\hline Country FE & Yes & Yes \\
Weekday FE & Yes & Yes \\
Observations & 14456 & 14456 \\
\hline \hline
\end{tabular}

Newey-West standard errors with 2 lags in parentheses.

${ }^{*} p<0.10,{ }^{* *} p<0.05,{ }^{* * *} p<0.01$

Finally, we perform a placebo test. To make sure that our main results are not driven by unobserved factors that happen simultaneously with social unrest events, we construct two placebo samples. For each country and event month in our main sample we find two counterpart countries - one that shares a border with the country in question, and the other one that does not. Both comparator countries are chosen to be (a) from the same geographical region; (b) as similar as possible in terms of GDP per capita in international dollars; (c) with stock market index data; and (d) without social unrest around the event month (months -1, 0, 1). For instance, the counterpart countries for France in December 2018 (Yellow Vest protests) are Italy (border) and Finland (nonborder). Of course, it is not always possible to find a comparable country within the same region: in case of clustered events (such as Arab Spring in 2011 and Latin American protests in 2019) social unrest happens simultaneously in many countries of the region. Thus, our 'border' placebo sample is somewhat smaller than the 'non-border' sample. We repeat our event-study estimation on the two placebo samples, expecting a null result: there should not be a significant change in stock index returns in unaffected countries around the dates of social unrest. The results are presented in Figure 14.

CInternational Monetary Bønd. Not for Redistribution 

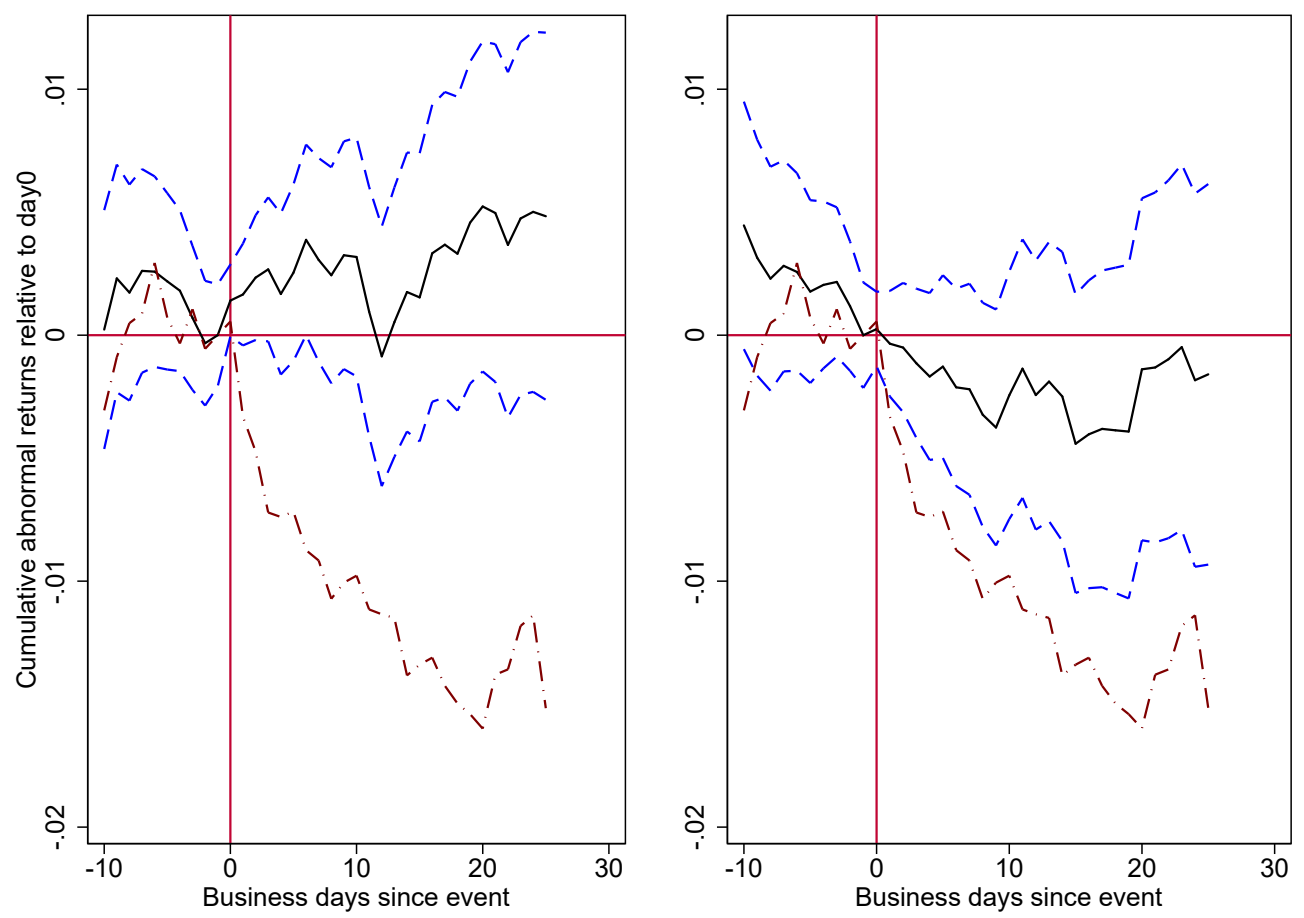

Figure 14: Placebo test - cumulative abnormal returns. Based on market model from equation (2), market returns based on MSCI ACWI. Blue dashed lines - 95\% confidence intervals, computed using Brown and Warner (1985) t-statistics. Red dash-dot lines - main results. The left panel is based on a placebo set of bordering countries from the same region. The right panel is based on a placebo set of non-bordering countries from the same region.

As expected, we do not observe any statistically significant change in cumulative abnormal returns in placebo countries around day 0. The left panel of Figure 14 shows the evolution of abnormal returns of the 'border' sample. Cumulative abnormal returns oscillate around zero, with a small (but insignificant) increase during the first week after day 0 . Thus, we do not find any evidence of the spillover effects of social unrest into neighboring countries. The right panel of Figure 14 depicts cumulative abnormal returns in the 'non-border' sample. Although the cumulative abnormal returns in non-bordering countries seem to exhibit a decreasing trend, there is no indication that it is triggered by social unrest in the region, since the trend clearly starts before day 0 and likely reflects the difficulty of matching countries. The returns in both panels are not statistically significant. Note, however, that the success of the placebo test is not driven by the lack of significance alone: Tables A10 and A11 of Appendix show that apart from being insignificant, the beta coefficients from regression (6) on both placebo samples are very close to zero. 


\section{Discussion}

Our analysis provides robust evidence that stock markets react negatively to social unrest, with notable differences between short versus long events and between advanced versus less developed countries. Perhaps this is not surprising: average effect masks important heterogeneities both across events (severity as measured by duration) and across countries (income and institutions).

A natural follow-up question is through which channel the impact of social unrest on stock markets materializes. Is the stock market reaction to unrest related to the physical disruption of economic activities? Or does social unrest provide market participants with new information, which affects stock markets indirectly through increased uncertainty and lower investor confidence? While a definitive answer is difficult to pin down, our findings offer insights into these alternative narratives.

First, the findings on short versus long events do not give a definitive answer to the question of transmission mechanisms. On the one hand, longer social unrest events are likely to be more severe: they involve a higher number of protesters and casualties, and cause more property damage. Hence, longer events may result in more economic disruptions. On the other hand, the severity of a social unrest event may be indicative of the severity of the underlying socioeconomic issues. Protests and demonstrations that last for one or two days - for example, the anti-migration protests in Estonia in 2018 and the protest against presidential reform in Uganda in 2017 - tend to be motivated by relatively narrow issues and could be rather inconsequential. Medium- and long-term events tend to reflect broader discontent about more deeply-rooted socioeconomic problems and hence can be expected to exert a stronger impact on stock index returns. If this is the case, long events, which serve as an indicator of socioeconomic issues, may lead to a surge in uncertainty about the future and force market participants to reevaluate their investment.

In contrast, the findings on institutional quality point us towards the uncertainty channel. Financial market responses to social unrest are larger in countries with weak democratic institutions and low regulatory quality. These findings are in line with the idea that social unrest generates different perceptions on how it would ultimately be resolved depending on the institutional quality. From the perspective of market participants, effective democratic institutions manage to mitigate the costs of social unrest. One possible explanation to this perception is that democratic institutions may be more flexible and robust; they

CInternational Monetary Band. Not for Redistribution 
provide a mechanism to aggregate divergent views, and address the underlying issues without major implications for future economic outcomes. This is especially visible in our election results: social unrest that coincides with elections has a positive impact on stock market performance. On the contrary, social unrest in a country with low voice and accountability is a challenge to the system of governance itself. There, unrest may lead to more uncertainty, a greater reduction in confidence, and a decline in asset prices, consistent with our results. In addition, when unrest happens in countries with weak institutions, investors may respond more negatively because stock markets in such countries may be dominated by government-dependent firms, which would be more vulnerable to potential shifts in the political landscape (Baker et al. (2016)).

Recall from Section 2 that our measure of duration is based solely on the data on media coverage of the social unrest event. According to our definition, the event is over as soon as media coverage drops back to the pre-event average. One might argue that instead of computing the duration of the event itself, we are in fact measuring the duration of the media coverage. This argument would not affect our estimation but would offer an alternative interpretation of the results: the events that are extensively covered by media influence stock market performance the most. Such interpretation reinforces our conclusions on the role of institutional quality. Countries with weak institutions are more likely to handle social unrest poorly, possibly escalating protests, which can stir the attention of the media and lead to more media coverage of the event and higher uncertainty. On the other hand, it is possible that countries with weak democratic institutions restrict freedom of press, suppressing the potential media coverage of social unrest events. If this is the case, then our estimates are if anything a lower bound on the magnitude of this effect.

We conduct an additional exercise to test the uncertainty channel. Specifically, we examine what happens to trading volume around social unrest events: according to market microstructure theory, disagreement and divergent expectations between investors must lead to an increase in trading activity (Karpoff (1986)). We find that trading volume goes up by more than $30 \%$ following a long-term social unrest event (Tables A13 and A14). An increase of such magnitude is consistent with the hypothesis that long-term events lead to higher uncertainty.

In sum, our findings are consistent with the notion that social unrest impacts stock market returns primarily through indirect information channels. Social unrest events reveal new information to market participants: they indicate the presence of deep socioeconomic 
discord and form expectations regarding future policy changes. Markets in countries with low-quality institutions react to this new information by increased uncertainty, which results in lower stock market returns and higher trading volume. It seems that protest in a country with strong democratic institutions is a routine part of the system of governance, but in a country with weak democratic institutions it may not be. 


\section{Conclusion}

Social unrest has increasingly become a part of the economic debate in the past decade. In this paper, we offer new evidence on the negative impact of social unrest on stock market performance. An average social unrest episode in an average country causes a 1.4 percentage point drop in cumulative abnormal returns over the two-week event window - a significant drop compared to average two-week abnormal returns. The effect is more pronounced for events that last longer and for events that happen in emerging markets. Stronger institutions, particularly better governance and more democratic systems, mitigate the adverse impact of social unrest on stock market returns.

While our focus is stock market reactions, social unrest has broad implications on macroeconomic outcomes and policies. The COVID-19 pandemic intensifies socio-economic fault lines such as economic and racial inequality that will likely sow the seeds for future unrest (Barrett and Chen (2021)). The short-run and long-run effects of social unrest on economic outcomes is an important area for future research. 


\section{References}

Abdelbaki, H. H. (2013). The Impact of Arab Spring on Stock Market Performance. British Journal of Economics, Management \& Trade, 3(3):169-185.

Acemoglu, D., Hassan, T. A., and Tahoun, A. (2017). The Power of the Street: Evidence from Egypt's Arab Spring. The Review of Financial Studies, 31(1):1-42.

Ahir, H., Bloom, N., and Furceri, D. (2018). The World Uncertainty Index. Stanford mimeo.

Aisen, A. and Veiga, F. J. (2013). How does political instability affect economic growth? European Journal of Political Economy, 29:151 - 167.

Alesina, A. and Perotti, R. (1996). Income distribution, political instability, and investment. European Economic Review, 40(6):1203 - 1228.

Alesina, A., Özler, S., Roubini, N., and Swagel, P. (1996). Political Instability and Economic Growth. Journal of Economic Growth, 1:189 - 211.

Arteaga-Garavito, M. J., Croce, M. M., Farroni, P., and Wolfskeil, I. (2020). When the Markets Get CO.V.I.D: COntagion, Viruses, and Information Diffusion. Available at SSRN: https://ssrn.com/abstract=356034\%.

Azzimonti, M. (2018). Partisan conflict and private investment. Journal of Monetary Economics, 93:114 - 131 .

Baker, S. R., Bloom, N., and Davis, S. J. (2016). Measuring Economic Policy Uncertainty. The Quarterly Journal of Economics, 131(4):1593-1636.

Barrett, P., Appendino, M., Nguyen, K., and de Leon Miranda, J. (2020). Measuring social unrest using media reports. IMF Working Papers, Working Paper No. 20/129.

Barrett, P. and Chen, S. (2021). Social repercussions of pandemics. Covid Economics, 68:47-68.

Bernal-Verdugo, L. E., Furceri, D., and Guillaume, D. (2013). The Dynamic Effect of Social and Political Instability on Output: The Role of Reforms. IMF Working Papers, Working Paper No. 13/91.

(CInternational Monetary Fand. Not for Redistribution 
Bloom, N. (2009). The Impact of Uncertainty Shocks. Econometrica, 77(3):623-685.

Bloom, N. (2014). Fluctuations in Uncertainty. Journal of Economic Perspectives, 28(2):153-176.

Bloom, N., Bond, S., and Van Reenen, J. (2007). Uncertainty and Investment Dynamics. Review of Economic Studies, 74:391-415.

Blum, J. and Gründler, K. (2020). Political Stability and Economic Prosperity: Are Coups Bad for Growth? CESifo Working Paper No., (8317). Available at SSRN: https://ssrn.com/abstract $=3618841$.

Briceño-Ruiz, J. (2019). The Crisis in Venezuela: A New Chapter, or the Final Chapter? Latin American Policy, 10(1):180-189.

Brown, S. J. and Warner, J. B. (1985). Using Daily Stock Returns: The Case of Event Studies. Journal of Financial Economics, 14:3-31.

Caldara, D. and Iacoviello, M. (2018). Measuring Geopolitical Risk. International Finance Discussion Papers 1222.

Campbell, C. J., Cowan, A. R., and Salotti, V. (2010). Multi-Country Event Study Methods. Available at SSRN: http://dx.doi.org/10.2139/ssrn.1359798.

Chen, A. H. and Siems, T. F. (2004). The effects of terrorism on global capital markets. European Journal of Political Economy, 20(2):349 - 366.

Dube, A., Kaplan, E., and Naidu, S. (2011). Coups, Corporations, and Classified Information. The Quarterly Journal of Economics, 126(3):1375-1409.

Eldor, R. and Melnick, R. (2004). Financial markets and terrorism. European Journal of Political Economy, 20(2):367-386.

Epstein, M. J. and Schnietz, K. E. (2002). Measuring the Cost of Environmental and Labor Protests to Globalization: An Event Study of the Failed 1999 Seattle WTO Talks. The International Trade Journal, 16(2):129-160.

Forbes, K. J. (2004). The Asian flu and Russian virus: the international transmission of crises in firm-level data. Journal of International Economics, 63(1):59-92. 
Guidolin, M. and La Ferrara, E. (2007). Diamonds Are Forever, Wars Are Not: Is Conflict Bad for Private Firms? American Economic Review, 97(5):1978-1993.

Guidolin, M. and La Ferrara, E. (2010). The economic effects of violent conflict: Evidence from asset market reactions. Journal of Peace Research, 47(6):671-684.

Hadzi-Vaskov, M., Pienknagura, S., and Ricci, L. A. (2020). Macroeconomic Impact of Social Unrest. IMF Working Papers, forthcoming.

Hlatshwayo, S. and Redl, C. (2020a). Forecasting social unrest. IMF Working Papers, forthcoming.

Hlatshwayo, S. and Redl, C. (2020b). The Macroeconomic Relevance of Social Unrest. IMF Working Papers, forthcoming.

Jong-A-Pin, R. (2009). On the measurement of political instability and its impact on economic growth. European Journal of Political Economy, 25:15 - 29.

Karpoff, J. M. (1986). A Theory of Trading Volume. The Journal of Finance, 41(5):10691087.

Kim, N. (2017). Candlelight and the Yellow Ribbon: Catalyzing Re-Democratization in South Korea. The Asia-Pacific Journal, 15(14).

Kolari, J. W. and Pynnonen, S. (2010). Event Study Testing with Cross-sectional Correlation of Abnormal Returns. The Review of Financial Studies, 23(11):3996-4025.

Kolari, J. W. and Pynnonen, S. (2011). Nonparametric rank tests for event studies. Journal of Empirical Finance, 18(5):953 - 971.

Latin America Monitor (2020). Fitch Solutions, 37(2). ISSN: 0265-9093.

MacKinlay, C. A. (1997). Event Studies in Economics and Finance. Journal of Economic Literature, 35(1):13-39.

Manela, A. and Moreira, A. (2017). News implied volatility and disaster concerns. Journal of Financial Economics, 123:137 - 162.

Montone, M. and Zwinkels, R. C. (2020). Investor Sentiment and Employment. Journal of Financial and Quantitative Analysis, 55(5):1581-1618. 
Mousavi, M. M. and Ouenniche, J. (2014). The Impact of MENA Conflicts (The Arab Spring) on Global Financial Markets. The Journal of Developing Areas, 48:21-40.

Pacicco, F., Vena, L., and Venegoni, A. Running event studies using Stata: the estudy command. Stata Journal, under review. Available at Researchgate.

Powell, J. and Thyne, C. (2011). Global Instances of Coups from 1950-Present. Journal of Peace Research, 48(2):249-259.

Raddatz, C. (2011). Multilateral Debt Relief through the Eyes of Financial Markets. The Review of Economics and Statistics, 93(4):1262-1288.

Rigobon, R. and Sack, B. (2005). The effects of war risk on US financial markets. Journal of Banking and Finance, (29):1769-1789.

Sedik, T. S. and Xu, R. (2020). A Vicious Cycle: How Pandemics Lead to Economic Despair and Social Unrest. IMF Working Papers, Working Paper No. 20/216.

Sraders, A. (2020). The stock market has a long history of ignoring social upheaval. Fortune. https://fortune.com/2020/06/01/stock-market-protests-civil-unrest-reactionmarkets-economy-stocks/.

Worth, R. F. (2016). A Rage for Order: The Middle East in Turmoil, from Tahrir Square to ISIS. Farrar, Straus and Giroux. 


\section{Appendix}

\section{Measuring Social Unrest}

Table A1: Sources of media reports

\begin{tabular}{cl}
\hline \hline US sources & The ABC Network, the CBS Network, the NBC Network, the \\
& Los Angeles Times, the Boston Globe, the New York Times, the \\
& Chicago Tribune, the Wall Street Journal, the Washington Post \\
UK sources & The BBC, the Financial Times, the Telegraph U.K., the Times \\
& U.K., the Telegraph, the Guardian U.K., the Economist \\
Canadian sources & The Canadian Broadcasting Corp, the Globe and Mail \\
\hline \hline
\end{tabular}


Table A2: Event listing. Column "Event" contains (when possible) a brief description of the events identified using $S U_{k t}$. Column "Daily identification" indicates whether the event enters the main sample based on daily identification ( $\boldsymbol{N}$ means that we were not able to find the day of the beginning of social unrest event based on our criterion $\left.S U_{k t}>15\right)$. Column "Duration" contains the information on the duration of each event ( $\boldsymbol{L}$ for long, $\boldsymbol{M}$ for medium and $\boldsymbol{S}$ for short, see Section 4.3 for detailed discussion). Column "Financial data available" indicates whether the event was matched with stock market index (Y). Events that are not matched with stock market data $(\boldsymbol{N})$ are not in our main sample. Thus, only the events with $\boldsymbol{Y}$ in both column 4 and column 6 are in the main sample. We use a regional stock market index BRVM Composite with country-specific weights for Burkina Faso, Mali, Niger, Senegal and Togo.

\begin{tabular}{|c|c|c|c|c|c|}
\hline Date & Country/Region & Event & $\begin{array}{l}\text { Daily } \\
\text { identi- } \\
\text { fication }\end{array}$ & Duration & $\begin{array}{l}\text { Fin } \\
\text { data } \\
\text { avail- } \\
\text { able }\end{array}$ \\
\hline $\operatorname{Jan} 2011$ & Lebanon & Constitution protests start & $\mathrm{Y}$ & $\mathrm{S}$ & $\mathrm{Y}$ \\
\hline $\operatorname{Jan} 2011$ & Tunisia & Tunisia Revolution & $\mathrm{Y}$ & $\mathrm{L}$ & $\mathrm{Y}$ \\
\hline Feb2011 & Uganda & Election protest & $\mathrm{Y}$ & $\mathrm{S}$ & $\mathrm{Y}$ \\
\hline Feb2011 & Egypt & Mubarak Resigns & $\mathrm{Y}$ & $\mathrm{L}$ & $\mathrm{Y}$ \\
\hline Feb2011 & Morocco & February 20th movement & $\mathrm{Y}$ & M & $\mathrm{Y}$ \\
\hline Feb2011 & Bahrain & Day of rage demonstrations & $\mathrm{Y}$ & S & $\mathrm{Y}$ \\
\hline Feb2011 & Iraq & Day of rage demonstrations & $\mathrm{Y}$ & $\mathrm{S}$ & $\mathrm{Y}$ \\
\hline Feb2011 & Iran & The Day of Rage demonstration & $\mathrm{Y}$ & $\mathrm{L}$ & $\mathrm{Y}$ \\
\hline Apr2011 & Finland & & Y & S & $\mathrm{Y}$ \\
\hline Apr2011 & Nigeria & Riots over presidential poll results & $\mathrm{Y}$ & M & $\mathrm{Y}$ \\
\hline Jun2011 & Greece & Syntagma Square Protest & $\mathrm{Y}$ & $\mathrm{L}$ & $\mathrm{Y}$ \\
\hline Jun2011 & Senegal & Anti-government riots & $\mathrm{Y}$ & $\mathrm{S}$ & $\mathrm{Y}$ \\
\hline Jul2011 & Malawi & Riots in Lilongwe and Mzuzu & $\mathrm{Y}$ & $\mathrm{S}$ & $\mathrm{Y}$ \\
\hline Jul2011 & Malaysia & Rally for electoral reform & Y & $\mathrm{S}$ & $\mathrm{Y}$ \\
\hline Sep2011 & Zambia & Zambia elections & $\mathrm{Y}$ & $\mathrm{S}$ & $\mathrm{Y}$ \\
\hline Oct2011 & Tunisia & Parliamentary elections & $\mathrm{Y}$ & $\mathrm{L}$ & $\mathrm{Y}$ \\
\hline Nov2011 & Morocco & Gdeim Izik protest & $\mathrm{Y}$ & M & $\mathrm{Y}$ \\
\hline Dec2011 & Korea & Anti-nuclear protests & $\mathrm{Y}$ & M & $\mathrm{Y}$ \\
\hline Jan2012 & Nigeria & Occupy Nigeria protests & Y & M & $\mathrm{Y}$ \\
\hline Jan2012 & Romania & Anti-austerity protests & $\mathrm{Y}$ & $\mathrm{L}$ & $\mathrm{Y}$ \\
\hline Feb2012 & Greece & $\begin{array}{l}\text { Protest outside Parliament House against austerity } \\
\text { measures }\end{array}$ & Y & $\mathrm{L}$ & $\mathrm{Y}$ \\
\hline Feb2012 & Panama & Violent protests in Colon and in Panama City & $\mathrm{Y}$ & M & $\mathrm{Y}$ \\
\hline Mar2012 & Netherlands & $\begin{array}{l}\text { Anti-Counterfeiting Trade Agreement protests across } \\
\text { Europe }\end{array}$ & Y & $\mathrm{S}$ & $\mathrm{Y}$ \\
\hline Mar2012 & Mali & Malian coup d'etat & Y & $\mathrm{S}$ & $\mathrm{Y}$ \\
\hline Apr2012 & Malawi & Malawi leader reported dead & Y & $\mathrm{S}$ & $\mathrm{Y}$ \\
\hline May2012 & North Macedonia & Rival ethnic protests & Y & $\mathrm{S}$ & $\mathrm{Y}$ \\
\hline Oct2012 & Panama & Protests over land sale bill in the Colon Free Zone & $\mathrm{Y}$ & M & $\mathrm{Y}$ \\
\hline Oct2012 & Georgia & Legislative elections & Y & M & Y \\
\hline Oct2012 & Senegal & $\begin{array}{l}\text { Senegalese supporters riot during the Africa Cup of } \\
\text { Nations tournament }\end{array}$ & Y & $\mathrm{S}$ & $\mathrm{Y}$ \\
\hline Dec2012 & Ghana & Opposition Protests & Y & $\mathrm{S}$ & Y \\
\hline Feb2013 & Bulgaria & Anti-government protest, PM quits & Y & M & $\mathrm{Y}$ \\
\hline Feb2013 & Tunisia & Belaid assasination & $\mathrm{Y}$ & M & $\mathrm{Y}$ \\
\hline
\end{tabular}




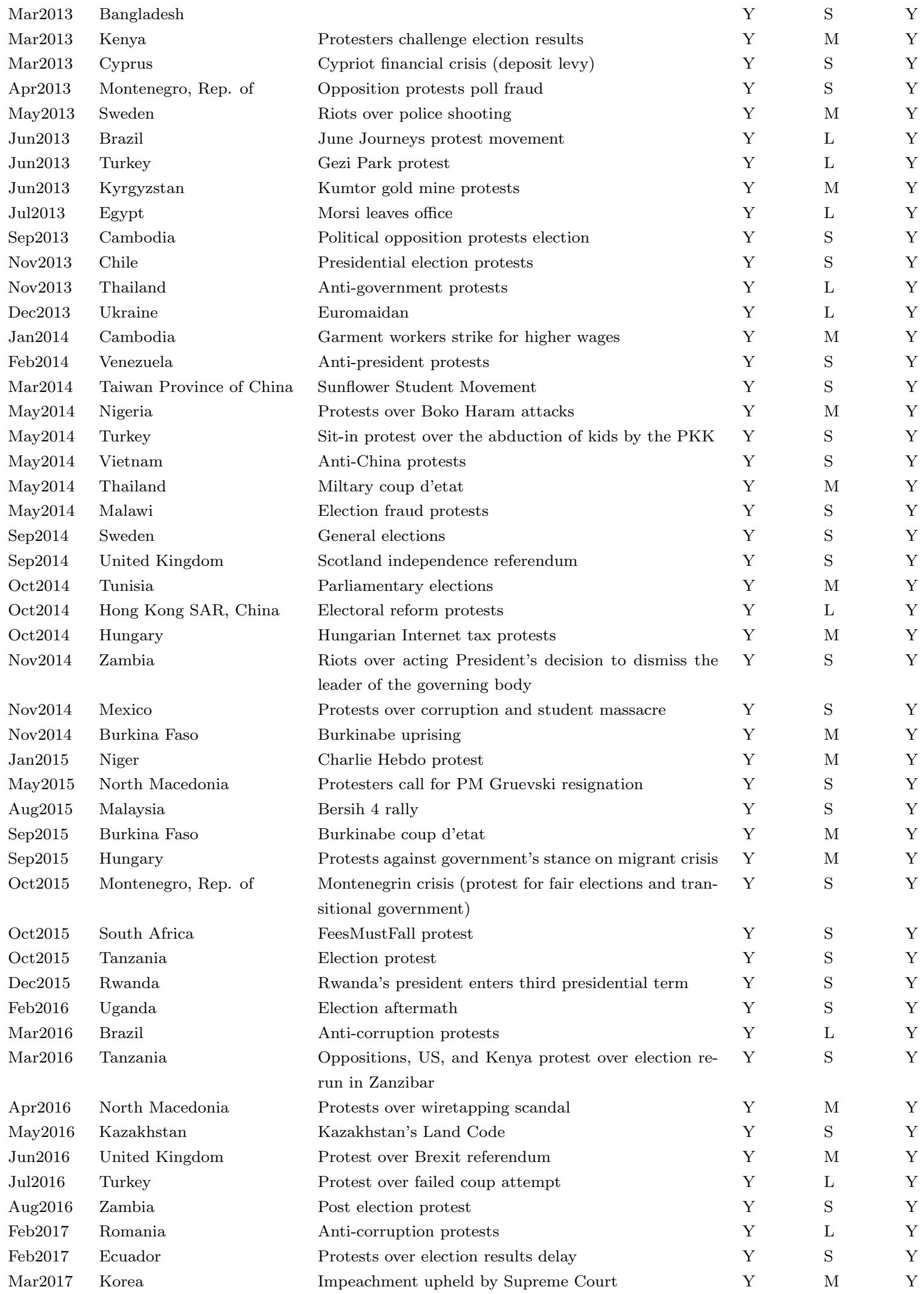




\begin{tabular}{|c|c|}
\hline Mar2017 & Netherlands \\
\hline Apr2017 & Hungary \\
\hline Apr2017 & North Macedonia \\
\hline Apr2017 & Ecuador \\
\hline Apr2017 & Venezuela \\
\hline Jun2017 & Qatar \\
\hline Jul2017 & Israel \\
\hline Jul2017 & Poland \\
\hline Aug2017 & Ghana \\
\hline Aug2017 & Kenya \\
\hline Sep2017 & Myanmar \\
\hline Sep2017 & Uganda \\
\hline Sep2017 & Cambodia \\
\hline Oct 2017 & Austria \\
\hline Oct 2017 & Kyrgyzstan \\
\hline Oct2017 & Spain \\
\hline Nov2017 & Zimbabwe \\
\hline Nov2017 & Belgium \\
\hline Dec2017 & Israel \\
\hline Dec2017 & Peru \\
\hline Jan2018 & Colombia \\
\hline Jan2018 & Iran \\
\hline $\operatorname{Jan} 2018$ & Switzerland \\
\hline Jan2018 & Tunisia \\
\hline Feb2018 & Bangladesh \\
\hline Mar2018 & Sri Lanka \\
\hline Mar2018 & Slovak Republic \\
\hline May2018 & Israel \\
\hline Jun2018 & Jordan \\
\hline Jun2018 & North Macedonia \\
\hline Jul2018 & Poland \\
\hline Jul2018 & Finland \\
\hline Aug2018 & Zimbabwe \\
\hline Aug2018 & Bangladesh \\
\hline Aug2018 & Argentina \\
\hline Aug2018 & Uganda \\
\hline Sep2018 & Germany \\
\hline Nov2018 & United Kingdom \\
\hline Dec2018 & Belgium \\
\hline Dec2018 & Hungary \\
\hline Dec2018 & France \\
\hline Dec2018 & Lithuania \\
\hline Dec2018 & Estonia \\
\hline Jan2019 & Venezuela \\
\hline $\operatorname{Jan} 2019$ & Zimbabwe \\
\hline Feb2019 & Senegal \\
\hline Feb2019 & Nigeria \\
\hline
\end{tabular}

Turkish election rallies dispute $\quad \mathrm{Y}$

Protest against bill that adjusts the operation of Soros $\quad Y$

University

$\begin{array}{llll}\text { Protesters storm Parliament over choice of speaker } & \text { Y } & \text { S } & \text { Y }\end{array}$

$\begin{array}{llll}\text { Protests over election results } & \text { Y } & \text { S } & \text { Y }\end{array}$

Anti-president protests

Diplomatic and economic ties cut

Temple Mount crisis

Protest against judicial reforms

Post-election protest after president is re-elected $\quad \mathrm{Y} \quad \mathrm{S}-\mathrm{Y}$

$\begin{array}{llll}\text { Rohingya crisis } & Y & \text { S } & \text { Y }\end{array}$

$\begin{array}{llll}\text { Protests over proposed plan to remove presidential age } & Y & S & \text { Y }\end{array}$

limit

Cambodia's opposition leader charged for treason in $\quad \mathrm{Y} \quad \mathrm{S} \quad \mathrm{Y}$ collusion with the US

$\begin{array}{llll}\text { Protests in Vienna over far-right in coalition } & \text { Y } & \text { S } & \text { Y }\end{array}$

Catalan crisis

Military takeover and President resigns

Slave market protests

US embassy relocates to Jerusalem

Protests over Alberto Fujimori's pardon and release

from jail

Indigenous protest demanding better healthcare and $\quad \mathrm{Y} \quad \mathrm{S} \quad \mathrm{Y}$

education

$\begin{array}{llll}\text { Economic/anti-government protests } & \mathrm{Y} & \mathrm{M} & \mathrm{Y}\end{array}$

$\begin{array}{llll}\text { Anti-Davos protests } & \mathrm{Y} & \mathrm{S} & \mathrm{Y}\end{array}$

$\begin{array}{llll}\text { Price protests } & \mathrm{Y} & \mathrm{M} & \mathrm{Y}\end{array}$

Violent protests over sentencing of opposition leader $\quad$ Y $\quad$ S $\quad$ Y

$\begin{array}{llll}\text { Anti-Muslim riots } & Y & \text { S } & \text { Y }\end{array}$

$\begin{array}{llll}\text { Political crisis - Investigative journalist killed } & \mathrm{Y} & \mathrm{S} & \mathrm{Y}\end{array}$

$\begin{array}{llll}\text { Protests as US embassy opens in Jerusalem } & \mathrm{Y} & \mathrm{S} & \mathrm{Y}\end{array}$

$\begin{array}{llll}\text { Anti-austerity protests } & \mathrm{Y} & \mathrm{M} & \mathrm{Y}\end{array}$

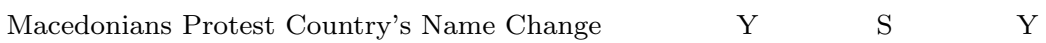

$\begin{array}{llll}\text { Protests over judicial reforms } & Y & S & Y\end{array}$

$\begin{array}{llll}\text { Human rights protest } & Y & S & Y\end{array}$

$\begin{array}{llll}\text { Zimbabwe election unrest } & \text { Y } & \text { L } & \text { Y }\end{array}$

$\begin{array}{llll}\text { Protests over safer roads } & \text { Y } & \text { M } & \text { Y }\end{array}$

Ugandan lawmakers detained at airport

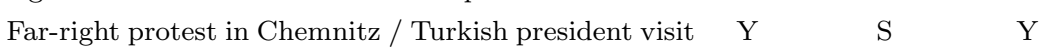

$\begin{array}{llll}\text { People's vote (anti-Brexit) marches } & \text { Y } & \text { M } & \text { Y }\end{array}$

$\begin{array}{llll}\text { Yellow Vests protests } & \text { Y } & \text { S } & \text { Y }\end{array}$

$\begin{array}{llll}\text { Protests against employee overtime law } & \text { Y } & \text { M } & \text { Y }\end{array}$

$\begin{array}{llll}\text { Yellow Vests protests } & \text { Y } & \text { L } & \text { Y }\end{array}$

$\begin{array}{llll}\text { Teachers' strike against education policies } & \text { Y } & \text { M } & \text { Y }\end{array}$

$\begin{array}{llll}\text { Anti-migration protest in Tallinn } & \text { Y } & \text { S } & \text { Y }\end{array}$

$\begin{array}{llll}\text { Anti-president protests } & \text { Y } & \text { L } & \text { Y }\end{array}$

$\begin{array}{llll}\text { Protests over hike in fuel prices } & \text { Y } & \text { M } & \text { Y }\end{array}$

$\begin{array}{llll}\text { Post-election protest } & \text { Y } & \text { S } & \text { Y }\end{array}$

$\begin{array}{llll}\text { Presidential election violence } & \text { Y } & \text { S } & \text { Y }\end{array}$ 


\begin{tabular}{|c|c|c|c|c|}
\hline Mar2019 & Montenegro, Rep. of & $\begin{array}{l}\text { Protests to demand the resignation of President Milo } \\
\text { Djukanovic }\end{array}$ & $\mathrm{Y}$ & $\mathrm{S}$ \\
\hline May2019 & Venezuela & Failed military uprising & $\mathrm{Y}$ & M \\
\hline May2019 & Austria & Austrian government collapses & $\mathrm{Y}$ & M \\
\hline May2019 & Indonesia & May Day demonstrations & $\mathrm{Y}$ & $\mathrm{S}$ \\
\hline Jun2019 & Czech Republic & Je to na nas protests & $\mathrm{Y}$ & $\mathrm{S}$ \\
\hline Jun2019 & Kazakhstan & Anti-government demonstrations & $\mathrm{Y}$ & M \\
\hline Jul2019 & Georgia & Gavrilov's Night ends & $\mathrm{Y}$ & $\mathrm{S}$ \\
\hline Aug2019 & Zimbabwe & Anti-government protest & $\mathrm{Y}$ & M \\
\hline Sep2019 & South Africa & Anti-foreigner riots & $\mathrm{Y}$ & M \\
\hline Oct2019 & Spain & Catalan crisis & $\mathrm{Y}$ & $\mathrm{M}$ \\
\hline Oct2019 & Argentina & Food crisis protests & $\mathrm{Y}$ & M \\
\hline Oct 2019 & Chile & Latin American protests & $\mathrm{Y}$ & $\mathrm{L}$ \\
\hline Oct2019 & Lebanon & Human chain on Martyr place & $\mathrm{Y}$ & $\mathrm{M}$ \\
\hline Oct2019 & Ecuador & $\begin{array}{l}\text { Protests by indigenous groups due to austerity mea- } \\
\text { sures }\end{array}$ & $\mathrm{Y}$ & $\mathrm{S}$ \\
\hline Nov2019 & Mexico & Day of the dead women' protest in Mexico City & $\mathrm{Y}$ & $\mathrm{S}$ \\
\hline Nov2019 & Georgia & Anti-government demonstrations & $\mathrm{Y}$ & $\mathrm{S}$ \\
\hline Nov2019 & Colombia & Latin American protests & $\mathrm{Y}$ & $\mathrm{S}$ \\
\hline Jan2020 & Montenegro, Rep. of & Ongoing political crisis & $\mathrm{Y}$ & S \\
\hline Jan2020 & Switzerland & Anti-WEF protests & $\mathrm{Y}$ & $\mathrm{S}$ \\
\hline Feb2020 & Togo & Contentious election & $\mathrm{Y}$ & S \\
\hline Jun2020 & Ghana & Anti-police brutality protests & $\mathrm{Y}$ & $\mathrm{S}$ \\
\hline Jun2020 & Mali & Anti-government protests against President Keita & $\mathrm{Y}$ & $\mathrm{S}$ \\
\hline Aug2020 & Lebanon & Anti-government protests after port explosion & $\mathrm{Y}$ & M \\
\hline Aug2020 & Mali & Army coup & $\mathrm{Y}$ & M \\
\hline Sep2020 & Colombia & Protests against police violence & $\mathrm{Y}$ & $\mathrm{S}$ \\
\hline Oct 2020 & Kyrgyzstan & Post-election protests, president resigns & $\mathrm{Y}$ & S \\
\hline Oct 2020 & Nigeria & EndSARS protests & $\mathrm{Y}$ & M \\
\hline Nov2020 & Peru & $\begin{array}{l}\text { Protests following sucessful impeachment of the Pres- } \\
\text { ident }\end{array}$ & $\mathrm{Y}$ & $\mathrm{S}$ \\
\hline Feb2011 & Libya & Civil war starts & $\mathrm{Y}$ & $\mathrm{S}$ \\
\hline Feb2011 & Yemen & Yemeni uprising & $\mathrm{Y}$ & $\mathrm{L}$ \\
\hline Nov2011 & Kuwait & Protesters storm Kuwaiti parliament & $\mathrm{Y}$ & $\mathrm{S}$ \\
\hline Dec2011 & D.R. Congo & Election protests & $\mathrm{Y}$ & $\mathrm{S}$ \\
\hline Jun2012 & Paraguay & Pro-president protest over impeachment & $\mathrm{Y}$ & M \\
\hline Oct 2012 & Kuwait & Constitution court ruling & $\mathrm{Y}$ & $\mathrm{S}$ \\
\hline Oct2012 & Kosovo & North Kosovo crisis & $\mathrm{Y}$ & $\mathrm{S}$ \\
\hline Mar2013 & Myanmar & $\begin{array}{l}\text { Ethnic violence between Muslims and Buddhists; state } \\
\text { of emergency declared }\end{array}$ & $\mathrm{Y}$ & $\mathrm{S}$ \\
\hline Sep2013 & Sudan & Protests over fuel subsidy cuts & $\mathrm{Y}$ & $\mathrm{L}$ \\
\hline Nov2013 & Honduras & Election protests & $\mathrm{Y}$ & $\mathrm{S}$ \\
\hline May2015 & Burundi & Burundi political protests and coup & $\mathrm{Y}$ & $\mathrm{S}$ \\
\hline Jun2015 & Armenia & Protests of Electricity Rate Hikes & $\mathrm{Y}$ & $\mathrm{L}$ \\
\hline Sep2015 & Guatemala & Anti-government protests & $\mathrm{Y}$ & M \\
\hline Oct 2015 & Guinea & Election-related violence & $\mathrm{Y}$ & $\mathrm{S}$ \\
\hline Jan2016 & Moldova & Protests against early elections & $\mathrm{Y}$ & $\mathrm{L}$ \\
\hline Jun2016 & Papua New Guinea & Students protest against Prime Minister Peter O'Neill & $\mathrm{Y}$ & $\mathrm{S}$ \\
\hline Aug2016 & Uzbekistan & Uzbekistan opens up on president's health & $\mathrm{Y}$ & S \\
\hline Aug2016 & Ethiopia & Protests in Oromiya and Amhara regions & $\mathrm{Y}$ & $\mathrm{S}$ \\
\hline Sep2016 & D.R. Congo & Anti-government protests & $\mathrm{Y}$ & $\mathrm{M}$ \\
\hline Dec2016 & D.R. Congo & Anti-Kabila protests & $\mathrm{Y}$ & M \\
\hline
\end{tabular}

\section{CInternational Monetary Fund. Not for Redistribution}




\begin{tabular}{|c|c|}
\hline Mar2017 & Belarus \\
\hline Apr2017 & Paraguay \\
\hline Jun2017 & Afghanistan \\
\hline Aug2017 & Guatemala \\
\hline Dec2017 & Honduras \\
\hline Jan2018 & Ethiopia \\
\hline Apr2018 & Nicaragua \\
\hline Apr2018 & Armenia \\
\hline Jun2018 & Guatemala \\
\hline Oct2018 & Mauritania \\
\hline Oct 2018 & Guatemala \\
\hline Nov2018 & Papua New Guinea \\
\hline Nov2018 & Tajikistan \\
\hline Jan2019 & D.R. Congo \\
\hline Jan2019 & Guatemala \\
\hline Jan2019 & Kosovo \\
\hline Apr2019 & Sudan \\
\hline Jun2019 & Ethiopia \\
\hline Jun2019 & Moldova \\
\hline Jun2019 & Mauritania \\
\hline Oct2019 & Ethiopia \\
\hline Oct2019 & Guinea \\
\hline Nov2019 & Bolivia \\
\hline Jun2020 & Belarus \\
\hline Jul2020 & Ethiopia \\
\hline Aug2020 & Belarus \\
\hline Oct2020 & Guinea \\
\hline Feb2011 & Jordan \\
\hline Apr2011 & Syria \\
\hline May2011 & Uganda \\
\hline Jun2011 & Syria \\
\hline Jun2011 & Turkey \\
\hline Jun2011 & Bahrain \\
\hline Jun2011 & Morocco \\
\hline Aug2011 & Syria \\
\hline Oct2011 & Greece \\
\hline Nov2011 & Egypt \\
\hline Nov2011 & Peru \\
\hline Nov2011 & Italy \\
\hline Nov2011 & Syria \\
\hline Nov2011 & Bahrain \\
\hline Dec2011 & United Kingdom \\
\hline Dec2011 & Russia \\
\hline Dec2011 & Belgium \\
\hline Jan2012 & Hungary \\
\hline
\end{tabular}

$\begin{array}{llll}\begin{array}{l}\text { Anti-government protests against President } \\ \text { Lukashenko }\end{array} & \mathrm{Y} & \mathrm{M} & \mathrm{N} \\ \begin{array}{l}\text { Protests over the senate allowing the president to run } \\ \text { for re-election }\end{array} & \mathrm{Y} & \mathrm{S} & \mathrm{N} \\ \begin{array}{l}\text { Bombings in Kabul } \\ \text { Anti-corruption protests }\end{array} & \mathrm{Y} & \mathrm{M} & \mathrm{N} \\ \text { Protests over presidential election results } & \mathrm{Y} & \mathrm{M} & \mathrm{N} \\ & \mathrm{Y} & \mathrm{S} & \mathrm{N} \\ \text { Anti-government protests } & \mathrm{Y} & \mathrm{S} & \mathrm{N} \\ \text { Armenian revolution } & \mathrm{Y} & \mathrm{M} & \mathrm{N} \\ & \mathrm{Y} & \mathrm{M} & \mathrm{N} \\ \text { Protest calling for the release of anti-slavery leader } & \mathrm{Y} & \mathrm{S} & \mathrm{N} \\ \text { Migrant caravan headed to US riot with police at } & \mathrm{Y} & \mathrm{S} & \mathrm{N} \\ \text { Gutemat } & & \mathrm{N}\end{array}$

Guatemala-Mexico border

$\begin{array}{lllll}\text { Police and Soldiers protest over unpaid APEC summit } & \text { Y } & \text { S } & \text { N }\end{array}$ bonuses

$\begin{array}{llll}\text { Tajik jail riot } & \mathrm{Y} & \mathrm{S} & \mathrm{N}\end{array}$

$\begin{array}{llll}\text { Congolese election result protests } & \mathrm{Y} & \mathrm{S} & \mathrm{N}\end{array}$

$\begin{array}{llll}\text { Protests against President Morales } & \text { Y } & \text { M } & \text { N }\end{array}$

Anti-Vucic Protests $\quad$ Y $\quad$ S $\quad$ N

Anti-government protests $\quad \mathrm{Y} \quad \mathrm{S} \quad \mathrm{N}$

$\begin{array}{llll}\text { Coup attempt } & \mathrm{Y} & \mathrm{S} & \mathrm{N}\end{array}$

Rally against the visit of Russian Deputy Prime Min- $\quad$ Y $\quad$ L $\quad$ N

ister

$\begin{array}{llll}\text { Post-election unrest } & \text { Y } & \text { S } & \text { N }\end{array}$

$\begin{array}{lllll}\text { Deadly unrest; clashes fueled by ethinicity and religion } & \mathrm{Y} & \mathrm{S} & \mathrm{N}\end{array}$

$\begin{array}{lllll}\text { Nationwide protests against constitutional change } & \mathrm{Y} & \mathrm{M} & \mathrm{N}\end{array}$

$\begin{array}{llll}\text { Bolivian elections and political crisis } & \mathrm{Y} & \mathrm{S} & \mathrm{N}\end{array}$

Anti-government protests against President $\mathrm{Y} \quad \mathrm{M} \quad \mathrm{N}$

Lukashenko

$\begin{array}{llll}\text { Inter-ethnic protests } & \mathrm{Y} & \mathrm{S} & \mathrm{N}\end{array}$

$\begin{array}{llll}\text { Pro-democracy protests } & \text { Y } & \text { L } & \text { N }\end{array}$

$\begin{array}{llll}\text { Political violence leaves dozens dead } & \text { Y } & \text { S } & \text { N }\end{array}$

Arab Spring Protests $\quad$ N

Arab Spring $\quad$ N

Inauguration protest $\quad \mathrm{N} \quad \mathrm{Y}$

Syrian Revolution $\quad N \quad$ Y

Pro-Kurdish protesters march to mosque $\quad \mathrm{N} \quad \mathrm{Y}$

$\begin{array}{lll}\text { Opposition protests } & \mathrm{N} & \mathrm{Y}\end{array}$

Arab Spring Protests $\quad$ N

Syrian Civil War $\quad$ N $\quad$ Y

$\begin{array}{lll}\text { Protests over new austerity bill } & \text { N } & \text { Y }\end{array}$

$\begin{array}{lll}\text { Tahrir Square protests } & \text { N } & \text { Y }\end{array}$

Protests over a proposed gold mine in northern Peru $\quad N \quad$ Y

$\begin{array}{lll}\text { Protesters rally against PM Berlusconi } & N & \text { Y }\end{array}$

Syrian Civil War $\quad \mathrm{N} \quad \mathrm{Y}$

Anti-government protests $\quad \mathrm{N}$ Y

References to Occupy movements in London and New N $\quad \mathrm{Y}$

York

$\begin{array}{lll}\text { Anti-government rally } & \text { N } & \text { Y }\end{array}$

$\begin{array}{lll}\text { Government formation crisis ends } & N & Y\end{array}$

Protests over changes in the constitution $\quad \mathrm{N} \quad \mathrm{Y}$ 


\begin{tabular}{|c|c|}
\hline Jan2012 & Kazakhstan \\
\hline Feb2012 & Senegal \\
\hline Feb2012 & United Kingdom \\
\hline Feb2012 & Belgium \\
\hline Mar2012 & Russia \\
\hline Apr2012 & Bahrain \\
\hline Apr2012 & Syria \\
\hline Jun2012 & Egypt \\
\hline Jul2012 & Syria \\
\hline Jul2012 & Mali \\
\hline Jul2012 & Mexico \\
\hline Oct2012 & Lebanon \\
\hline Nov2012 & Jordan \\
\hline Dec2012 & Egypt \\
\hline $\operatorname{Jan} 2013$ & Jordan \\
\hline $\operatorname{Jan} 2013$ & Pakistan \\
\hline Feb2013 & Slovenia \\
\hline Mar2013 & North Macedonia \\
\hline Apr2013 & Bahrain \\
\hline May2013 & Bulgaria \\
\hline Jul2013 & Tunisia \\
\hline Jul2013 & Bulgaria \\
\hline Aug2013 & Morocco \\
\hline Nov2013 & Colombia \\
\hline Dec2013 & Turkey \\
\hline Jan2014 & Thailand \\
\hline $\operatorname{Jan} 2014$ & Bangladesh \\
\hline Feb2014 & Ukraine \\
\hline Feb2014 & Russia \\
\hline Mar2014 & Turkey \\
\hline May2014 & India \\
\hline Jun2014 & Brazil \\
\hline Jul2014 & Israel \\
\hline Aug2014 & Pakistan \\
\hline Dec2014 & Hong Kong SAR, China \\
\hline Dec2014 & Tunisia \\
\hline Jul2015 & Greece \\
\hline Sep2015 & Nepal \\
\hline Nov2016 & Korea \\
\hline Dec2016 & Poland \\
\hline Apr2017 & South Africa \\
\hline May2017 & Brazil \\
\hline Jun2017 & Morocco \\
\hline Aug2017 & Venezuela \\
\hline Sep2017 & Togo \\
\hline Oct2017 & Kenya \\
\hline Nov2017 & Togo \\
\hline Nov2017 & Pakistan \\
\hline Dec2017 & Poland \\
\hline Feb2018 & South Africa \\
\hline
\end{tabular}

Zhaozen clashes $\quad \mathrm{N}$

Post-election protests N

Occupy London protesters evicted from St. Paul's N

Cathedral

Anti-austerity?protests in Brussels, Athens and $\mathrm{N}$ Y

Madrid

Opposition protest

Syrian Civil War

Morsi elected

Syrian Civil War

Rebel occupation protests

Protests over Nieto's win

Fuel price protests

Morsi's decree of immunity

Post-election protest

Long March

Pro-government rally

Ethnic Protests In Skopje

Protests over F1 race

Election protest

Brahmi assasination

Protesters call for resignation of entire government $\quad \mathrm{N}$

Daniel Galvan scandal N N

Protests over healthcare reform bill N

Anti-government protest over corruption scandal $\quad \mathrm{N}$

Anti-government protests $\mathrm{N}$

Election protest $\quad \mathrm{N}$

Maidan revolution $\quad \mathrm{N}$

Anti-war protests $\quad \mathrm{N}$

Ukrainian feminist group protest on election day N

Election protest $\quad \mathrm{N}$

Pre-World cup protests $\quad$ N

Israel-Gaza conflict

Azadi March

Pro-democracy protests

Presidential elections

Anti-austerity march

Constitutional protests

Candlelight Revolution

Anti-president protests

Protesters call for President Temer's resignation

Hirak Rif protests

End of anti-president protests

Anti-government protest (oligarchy)

Post-election protests

Togo opposition protest

Protests against law minister

Protests over judicial reforms

President Zuma steps down

Y

Y

Y

Y

$\mathrm{Y}$

Y

Y

Y

$\mathrm{Y}$

Y

Y

Y

Y

Y

Y

$\mathrm{Y}$

Y

Y

$\mathrm{Y}$

Y

Y

Y

Y

$\mathrm{Y}$

$\mathrm{Y}$

$\mathrm{Y}$

$\mathrm{Y}$

$\mathrm{Y}$

$\mathrm{Y}$

$\mathrm{Y}$

Y

Y

Y

Y

Y

Y

Y

Y

Y

Y

Y

Y

Y

Y

Y

Y

Y

\section{CInternational Monetary Fund. Not for Redistribution}




\begin{tabular}{|c|c|c|c|c|}
\hline Apr2018 & India & Caste protests & $\mathrm{N}$ & $\mathrm{Y}$ \\
\hline Apr2018 & Hungary & Protests over election results & $\mathrm{N}$ & $\mathrm{Y}$ \\
\hline May2018 & Korea & Hyehwa Station Protest & $\mathrm{N}$ & $\mathrm{Y}$ \\
\hline Jul2018 & Iraq & Anti-Iran protests, starting in Basra & $\mathrm{N}$ & $\mathrm{Y}$ \\
\hline Aug2018 & Romania & Anti-corruption protests & $\mathrm{N}$ & $\mathrm{Y}$ \\
\hline Aug2018 & Mali & Anti-government protests against President Keita & $\mathrm{N}$ & $\mathrm{Y}$ \\
\hline Oct2018 & Brazil & Anti-Bolsonaro protests & $\mathrm{N}$ & $\mathrm{Y}$ \\
\hline Nov2018 & Sri Lanka & Constitutional crisis & $\mathrm{N}$ & $\mathrm{Y}$ \\
\hline Nov2018 & Pakistan & Asia Bibi: Anti-blasphemy protests & $\mathrm{N}$ & $\mathrm{Y}$ \\
\hline Dec2018 & Poland & & $\mathrm{N}$ & $\mathrm{Y}$ \\
\hline Aug2019 & India & Kashmir unrest & $\mathrm{N}$ & $\mathrm{Y}$ \\
\hline Aug2019 & Hong Kong SAR, China & General strike and mass protests & $\mathrm{N}$ & $\mathrm{Y}$ \\
\hline Aug2019 & Russia & & $\mathrm{N}$ & $\mathrm{Y}$ \\
\hline Aug2019 & Malawi & Election fraud protests & $\mathrm{N}$ & $\mathrm{Y}$ \\
\hline Sep2019 & Kazakhstan & & $\mathrm{N}$ & $\mathrm{Y}$ \\
\hline Oct2019 & India & & $\mathrm{N}$ & $\mathrm{Y}$ \\
\hline Oct2019 & Peru & Protests in support of suspended president & $\mathrm{N}$ & $\mathrm{Y}$ \\
\hline Nov2019 & Australia & Climate change strike & $\mathrm{N}$ & $\mathrm{Y}$ \\
\hline Nov2019 & Iran & Anti-government demonstrations & $\mathrm{N}$ & $\mathrm{Y}$ \\
\hline Nov2019 & Iraq & Tishreen Revolution & $\mathrm{N}$ & $\mathrm{Y}$ \\
\hline Nov2019 & Hong Kong SAR, China & Takeover of Polytechnic University & $\mathrm{N}$ & $\mathrm{Y}$ \\
\hline Dec2019 & India & Citizenship law protests & $\mathrm{N}$ & $\mathrm{Y}$ \\
\hline Dec2019 & France & Pension reform protests & $\mathrm{N}$ & $\mathrm{Y}$ \\
\hline $\operatorname{Jan} 2020$ & Iraq & Protests against foreign influence & $\mathrm{N}$ & $\mathrm{Y}$ \\
\hline $\operatorname{Jan} 2020$ & Iran & Attack on U.S. forces, Ukrainian airliner downed & $\mathrm{N}$ & $\mathrm{Y}$ \\
\hline Feb2020 & Kazakhstan & Anti-government protests & $\mathrm{N}$ & $\mathrm{Y}$ \\
\hline Feb2020 & India & Delhi riots & $\mathrm{N}$ & $\mathrm{Y}$ \\
\hline Feb2020 & Canada & Railway and pipeline protests & $\mathrm{N}$ & $\mathrm{Y}$ \\
\hline Feb2020 & Malawi & Electoral commission protests & $\mathrm{N}$ & $\mathrm{Y}$ \\
\hline Apr2020 & Lebanon & Economic/anti-government protests & $\mathrm{N}$ & $\mathrm{Y}$ \\
\hline Apr2020 & Brazil & Anti-Lockdown protests & $\mathrm{N}$ & $\mathrm{Y}$ \\
\hline Jun2020 & United States & Anti-police brutality protests & $\mathrm{N}$ & $\mathrm{Y}$ \\
\hline Aug2020 & Russia & Anti-Moscow protests in far East & $\mathrm{N}$ & $\mathrm{Y}$ \\
\hline Oct2020 & Poland & Pro-choice protests & $\mathrm{N}$ & $\mathrm{Y}$ \\
\hline Nov2020 & Georgia & Anti-government and post-election protests & $\mathrm{N}$ & $\mathrm{Y}$ \\
\hline Feb2011 & Algeria & May First Square protests & $\mathrm{N}$ & $\mathrm{N}$ \\
\hline Nov2011 & Yemen & Transition agreed & $\mathrm{N}$ & $\mathrm{N}$ \\
\hline $\operatorname{Jan} 2012$ & Kosovo & $\begin{array}{l}\text { Self-Determination (Vetevendosje) protest in northern } \\
\text { Kosovo }\end{array}$ & $\mathrm{N}$ & $\mathrm{N}$ \\
\hline Mar2012 & Azerbaijan & & $\mathrm{N}$ & $\mathrm{N}$ \\
\hline Apr2012 & Mauritania & Opposition protests & $\mathrm{N}$ & $\mathrm{N}$ \\
\hline May2012 & Azerbaijan & Anti-government protests in runup to Eurovision & $\mathrm{N}$ & $\mathrm{N}$ \\
\hline Sep2012 & Libya & US ambassador killed & $\mathrm{N}$ & $\mathrm{N}$ \\
\hline Dec2012 & Kuwait & Elections boycott & $\mathrm{N}$ & $\mathrm{N}$ \\
\hline Jan2013 & Algeria & In Ames hostage crisis & $\mathrm{N}$ & $\mathrm{N}$ \\
\hline Sep2014 & Yemen & Houthi protests & $\mathrm{N}$ & $\mathrm{N}$ \\
\hline $\operatorname{Jan} 2015$ & Yemen & Pro-government protest against Houthis rebels & $\mathrm{N}$ & $\mathrm{N}$ \\
\hline Oct2015 & Moldova & Anti-government protest & $\mathrm{N}$ & $\mathrm{N}$ \\
\hline Nov2015 & Myanmar & Protests over killing of two ethnic politicians & $\mathrm{N}$ & $\mathrm{N}$ \\
\hline Dec2015 & Burundi & Burundi crisis & $\mathrm{N}$ & $\mathrm{N}$ \\
\hline Oct2016 & Ethiopia & State of emergency declared & $\mathrm{N}$ & $\mathrm{N}$ \\
\hline Jun2018 & Ethiopia & Grenade attack at pro-PM rally & $\mathrm{N}$ & $\mathrm{N}$ \\
\hline
\end{tabular}




\begin{tabular}{lllll} 
Jun2018 & Madagascar & Protests against new electoral laws & $\mathrm{N}$ & $\mathrm{N}$ \\
Jun2018 & Moldova & Election protest in Chisinau & $\mathrm{N}$ & $\mathrm{N}$ \\
Jul2018 & Nicaragua & Anti-government protests & $\mathrm{N}$ & $\mathrm{N}$ \\
Dec2018 & Nicaragua & Raids on journalists & $\mathrm{N}$ & $\mathrm{N}$ \\
Jan2019 & Sudan & Civil society protests & $\mathrm{N}$ & $\mathrm{N}$ \\
Mar2019 & Algeria & Smile revolution protests & $\mathrm{N}$ & $\mathrm{N}$ \\
Apr2019 & Kosovo & Political protest in north Kosovo & $\mathrm{N}$ & $\mathrm{N}$ \\
May2019 & Tajikistan & Tajik jail riot & $\mathrm{N}$ & $\mathrm{N}$ \\
Jun2019 & Sudan & Pro-democracy protest against the military regime & $\mathrm{N}$ & $\mathrm{N}$ \\
Jun2019 & Algeria & Smile revolution protests & $\mathrm{N}$ & $\mathrm{N}$ \\
Jul2019 & Guatemala & Activists Protest Migrant Asylum Pact With US & $\mathrm{N}$ & $\mathrm{N}$ \\
Dec2019 & Algeria & Smile revolution protests & $\mathrm{N}$ \\
Jan2020 & Guatemala & Inauguration day protest against outgoing officials & $\mathrm{N}$ \\
Feb2020 & Guinea & Constitutional poll & $\mathrm{N}$ \\
\hline \hline
\end{tabular}




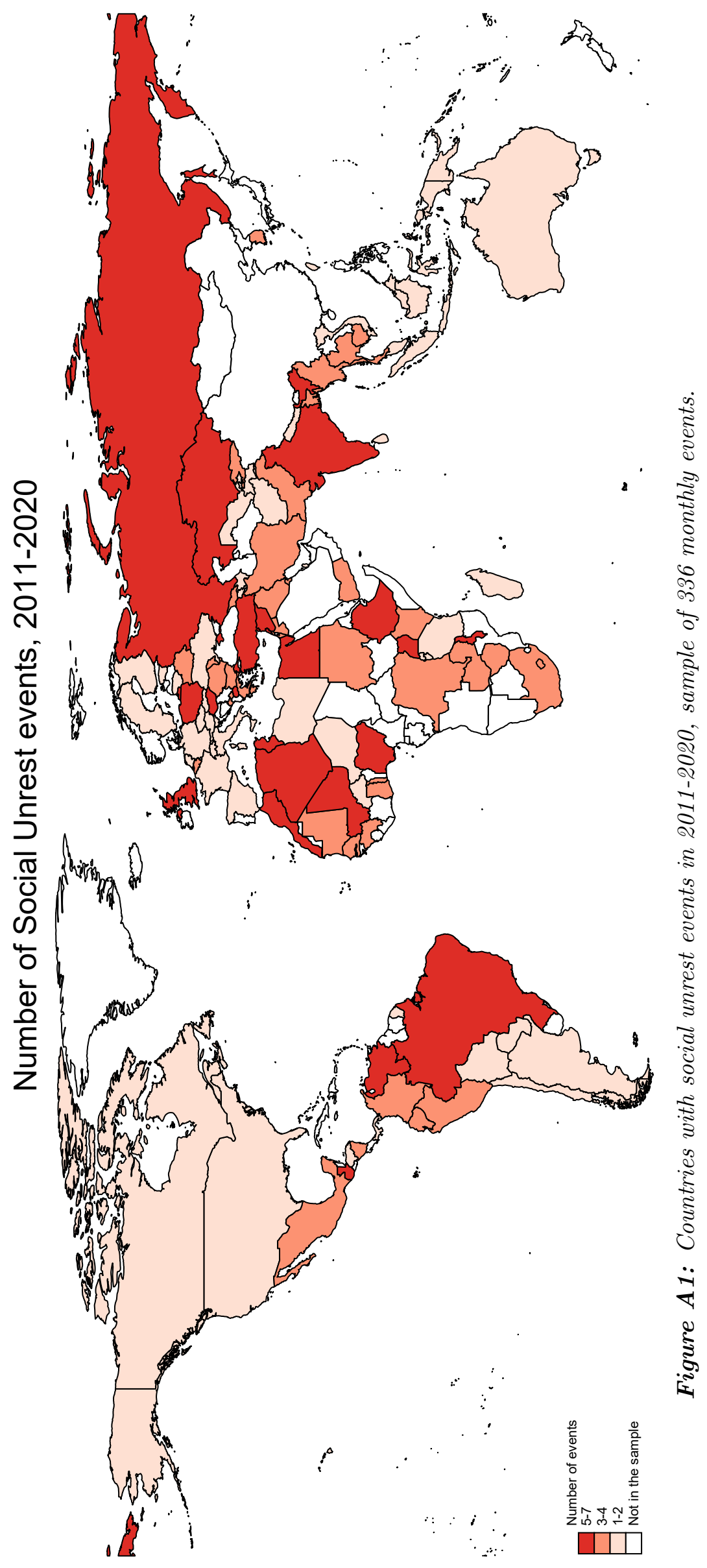

CInternational Monetary Fund. Not for Redistribution 


\section{Validation}
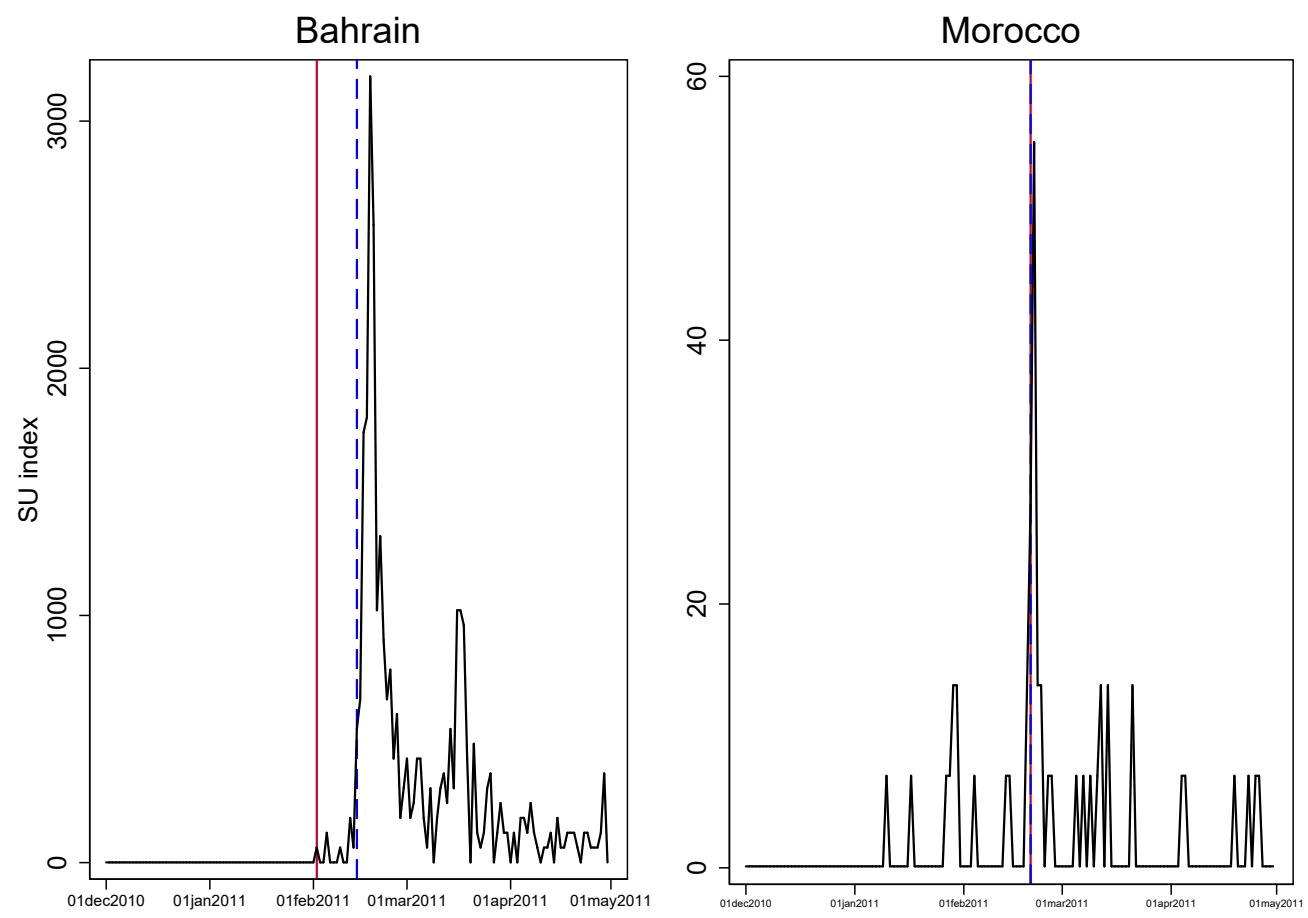

Figure A2: $S U_{k t}$. Red line - date identified using criterion $S U_{k t}>15$; blue dashed line date from external source. Source: Worth (2016) as cited in Barrett et al. (2020). The case of Bahrain is particularly interesting due to the abnormally high relative number of unrestrelated articles. Media coverage of Bahrain's unrest has increased by more than 3000 times compared to the pre-event average. This result comes from the fact, that before February 2011 media coverage of Bahrain was essentially zero (and thus the denominator is close to zero). 

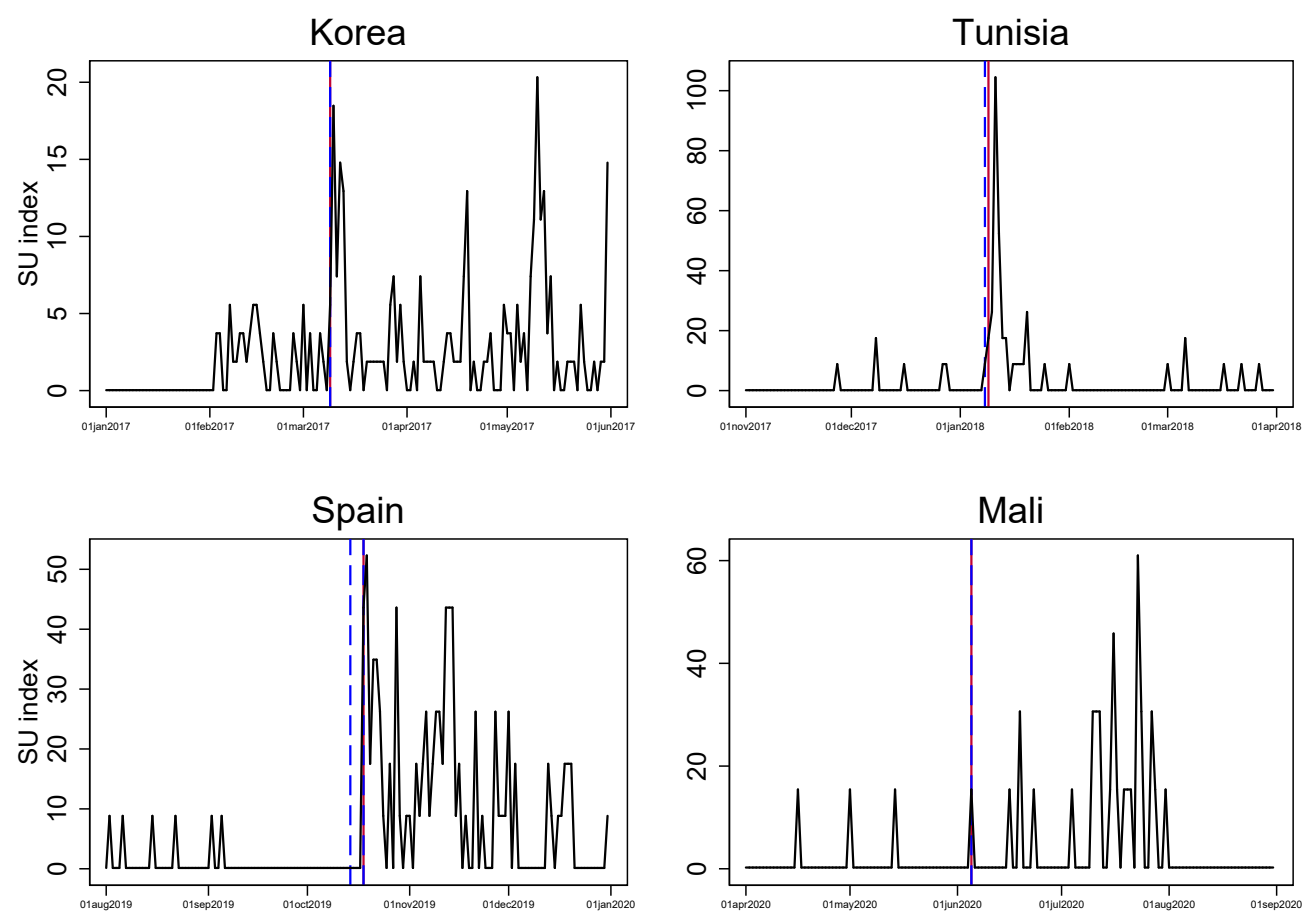

Figure A3: $S U_{k t}$. Red line - date identified using criterion $S U_{k t}>15$; blue dashed lines - dates from external sources. Sources: Kim (2017) as cited in Barrett et al. (2020) for Korea, Barrett et al. (2020) for Tunisia, BBC and Aljazeera news reports for Spain and Mali. 


\section{Main results}

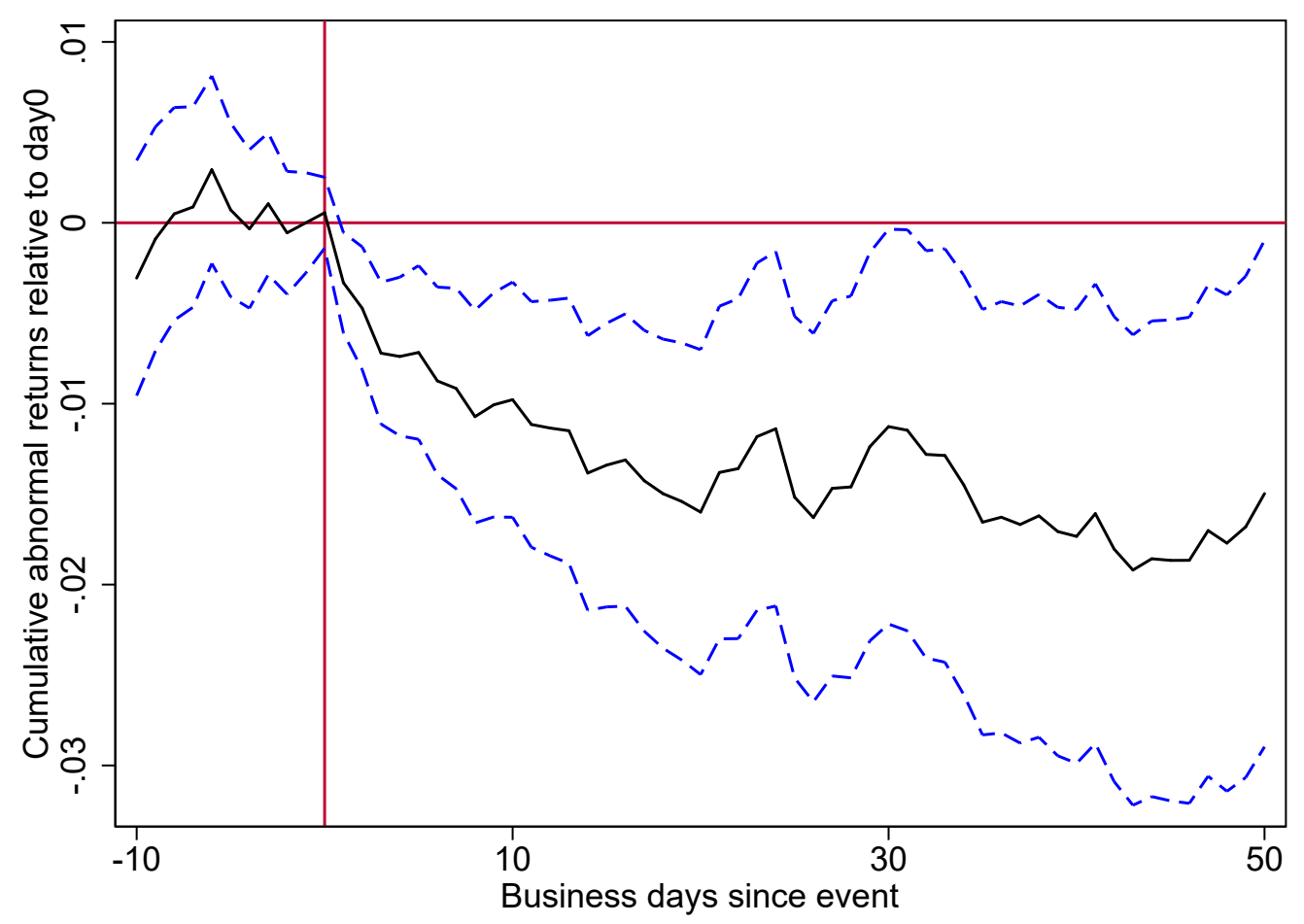

Figure A4: Cumulative abnormal returns, based on market model from equation (2), market returns based on MSCI ACWI. Blue dashed lines - 95\% confidence intervals, computed using Brown and Warner (1985) t-statistics. Event window - 50 business days. 


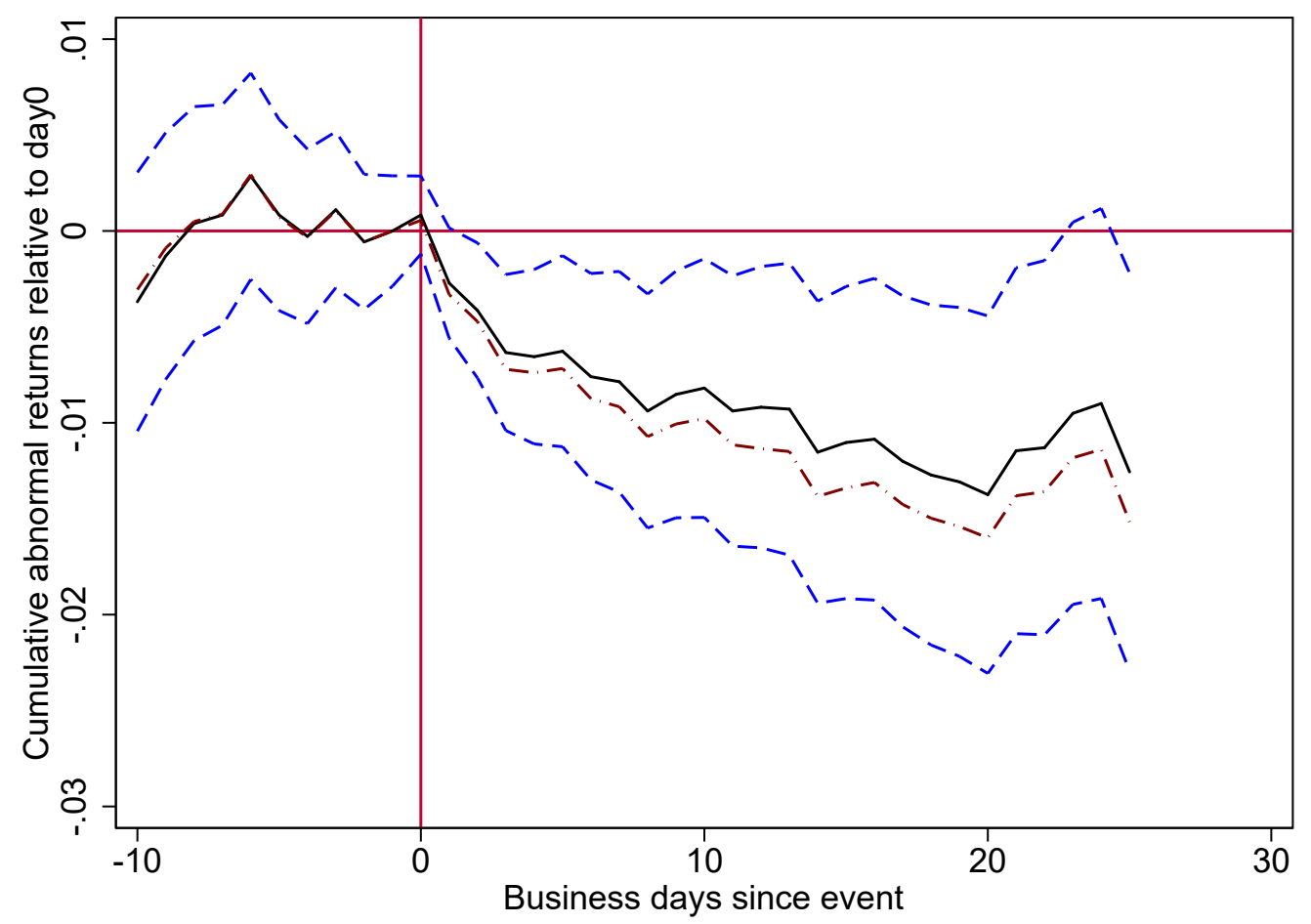

Figure A5: Cumulative abnormal returns, based on market model from equation (2), market returns based on SEP Global Index. Blue dashed lines - 95\% confidence intervals, computed using Brown and Warner (1985) t-statistics. Red dash-dot line-main results. 
Table A3: Estimating equation (6); dependent variable - stock market index returns. Alternative event windows to evaluate anticipation effects.

\begin{tabular}{lcc}
\hline \hline & {$[-1,+3]$} & {$[-1,+7]$} \\
\hline Dummy for social unrest & $-0.00121^{*}$ & $-0.000904^{*}$ \\
& $(0.001)$ & $(0.001)$ \\
\hline Country FE & Yes & Yes \\
Weekday FE & Yes & Yes \\
Observations & 15075 & 15075 \\
\hline \hline
\end{tabular}

Newey-West standard errors with 2 lags in parentheses.

${ }^{*} p<0.10,{ }^{* *} p<0.05,{ }^{* * *} p<0.01$ 


\section{Heterogeneities: regression results}

Table A4: Estimating equation (6); dependent variable - stock market index returns. Includes interaction terms between Social Unrest dummy and dummies for duration groups.

\begin{tabular}{lcc}
\hline \hline & {$[0,+3]$} & {$[0,+7]$} \\
\hline Dummy for social unrest & 0.000214 & 0.000146 \\
& $(0.001)$ & $(0.000)$ \\
SU*Medium & $-0.00225^{*}$ & -0.000141 \\
& $(0.001)$ & $(0.001)$ \\
SU*Long & $-0.00750^{* *}$ & $-0.00752^{* * *}$ \\
& $(0.003)$ & $(0.003)$ \\
\hline Weekday FE & Yes & Yes \\
Event FE & Yes & Yes \\
Observations & 15075 & 15075 \\
\hline \hline
\end{tabular}

Newey-West standard errors with 2 lags in parentheses.

${ }^{*} p<0.10,{ }^{* *} p<0.05,{ }^{* * *} p<0.01$

Table A5: Estimating equation (6); dependent variable - stock market index returns. Includes interaction terms between Social Unrest dummy and dummies for income groups.

\begin{tabular}{lcc}
\hline \hline & {$[0,+3]$} & {$[0,+7]$} \\
\hline Dummy for social unrest & 0.000513 & -0.000114 \\
& $(0.001)$ & $(0.001)$ \\
SU*LIDC & -0.00265 & -0.00124 \\
& $(0.002)$ & $(0.001)$ \\
SU*EMDE & $-0.00281^{*}$ & -0.00124 \\
& $(0.001)$ & $(0.001)$ \\
\hline Country FE & Yes & Yes \\
Weekday FE & Yes & Yes \\
Observations & 15075 & 15075 \\
\hline \hline
\end{tabular}

Newey-West standard errors with 2 lags in parentheses.

${ }^{*} p<0.10,{ }^{* *} p<0.05,{ }^{* * *} p<0.01$ 


\section{Robustness checks}

Table A6: Additional significance tests

\begin{tabular}{|c|c|c|c|c|c|}
\hline & $\mathrm{CAR}[0,3]$ & $\mathrm{CAR}[0,7]$ & $\operatorname{CAR}[0,14]$ & $\operatorname{CAR}[0,25]$ & $\operatorname{CAR}[1,1]$ \\
\hline \multicolumn{6}{|c|}{ Patell test, with the Kolari and Pynnonen adjustment } \\
\hline Ptf CARs & $-0.66 \% * * *$ & $-0.85 \% * *$ & $-1.16 \% * *$ & $-1.38 \% * *$ & $-0.36 \% * * *$ \\
\hline CAAR & $-0.62 \% * *$ & $-0.76 \%$ & $-0.99 \%$ & $-1.12 \%$ & $-0.36 \% * *$ \\
\hline \multicolumn{6}{|c|}{ Boehmer, Musumeci, Poulsen test, with the Kolari and Pynnonen adjustmen } \\
\hline Ptf CARs & $-0.66 \% * * *$ & $-0.85 \% * *$ & $-1.16 \% * *$ & $-1.38 \% * *$ & $-0.36 \% * * *$ \\
\hline CAAR & $-0.62 \% * *$ & $-0.76 \%$ & $-0.99 \%$ & $-1.12 \%$ & $-0.36 \% * * *$ \\
\hline \multicolumn{6}{|c|}{ Generalised Rank test by Kolari and Pynnonen } \\
\hline Ptf CARs & $-0.66 \% * * *$ & $-0.85 \% * *$ & $-1.16 \% * *$ & $-1.38 \% * *$ & $-0.36 \% * * *$ \\
\hline CAAR & $-0.62 \%$ & $-0.76 \%$ & $-0.99 \%$ & $-1.12 \%$ & $-0.36 \% * *$ \\
\hline
\end{tabular}

In our baseline results we use Brown and Warner (1985) test statistics to estimate the significance of cumulative abnormal returns and Newey-West HAC standard errors in the regression estimation. In this table we follow the research by Kolari and Pynnonen (2010) and Kolari and Pynnonen (2011) and conduct additional significance tests. All three tests account for potential cross-sectional correlation and autocorrelation of abnormal returns. The Generalized Rank (GRANK) test also relaxes the assumption about normality of stock market returns. We use a user-written Stata command estudy, which allows us to compute cumulative abnormal returns using two methods: portfolio CARs and CAAR (see Pacicco et al. for details). The latter corresponds to the method described in Section 3.2 of this paper. The cumulative abnormal returns presented in this table differ from our baseline results in one important respect: they are calculated using a Historical Mean Model, i.e. without controlling for the returns of the global stock market index. Nevertheless, the magnitude of the cumulative abnormal returns is comparable to our baseline results. 
Table A7: Estimating equation (6); dependent variable - stock market index returns. Uses a larger sample of events based on lower selection threshold $S U_{i t}>10$.

\begin{tabular}{lcc}
\hline \hline & {$[0,+3]$} & {$[0,+7]$} \\
\hline Dummy for social unrest & $-0.00165^{* *}$ & -0.000782 \\
& $(0.001)$ & $(0.000)$ \\
\hline Country FE & Yes & Yes \\
Weekday FE & Yes & Yes \\
Observations & 17954 & 17954 \\
\hline \hline
\end{tabular}

Newey-West standard errors with 2 lags in parentheses.

${ }^{*} p<0.10,{ }^{* *} p<0.05,{ }^{* * *} p<0.01$

Table A8: Estimating equation (6); dependent variable - stock market index returns. Includes interaction terms between Social Unrest dummy and dummies for duration groups. Uses a larger sample of events based on lower selection threshold $S U_{i t}>10$.

\begin{tabular}{lcc}
\hline \hline & {$[0,+3]$} & {$[0,+7]$} \\
\hline Dummy for social unrest & -0.000444 & 0.0000172 \\
& $(0.001)$ & $(0.000)$ \\
SU*Medium & -0.000738 & 0.000685 \\
& $(0.001)$ & $(0.001)$ \\
SU*Long & $-0.00553^{* *}$ & $-0.00523^{* * *}$ \\
& $(0.003)$ & $(0.002)$ \\
\hline Weekday FE & Yes & Yes \\
Event FE & Yes & Yes \\
Observations & 17954 & 17954 \\
\hline \hline
\end{tabular}

Newey-West standard errors with 2 lags in parentheses.

${ }^{*} p<0.10,{ }^{* *} p<0.05,{ }^{* * *} p<0.01$ 
Table A9: Estimating equation (6); dependent variable - stock market index returns. Includes interaction terms between Social Unrest dummy and dummies for income groups. Uses a larger sample of events based on lower selection threshold $S U_{i t}>10$.

\begin{tabular}{lcc}
\hline \hline & {$[0,+3]$} & {$[0,+7]$} \\
\hline Dummy for social unrest & -0.00102 & -0.0000143 \\
& $(0.001)$ & $(0.001)$ \\
SU*LIDC & -0.00131 & -0.00103 \\
& $(0.002)$ & $(0.001)$ \\
SU*EMDE & -0.000501 & -0.000932 \\
& $(0.001)$ & $(0.001)$ \\
\hline Country FE & Yes & Yes \\
Weekday FE & Yes & Yes \\
Observations & 17954 & 17954 \\
\hline \hline
\end{tabular}

Newey-West standard errors with 2 lags in parentheses.

${ }^{*} p<0.10,{ }^{* *} p<0.05,{ }^{* * *} p<0.01$ 
Table A10: Estimating equation (6); dependent variable - stock market index returns. Uses a 'border' placebo sample.

\begin{tabular}{lcc}
\hline \hline & {$[0,+3]$} & {$[0,+7]$} \\
\hline Dummy for social unrest & 0.000470 & 0.0000249 \\
& $(0.001)$ & $(0.000)$ \\
\hline Country FE & Yes & Yes \\
Weekday FE & Yes & Yes \\
Observations & 9755 & 9755 \\
\hline \hline
\end{tabular}

Newey-West standard errors with 2 lags in parentheses.

${ }^{*} p<0.10,{ }^{* *} p<0.05,{ }^{* * *} p<0.01$

Table A11: Estimating equation (6); dependent variable - stock market index returns. Uses a 'non-border' placebo sample.

\begin{tabular}{lcc}
\hline \hline & {$[0,+3]$} & {$[0,+7]$} \\
\hline Dummy for social unrest & -0.0000475 & -0.000283 \\
& $(0.000)$ & $(0.000)$ \\
\hline Country FE & Yes & Yes \\
Weekday FE & Yes & Yes \\
Observations & 11538 & 11538 \\
\hline \hline
\end{tabular}

Newey-West standard errors with 2 lags in parentheses.

${ }^{*} p<0.10,{ }^{* *} p<0.05,{ }^{* * *} p<0.01$ 


\section{Additional results}

Table A12: Estimating equation (6); dependent variable - stock market index returns. Includes interaction terms between Social Unrest dummy and Cluster dummy.

\begin{tabular}{lcc}
\hline \hline & {$[0,+3]$} & {$[0,+7]$} \\
\hline Dummy for social unrest & $-0.00159^{* *}$ & $-0.00107^{*}$ \\
SU*Clustered event & $(0.001)$ & $(0.001)$ \\
& -0.000570 & -0.000141 \\
\hline Country FE & $(0.002)$ & $(0.002)$ \\
Weekday FE & Yes & Yes \\
Observations & Yes & Yes \\
\hline \hline
\end{tabular}

Newey-West standard errors with 2 lags in parentheses.

${ }^{*} p<0.10,{ }^{* *} p<0.05,{ }^{* * *} p<0.01$

Table A13: Estimating equation (6); dependent variable - log trading volume.

\begin{tabular}{lcc}
\hline \hline & {$[0,+3]$} & {$[0,+7]$} \\
\hline Social unrest & 0.0552 & 0.0406 \\
& $(0.060)$ & $(0.043)$ \\
\hline Country FE & Yes & Yes \\
Weekday FE & Yes & Yes \\
Observations & 8437 & 8437 \\
\hline \hline
\end{tabular}

Newey-West standard errors with 2 lags in parentheses.

${ }^{*} p<0.10,{ }^{* *} p<0.05,{ }^{* * *} p<0.01$ 
Table A14: Estimating equation (6); dependent variable - log trading volume.

\begin{tabular}{lcc}
\hline \hline & {$[0,+3]$} & {$[0,+7]$} \\
\hline Social unrest & -0.0144 & 0.0105 \\
& $(0.072)$ & $(0.046)$ \\
Medium*Unrest & -0.00128 & -0.0667 \\
& $(0.112)$ & $(0.081)$ \\
Long*Unrest & $0.289^{* * *}$ & $0.195^{* * *}$ \\
& $(0.100)$ & $(0.067)$ \\
\hline Event FE & Yes & Yes \\
Weekday FE & Yes & Yes \\
Observations & 8437 & 8437 \\
\hline \hline
\end{tabular}

Newey-West standard errors with 2 lags in parentheses.

${ }^{*} p<0.10,{ }^{* *} p<0.05,{ }^{* * *} p<0.01$ 